\title{
Three essays on stock market anomalies, behavioral finance, and financial econometrics
}

Ding Du

West Virginia University

Follow this and additional works at: https://researchrepository.wvu.edu/etd

\section{Recommended Citation}

Du, Ding, "Three essays on stock market anomalies, behavioral finance, and financial econometrics" (2003). Graduate Theses, Dissertations, and Problem Reports. 1854.

https://researchrepository.wvu.edu/etd/1854

This Dissertation is protected by copyright and/or related rights. It has been brought to you by the The Research Repository @ WVU with permission from the rights-holder(s). You are free to use this Dissertation in any way that is permitted by the copyright and related rights legislation that applies to your use. For other uses you must obtain permission from the rights-holder(s) directly, unless additional rights are indicated by a Creative Commons license in the record and/ or on the work itself. This Dissertation has been accepted for inclusion in WVU Graduate Theses, Dissertations, and Problem Reports collection by an authorized administrator of The Research Repository @ WVU.

For more information, please contact researchrepository@mail.wvu.edu. 


\title{
Three Essays on Stock Market Anomalies, Behavioral Finance, and Financial Econometrics
}

\author{
Ding Du \\ Dissertation submitted to the \\ College of Business and Economics \\ at West Virginia University \\ in partial fulfillment of the requirements \\ for the degree of \\ Doctor of Philosophy \\ in \\ Economics
Ronald J. Balvers, Ph.D., Chair
Victor K. Chow, Ph.D.
Karen Denning, Ph.D.
Stratford M. Douglas, Ph.D.
Kern O. Kymn, Ph.D. \\ Division of Economics and Finance \\ Morgantown, West Virginia \\ 2003
}

Keywords: Monetary Policy Regime, Serial Correlation, Common Factor

Copyright 2003 Ding Du 


\title{
Abstract \\ Three Essays on Stock Market Anomalies, Behavioral Finance, and Financial Econometrics
}

\author{
Ding Du
}

This dissertation studies two important stock market anomalies, the correlation between stock returns and inflation and the predictability of stock returns. Chapter 1 is an introduction. Chapter 2 investigates why the stock return-inflation relation changes over time. Kaul (1987) considers changes in the monetary policy regime, while Hess and Lee (1999) propose changes in the composition of structural shocks. I show in Chapter 2: (1) different from Kaul (1987) and Hess and Lee (1999), both changes in the monetary policy regime and changes in the composition of structural shocks can in principle cause changes in the stock return-inflation relation; (2) empirically, the change in the monetary policy regime is quantitatively more important in explaining the data. In Chapter 3, I propose a new test that is particularly powerful against the type of alternative proposed by the recent behavioral models. When the test is applied to the data, I find evidence supporting the behavioral models in that (1) prices of stocks with more uncertainty and slower information diffusion tend to have both short-run positive and long-run negative autocorrelations; (2) the three-factor model cannot explain all observed autocorrelation patterns. The results are not likely due to data mining, because similar autocorrelation patterns are found in different sets of portfolios, different stock markets, different sample periods, and even for using different intervals to measure autocorrelations. Motivated by the same behavioral models and the contradictory empirical evidence regarding the stock price reaction to the common factor, in Chapter 4, I propose a regression-based test that is robust to serial correlation and heteroskedasticity in stock returns. When the test is used to the data, contrary to Lewellen (2002), I find evidence in support of the behavioral models in that stock prices also short-run under- and long-run overreact to market-wide information. 


\section{Acknowledgements}

Upon completion of my dissertation, I have reached a milestone of my life. I shall be proud of myself not only for my academic achievement - my Ph. D. degree - but also for my life achievement - my daughter. However, I do know that I could have done better if I had worked harder. My greatest weakness is that I am not always self-motivated. I tend to compromise with myself. Fortunately, my wife is much more "ambitious". I would have achieved much less if without her "push".

I shall also thank many other people for their generous help. Professor Balvers, as the dissertation advisor, directed me into an extremely exciting and promising area. His comments greatly enhanced this dissertation. Professor Chow had important insights on the simulation part of Chapter 3. I am also very grateful the two summer employment opportunities he offered me. Professor Denning not only served on my dissertation committee but also provided tremendous help on my job searching. Professor Douglas taught an excellent econometrics class that was so critical for my dissertation research. Professor Kymn served on my dissertation committee and came to Morgantown from Washington D.C. during the summer only for my dissertation defense. Professor Vilasuso (deceased) made important suggestions on Chapter 2. As a matter of fact, the econometric methods used in that chapter were all suggested by him. Barbara is the best secretary I have ever seen. She does much more than what she has to do.

There is an insightful Chinese saying "you can only truly understand your parents when you become a parent". As a parent, now I understand how deep my parents love me. They have sacrificed so much for me. My father stayed here alone for one year to take care of my daughter for me so that I could concentrate on my dissertation. It turned out that his stay was so critical that I made most progress during that period.

I will try to not make compromise with myself in the future and hope I could be more proud of myself at next milestone of my life. 


\section{Table of Contents}

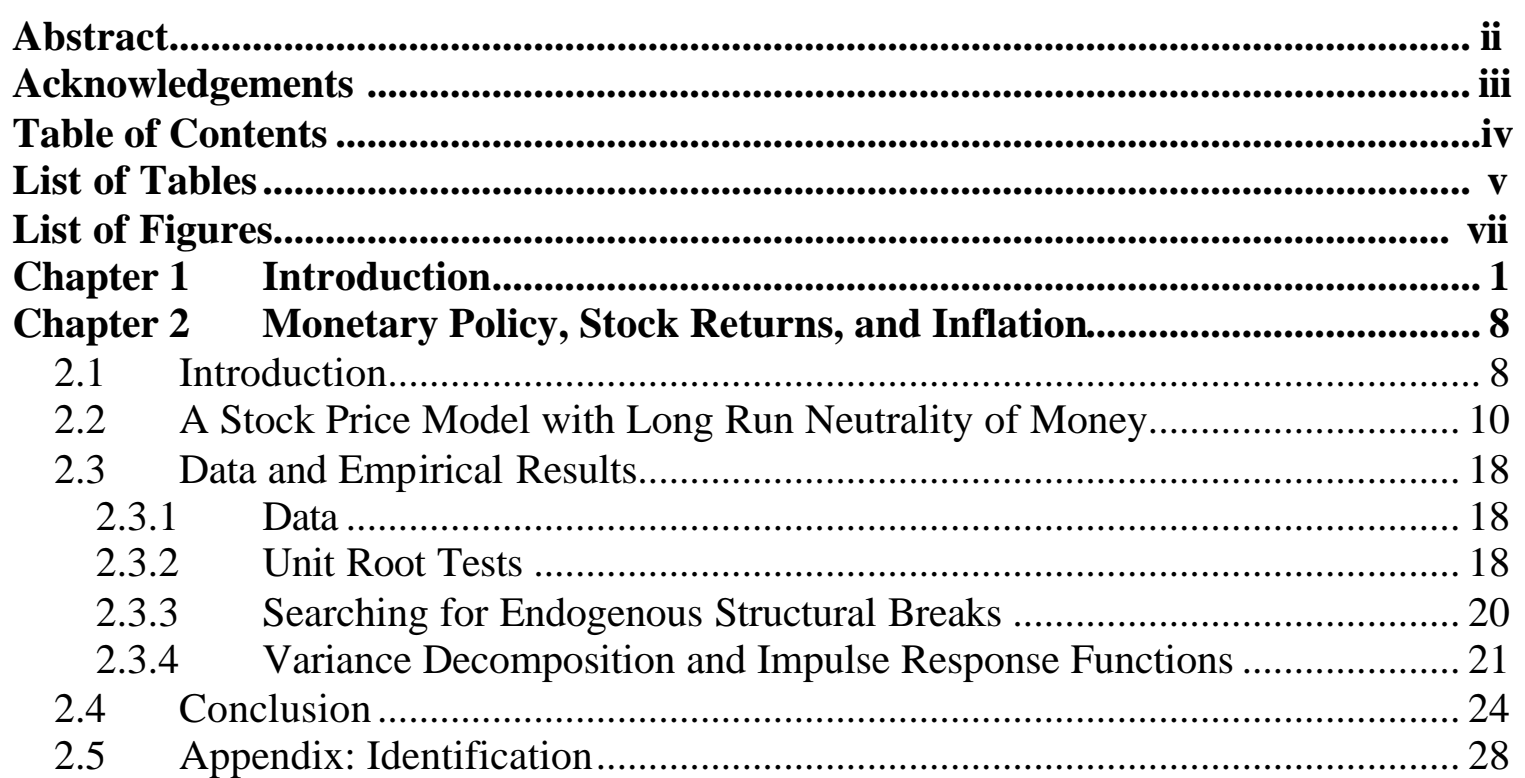

Chapter 3 Behavioral Finance and Mean Reversion: Evidence from a New

Specification Test........................................................................................................30

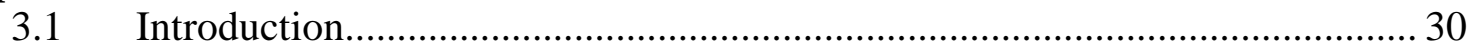

3.2 The Covariance-Variance Ratio Statistic ………........................................... 38

3.2.1 The Variance Ratio Test .................................................................... 38

3.2.2 The Covariance-Variance Ratio Test .......................................................... 40

3.3 The Size and Power of the Covariance-Variance Ratio Test.............................. 47

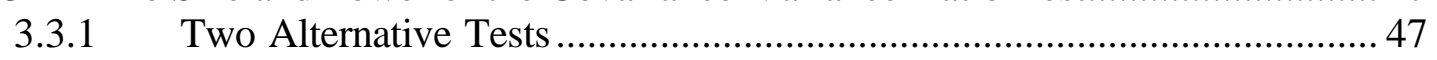

3.3.2 The Size of the Covariance-Variance Ratio Test........................................ 49

3.3.3 The Power of the Covariance-Variance Ratio Test ................................... 51

3.4 Data and Empirical Results......................................................................... 52

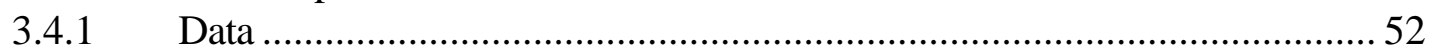

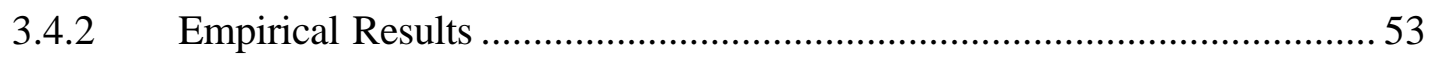

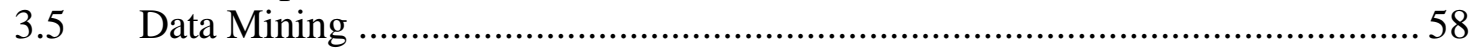

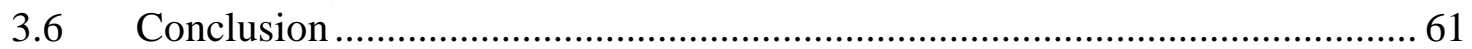

Chapter 4 Under- and Over-reaction to a Common Factor in Stock Markets ... 77

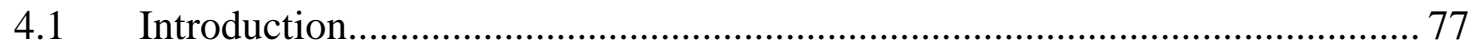

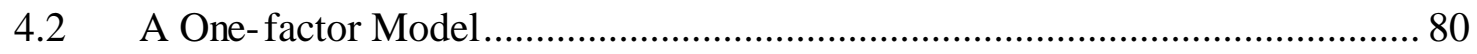

4.3 A Regression-based Test........................................................................... 82

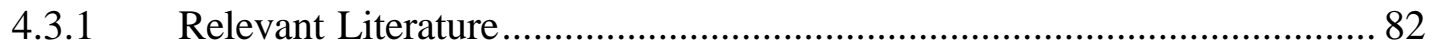

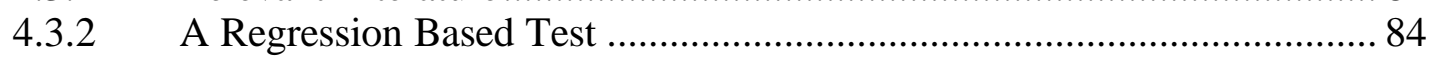

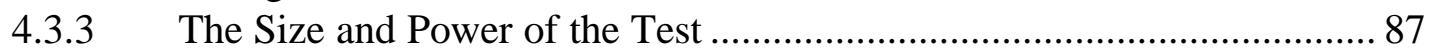

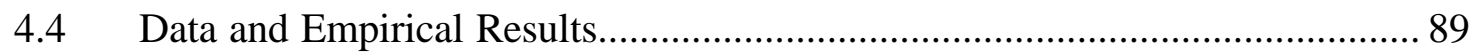

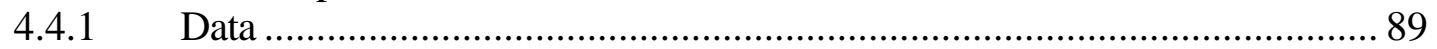

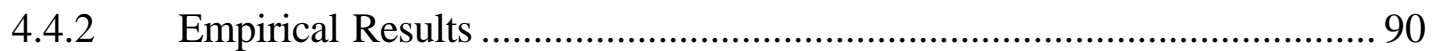

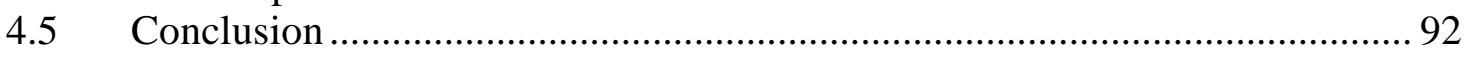

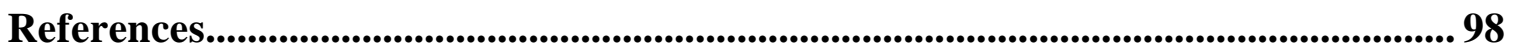




\section{List of Tables}

Table 2-1 Tests for unit roots 1926:I - 2001:IV 25

Table 2-2 Structural breaks in the stock return-inflation relation: 1926:1 - 2001:IV ...... 25

Table 2-3 Variance decomposition: percentage of forecast error variance explained by supply and money supply shocks............................................................. 26

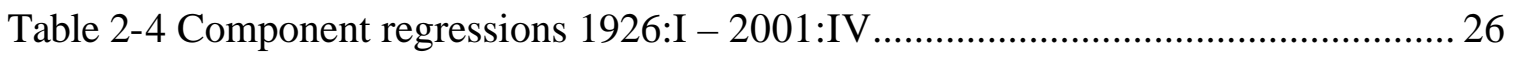

Table 3-1 The theoretical values of variance ratios and covariance-variance ratios ........ 63

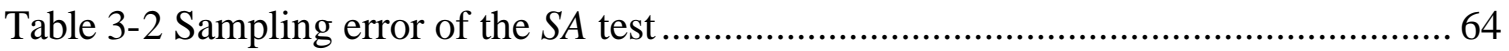

Table 3-3 Empirical sizes of the nominal 1, 5, 10 percent variance ratio tests, covariancevariance ratio tests, rescaled variance ratio tests, and SA tests of the random walk

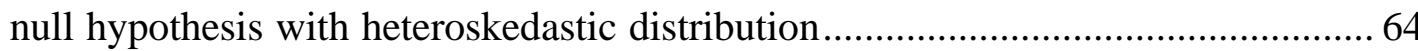

Table 3-4 Empirical critical values of the 1, 5, 10 percent variance ratio tests, covariancevariance ratio tests, rescaled variance ratio tests, and SA tests of the random walk null hypothesis with heteroskedastic distribution

Table 3-5 Power of the two-sided variance ratio test, covariance-variance ratio test,

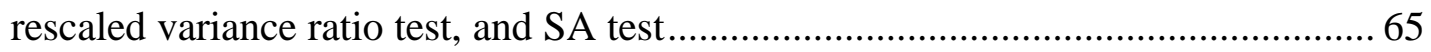

Table 3-6 Tests for excess returns of industry portfolios: 1947:01-2001:12 ….............. 66

Table 3-7 Tests for excess returns of size portfolios: 1947:01-2001:12 _...................... 67

Table 3-8 Tests for excess returns of book-to-market portfolios: 1947:01-2001:12 ....... 68

Table 3-9 Variance ratio tests for excess returns of size and book-to-market portfolios: 1947:01-2001:12

Table 3-10 Covariance-variance ratio tests for excess returns of size and book-to-market portfolios: 1947:01-2001:12

Table 3-11 Covariance-variance ratio tests for residuals of returns of size portfolios: 1947:01-2001:12

Table 3-12 Covariance-variance ratio tests for residuals of returns of book-to-market portfolios: 1947:01-2001:12

Table 3-13 Covariance-variance ratio tests for residuals of returns of industry portfolios: 1947:01-2001:12

Table 3-14 Covariance-variance ratio tests for real returns of S\&P Index 1871:022001:12.

Table 3-15 Covariance-variance ratio tests for international data on real monthly returns

Table 3-16 Covariance-variance ratio tests for excess returns of size, industry, and bookto-market portfolios using the interval of 2 years: 1947:01-2001:12 . 
Table 3-17 Covariance-variance ratio tests for excess returns of size, industry, and bookto-market portfolios using the interval of 3 years: 1947:01-2001:12

Table 3-18 Covariance-variance ratio tests for excess returns of size, industry, and bookto-market portfolios using the interval of 6 years: 1947:01-2001:12 ….................. 76

Table 4-1 Empirical sizes of the nominal 1, 5, 10 percent tests ..................................... 94

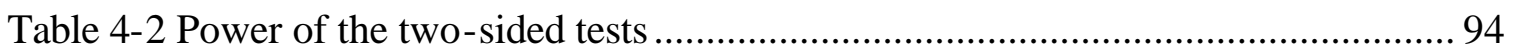

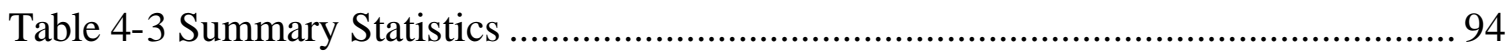

Table 4-4 Tests for returns of size portfolios 1941:01-2002:12 …............................ 95

Table 4-5 Tests for returns of industry portfolios 1941:01-2002:12 …........................ 96

Table 4-6 Tests for returns of book-to- market portfolios 1941:01-2002:12 .................. 97 


\section{List of Figures}

Figure 2-1 Cumulative Impulse Responses to One Standard-Deviation Structural Shocks



Figure 3-1 The theoretical autocorrelation structure. 


\section{Chapter 1 Introduction}

Stock market anomalies are empirical findings that cannot be explained by the widely accepted financial theories. It is very important to study stock market anomalies because understanding them can greatly improve our understanding of financial markets. Two of the most important stock market anomalies in recent history are the correlation between stock returns and inflation and the predictability of stock returns. My dissertation extends the literature and provides some new insights regarding these two anomalies. Chapter 2 is related to the first anomaly and Chapters 3 and 4 are related to the second anomaly.

The Fisherian view (1930) had been a widely accepted "wisdom" before the 1980's. This view entails that stocks, representing claims to real output, should be a good hedge against inflation. In other words, (real) stock returns should be uncorrelated with the inflation rate. However, Bodie (1976), Jaffe and Mandelker (1976), Nelson (1976), and Fama and Schwert (1977) present evidence that stock returns and inflation are negatively correlated in the post-1953 period. Ten years later, Kaul (1987) further finds that stock returns and inflation are positively but insignificantly correlated in the pre1940 period. Although the literature now agrees that the correlation between stock returns and inflation is "spurious" in the sense that there is no direct causal relationship between stock returns and inflation [Fama (1981)], the literature still disagrees what causes the change in the stock return-inflation relation. 
Kaul (1987) explains the time-varying stock return-inflation relation by a change in the monetary policy regime. A recent study by Hess and Lee (1999), in contrast, finds that time variation in the relative importance of supply and demand shocks can explain the different stock return-inflation relations in the pre-1944 and post-1947 periods.

I show in Chapter 2 that the models in Kaul (1987) and Hess and Lee (1999) are not mutually exclusive but rather two special cases of a more general model. This suggests that both changes in the monetary policy regime and changes in the relative importance of demand and supply shocks can in principle cause changes in the stock return-inflation relation. Then the question is which factor is quantitatively more important in explaining the actual change in the stock return-inflation relation.

Before we can address this question, we first need to determine the structural break in the stock return-inflation relation because not only does the literature not have a consensus regarding the break date, ${ }^{1}$ but also the approaches used by researchers to determine the break are unwarranted. Kaul (1987) chooses the structural break only based on a change in the monetary policy regime. He ignores possible changes in the relative importance of supply and demand shocks. Hess and Lee (1999) claim that their choice of the structural break is based on the study of Kaul (1987). But ironically, they effectively use a different break.

The model I develop in Chapter 2 indicates that the structural break in the stock return-inflation relation is difficult to determine analytically because changes in the stock return-inflation relation may be caused by changes in the monetary policy regime or changes in the relative importance of supply and demand shocks or both. So a datadependent econometric procedure that can search endogenously for structural breaks in

\footnotetext{
${ }^{1}$ Kaul (1987) believes that 1940 is the break, while Hess and Lee (1999) believes that 1944 is the break
} 
the stock return-inflation relation is more attractive. Fortunately, Bai and Perron (1998, 2000,2001 ) have developed such a procedure. I employ their procedure and find that the structural break in the stock return-inflation relation occurs in 1939. I further investigate what causes this structural change. I find evidence that the change in the monetary policy regime is relatively more important than the change in the relative importance of demand and supply shocks.

The contributions of Chapter 2 thus are: (1) I develop a generalized theoretical model that nests the models of Kaul (1987) and Hess and Lee (1999) to analyze the relation between stock returns and inflation. Although it is simplified and illustrative, the idea it delivers is constructive. (2) I find the structural break in the stock return-inflation relation using a more appropriate approach. (3) I find that the change in the monetary policy is quantitatively more important in explaining the change in the stock returninflation relation. In brief, I confirm the findings of Kaul (1987) in a more plausible way.

Chapters 3 and 4 are both related to the predictability of stock returns. Market efficiency with constant expected returns implies that stock returns are unpredictable. This model had been widely accepted before the 1980's, at least "as a good working model" [Fama (1991), p1578]. For instance, Jensen (1978) called it the best established empirical fact in financial economics. However, since the 1980's, this model has been repeatedly rejected by the mounting evidence of the predictability of stock returns.

Against the market efficiency model, Shiller (1981) and Summers (1986) propose the fads model, in which stock prices have a mean reverting component due to overreaction and stock returns are negatively serially correlated. However, "the tests (of 
mean reversion) turn out to be largely fruitless" [Fama (1991), p1581]. And "most researchers now agree that the mean-reversion evidence is statistically quite weak" [Richardson and Smith (1994), p379].

Recently, Barberis, Shleifer, and Vishny (1998) (hereafter, "BSV”), Daniel, Hirshleifer, and Subrahmanyam (1998) (“DHS”), and Hong and Stein (1999) (“HS”) have proposed new alternative behavioral models to the market efficiency, in which stock prices undereact (delayed overreact) in the short run and overreact in the long run. Consequently, stock returns are positively serially correlated at short horizons and negatively serially correlated at some longer horizons. HS even show that the autocorrelation may even alter sign multiple times.

The alternatives proposed by BSV, DHS, and HS are very different from that proposed by Shiller (1981) and Summers (1986). First, the autocorrelation in BSV, DHS, and HS has different signs across lags, while the autocorrelation is always negative in Shiller (1981) and Summers (1986). Second, the autocorrelation in HS may even alter sign multiple times. In contrast, the autocorrelation in the fads model is thought to be persistent. I show in Chapter 3 that these differences make the commonly used statistical tests lack power against this type of alternatives, in particular detecting negative longhorizon autocorrelations for they are not able to differentiate autocorrelations at different horizons. This may in part explain why the literature has so far found little evidence in support of mean reversion, even in the long run.

I therefore propose a new statistical test in Chapter 3 that is particularly powerful against the type of alternatives proposed by BSV, DHS, and HS. The test is shown to 
have good size and is significantly more powerful than the commonly used tests, particularly in detecting negative long-horizon autocorrelations.

When this test is applied to the data, there is statistical evidence in support of the behavioral models in that prices of stocks with more uncertainty and slower information diffusion (small, high book-to-market, or cyclical stocks) tend to have both positive short-run and negative long-run autocorrelations. Furthermore, the fact that the Fama and French three-factor model cannot absorb autocorrelations in industry portfolios lends more support to the behavioral models. The autocorrelation patterns show up in different sets of portfolios (industry, size, book-to- market, and size and book-to-market portfolios), different stock markets (15 international stock markets), different sample periods (18711946 and 1947-2001), and even for different non-overlapping intervals (1 year, 2 years, 3 years, and 6 years) used to measure autocorrelations. So the results are not likely due to data mining.

The main contributions of Chapter 3 thus are: (1) I propose a new statistical test that is particular powerful against the behavioral alternatives proposed by BSV, DHS, and HS. (2) Contrary to previous studies, when this test is applied to the data, I find reliable statistical evidence that stock prices do have a long-run mean-reverting component.

The behavioral models of BSV, DHS, and HS, as Lewellen (2002) points out, do not differentiate between firm specific and market-wide information, and predict that stock prices underreact (delayed overreact) to information in the short run and overreact in the long run. 
So far there is consistent evidence supporting that stock prices underreact to firmspecific information in the short run and overreact in the longer run [Bernard and Thomas (1989, 1990) Brown and Pope (1996), DeBondt and Thaler (1987), and Lakonishok, Shleifer, and Vishny (1994)].

However, there is still no supporting evidence that stock prices also underreact to market-wide information in the short run and overreact in the longer run. Lo and MacKinlay (1990) and Jegadeesh and Titman (1995) find that prices of (small) stocks underreact to market-wide information in the short run (one week to one month). Lewellen (2002) on the other hand presents evidence that stock prices overreact to market-wide information at all horizons, which is interpreted as a rejection of the recent behavioral models of DHS, BSV, and HS.

I show in Chapter 4 that the empirical methodology of Lewellen (2002) is not informative, because if short-run underreaction co-exists with long-run overreaction, his methodology will mask different reaction patterns at different horizons. Based on a onefactor model, I therefore propose a regression-based test that is able to differentiate different reaction patterns at different horizons. The test is also robust to serial correlation and heteroskedasticity in stock returns. When this test is applied to the data, I find statistical evidence that stock prices do underreact to market-wide information in the short run and overreact in the longer run.

The contributions of Chapter 4 thus are: (1) I develop a formal test of stock price reaction to the common factor. (2) Contrary to previous studies, when I apply the test to the data, I find evidence that stock prices underreact to the common factor in the short run and overreact in the long run. 
The methodology used in Chapter 2 may also be applied to explain the stock return-inflation relation in other countries. For instance, in high-inflation countries, stock returns are generally positively correlated with inflation. It may be interesting to see why.

The findings in Chapter 3 suggest that the autocorrelation is not as persistent as the literature believes. Stock returns only have significant positive autocorrelations at one-month lag and negative autocorrelations at two longer horizons (1 to 2 year and 5 to 6 year intervals). But the literature believes that stock returns have persistent positive autocorrelations up to one-year lag and persistent negative autocorrelations thereafter, which create momentum and contrarian profits. This thus raises a very important question, which will be my research topic in the near future. Are momentum and contrarian profits for real?

In Chapter 3, I use international data to check the robustness of the empirical results. To gain power, I do not use dividend-adjusted data, because the dividendunadjusted data has a much longer sample period. Although it may not be a serious issue as suggested by Poterba and Summers (1988), it is still interesting to develop other tests that can have reasonable power even for relative small samples, for instance, a panel approach. I will also look at this issue in the near future.

The test in Chapter 4 may also be used to examine how international markets react to worldwide information. 


\section{Chapter 2 Monetary Policy, Stock Returns, and Inflation}

\subsection{Introduction}

Contrary to the Fisherian view (1930) that stocks, representing claims to real output, should be a good hedge against inflation, Bodie (1976), Jaffe and Mandelker (1976), Nelson (1976), Fama and Schwert (1977), and Kaul (1987) present evidence that common stock returns and inflation are negatively correlated in the post-1953 period and positively but insignificantly correlated in the pre-1940 period. ${ }^{2}$ Kaul (1987) explains this time- varying stock return-inflation relation by a change in the monetary reaction function with respect to exogenous supply shocks. Exogenous demand shocks are not allowed. ${ }^{3} \mathrm{~A}$ recent study by Hess and Lee (1999), in contrast, finds that the time variation in the relative importance of supply and demand shocks can explain the different stock returninflation relations in the pre-1944 and post-1947 periods. Monetary policy is modeled to not react to exogenous supply shocks. ${ }^{4}$

Theoretically, the assumptions in Kaul (1987) and Hess and Lee (1999) are not appealing. Kaul (1987) assumes no exogenous demand shocks, while Hess and Lee

\footnotetext{
${ }^{2}$ For more US evidence see Lintner (1975), Schwert (1981), Kaul (1990), Kaul and Seyhun (1990), Wei and Wang (1992), Boudoukh et al (1994), Domian et al (1996), Graham (1996), Lee and Ni (1996), Groenewold et al (1997), and Aarstol (2000). The evidence regarding the stock return-inflation relation in other countries is also mixed. Cohn and Lessard (1981), Gultekin (1983), Solnik (1983), Amihud (1996), and Jaeuk and Lee (2000) find a negative stock return-inflation relation in some countries, while Firth (1979), Gultekin (1983), Barnes et al (1999), Khil and Lee (2000), Crosby (2001), and Choudhry (2001) find a positive relation in some other countries, especially in high inflation countries. The evidence on the long horizon relation between stock returns and inflation tends to support the Fisherian view. Gultekin (1983), Boudoukh and Richardson (1993), and Solnik and Solnik (1997) all find a positive correlation between the expected nominal stock return and expected inflation at long horizons.

${ }^{3}$ His logic is an extension of the "proxy hypothesis" of Fama (1981) and Geske and Roll (1983), and is formalized by Boyle and Peterson (1995).

${ }^{4}$ Danthine and Donaldson (1986) and Boyle and Young (1988) use a more formal approach to establish similar results.
} 
(1999) assume no monetary policy. However, they are all fundamental driving forces of the economy. I therefore relax these assumptions and propose a generalized model that allows both monetary policy and two types of exogenous shocks. Contrary to Kaul (1987) and Hess and Lee (1999), it is found that both changes in the monetary policy regime and changes in the relative importance of demand and supply shocks can cause changes in the stock return-inflation relation. The model hence permits a direct quantitative assessment of the relative importance of these two factors in explaining the actual time-varying stock return-inflation relation in the US.

Empirically, the methodologies of determining the structural break in the stock return-inflation relation in Kaul (1987) and Hess and Lee (1999) are unwarranted. Kaul (1987) first chooses the structural break in the monetary policy regime, 1940, and then tests whether the stock return-inflation relation also changes. However, since changes in the stock return-inflation relation may be caused by changes in the monetary policy regime or changes in the relative importance of supply and demand shocks or both as shown in the model developed in this chapter, it is not appropriate to choose the structural break in the stock return-inflation relation based only on the change in the monetary policy regime. Differently, Hess and Lee (1999) first determine the structural break in the stock return-inflation relation and them examine whether it is due to the change in the relative importance of supply and demand shocks. However, their approach to determine the structural break is ad hoc. They argue, "Unlike the postwar period, there is evidence that the relation between real stock returns and inflation is positive in the prewar period [e.g. Kaul (1987)]" [Hess and Lee (1999, p1212)]. But what is found in Kaul (1987) does not justify their choice of the structural break, 1944, in the stock return-inflation relation. 
The structural break in the stock return-inflation relation is difficult to determine analytically (due to that changes in the stock return-inflation relation may be caused by changes in the monetary policy regime or changes in the relative importance of supply and demand shocks or both), so I use a data-dependent econometric procedure developed by Bai and Perron $(1998,2000,2001)$ to search endogenously for structural breaks in the stock return-inflation relation during the 1926 to 2001 period. Interestingly, the structural break is found to occur in the fourth quarter of 1939, which is largely consistent with what Kaul (1987) finds. Then by utilizing the model outlined in this chapter, it is found that the change in the monetary policy regime is more important in explaining the observed time-varying stock return-inflation relation in the US, which is again interestingly consistent with what Kaul (1987) finds.

The remainder of this chapter is organized as follows. Section 2.2 sketches the economic model motivating the empirical analysis. Section 2.3 describes the data and presents the empirical results. Section 2.4 concludes the chapter with a brief summary. The appendix (Section 2.5) presents the empirical methodology employed.

\subsection{A Stock Price Model with Long Run Neutrality of Money}

By assuming no exogenous demand shocks, Kaul (1987) finds that changes in the stock return-inflation relation depend only on changes in the monetary policy regime. ${ }^{5}$ In contrast, Hess and Lee (1999) assume no monetary policy and find that changes in the stock return-inflation relation are solely due to changes in the relative importance of

\footnotetext{
${ }^{5}$ Although the model in Boyle and Peterson (1995) allows for both exogenous demand shocks and the monetary policy, their model is constructed in such a way that demand shocks cannot affect the stock return-inflation relation and therefore again only changes in the monetary policy can cause changes in the stock return-inflation relation.
} 
demand and supply shocks. However, both demand shocks and monetary policy seem to be fundamental driving forces of the economy, so it is important to relax these assumptions and study the stock return-inflation relation in a generalized model. This chapter proposes such a generalized model that allows both monetary policy and two types of exogenous structural shocks. Let

$$
\begin{aligned}
& y_{t}^{d}=m_{t}-p_{t} \\
& y_{t}^{s}=\mu+\alpha\left(p_{t}-E_{t-1} p_{t}\right)+\Theta_{t} \quad 0<\alpha<1
\end{aligned}
$$

where $y^{d}=\log$ of aggregate demand; $y^{s}=\log$ of aggregate supply; $m=\log$ of the money supply; $p=\log$ of the price level; $\boldsymbol{\theta}=\log$ of productivity; and $\mathrm{E}_{-1}$ denotes a rational expectation formed by using the information set $\mathrm{I}_{\mathrm{t}-1}$ that is available to market participants in period $t-1$.

Equation (1) states that aggregate demand is a function of real balances, presuming a constant velocity of money circulation, which is omitted for simplicity. Equation (2) is a Lucas-type aggregate supply function stating that output supplied depends positively on productivity and unexpected changes in the price level. ${ }^{6}$ To close the model, how $m$ and $\theta$ evolve needs to be specified. I assume:

$$
\begin{aligned}
& \boldsymbol{\theta}_{t}=\boldsymbol{\theta}_{t-1}+e_{t}^{s} \\
& m_{t}=m_{t-1}+\lambda e_{t}^{s}+e_{t}^{m}
\end{aligned}
$$

where $e^{s}$ and $e^{m}$ are serially uncorrelated and mutually orthogonal supply and money supply shocks. Monetary policy is modeled in much the same way as Boyle and Peterson (1995), and the interpretation of (4) is as follows. Each period, the monetary authority

\footnotetext{
${ }^{6}$ This may be due to stickiness in the nominal wage or to informational imperfections.
} 
adjusts the money supply in response to contemporaneous supply shocks. Additional exogenous shocks to the money supply, $e^{m}$, are allowed because implementation of monetary policy is imperfect so that unplanned disturbances occur. Alternatively, the monetary authority may have other, non-systematic or unknown, targets. It follows that if $\lambda$ is positive, negative, or zero, then monetary policy, respectively, is pro-cyclical, counter-cyclical, or neutral.

Solving for output growth and inflation gives:

$$
\begin{aligned}
\Delta y_{t} & =\frac{1+\lambda \alpha}{1+\alpha} e_{t}^{s}+\frac{\alpha-\lambda \alpha}{1+\alpha} e_{t-1}^{s}+\frac{\alpha}{1+\alpha} e_{t}^{m}-\frac{\alpha}{1+\alpha} e_{t-1}^{m} \\
& =\sum_{j=0}^{1} c_{31}(j) e_{t-j}^{s}+\sum_{j=0}^{1} c_{32}(j) e_{t-j}^{m} \\
& =\Delta y_{t}^{s}+\Delta y_{t}^{m} \\
\Delta p_{t} & =\frac{\lambda-1}{1+\alpha} e_{t}^{s}+\frac{\alpha(\lambda-1)}{1+\alpha} e_{t-1}^{s}+\frac{1}{1+\alpha} e_{t}^{m}+\frac{\alpha}{1+\alpha} e_{t-1}^{m} \\
& =\sum_{j=0}^{1} c_{21}(j) e_{t-j}^{s}+\sum_{j=0}^{1} c_{22}(j) e_{t-j}^{m} \\
& =\Delta p_{t}^{s}+\Delta p_{t}^{m}
\end{aligned}
$$

where $\Delta \mathrm{y}^{\mathrm{s}}$ and $\Delta \mathrm{y}^{\mathrm{m}}$ are supply and money supply components of real output growth, $\Delta \mathrm{p}^{\mathrm{s}}$ and $\Delta \mathrm{p}^{\mathrm{m}}$ are supply and money supply components of inflation. Note that the notation $c_{i k}(j)$ indicates the structural vector moving average (VMA) coefficients for variable $i$ (stock returns, inflation, and real output growth are, respectively, variables 1, 2, and 3), at lag $j$, with $k$ representing either the supply or the demand (money supply) component of each variable. 
Assume that firms pay a constant fraction of revenues to shareholders. Then, dividends are proportionally related to output: and $\Delta \mathrm{d}_{\mathrm{t}}=\Delta \mathrm{y}_{\mathrm{t}}$ where $d_{t}$ is the log of real dividends paid in period t. By using the log-linear approximation of Campbell and Shiller $(1988,1989)$ to the present value formula and employing the relationship between output and dividends, I obtain the log of stock prices, $s p_{t}$, as

$$
s p_{t}=y_{t-1}+k+E_{t} \sum_{k} \rho^{k}\left(\Delta y_{t+k}\right)
$$

where $k$ is a constant, and $\rho$ is a discount factor very close to one, which is determined by the mean of the dividend-price ratio.

In order to compute the discounted value of the expected output growth in (7), I use a result due to Hansen and Sargent (1980). For any given covariance-stationary process $x_{t}=c(L) u_{t}, u_{t} \sim N\left(0, \sigma^{2}\right)$, Hansen and Sargent show that

$$
E_{t} \sum_{j=0}^{\infty} \rho^{j} x_{t+j}=[c(L) L-\rho c(\rho)](L-\rho)^{-1} u_{t}
$$

Using this result, I obtain,

$$
s p_{t}=y_{t-1}+k+\frac{1+\lambda \alpha+\alpha \rho-\lambda \alpha \rho}{1+\alpha} e_{t}^{s}+\frac{\alpha-\lambda \alpha}{1+\alpha} e_{t-1}^{s}+\frac{\alpha-\alpha \rho}{1+\alpha} e_{t}^{m}-\frac{\alpha}{1+\alpha} e_{t-1}^{m}
$$

Following Hess and Lee (1999), I obtain real stock returns by solving Equation (8) for the first difference of the stock price, $\Delta \mathrm{sp}_{\mathrm{t}}$

$$
\begin{aligned}
\Delta s p_{t} & =\frac{1+\lambda \alpha+\alpha \rho-\lambda \alpha \rho}{1+\alpha} e_{t}^{s}+\frac{\alpha-\lambda \alpha-\alpha \rho+\lambda \alpha \rho}{1+\alpha} e_{t-1}^{s}+\frac{\alpha-\alpha \rho}{1+\alpha} e_{t}^{m}-\frac{\alpha-\alpha \rho}{1+\alpha} e_{t-1}^{m} \\
& =\sum_{j=0}^{1} c_{11}(j) e_{t-j}^{s}+\sum_{j=0}^{1} c_{12}(j) e_{t-j}^{m} \\
& =\Delta s p_{t}^{s}+\Delta s p_{t}^{m}
\end{aligned}
$$

where $\Delta \mathrm{sp}^{\mathrm{s}}$ and $\Delta \mathrm{sp}^{\mathrm{m}}$ are supply and money supply components of real stock returns. 
The model implies: the long-run effects of money supply shocks on real stock prices $\left(\sum_{k} \frac{\partial \Delta s p_{t}}{\partial e_{t-k}^{m}}=\frac{\alpha-\alpha \rho}{1+\alpha}-\frac{\alpha-\alpha \rho}{1+\alpha}\right)$ and the price level $\left(\sum_{k} \frac{\partial \Delta p_{t}}{\partial e_{t-k}^{m}}=\frac{1}{1+\alpha}+\frac{\alpha}{1+\alpha}\right)$ are 0 and 1 , respectively. Thus, money supply shocks have no long-run effect on real stock prices. This result will be used in the next section to recover the structural shocks from a vector autoregression (VAR) model of $\left[\Delta \mathrm{sp}_{\mathrm{t}}, \Delta \mathrm{p}_{\mathrm{t}}\right]$. The long-run effects of supply shocks on real stock prices $\left(\sum_{k} \frac{\partial \Delta s p_{t}}{\partial e_{t-k}^{s}}=\frac{1+\lambda \alpha+\alpha \rho-\lambda \alpha \rho}{1+\alpha}+\frac{\alpha-\lambda \alpha-\alpha \rho+\lambda \alpha \rho}{1+\alpha}\right)$ and the price level $\left(\sum_{k} \frac{\partial \Delta p_{t}}{\partial e_{t-k}^{s}}=\frac{\lambda-1}{1+\alpha}+\frac{\alpha(\lambda-1)}{1+\alpha}\right)$ are 1 and $\lambda-1 .^{7}$ Thus,

Proposition 1: A positive supply shock does not decrease the price level permanently if monetary policy is strongly pro-cyclical $(\lambda \geq 1)$; it decreases the price level permanently if monetary policy is weakly pro-cyclical, neutral, or counter-cyclical $(\lambda<1)$.

This result enables us to identify directly the monetary policy regime from the long-run effect of supply shocks on the price level.

The least squares coefficient of the inflation rate, $\beta$, in a regression model such as

$$
\begin{aligned}
\Delta s p_{t}=\alpha & +\beta \Delta p_{t}+\varepsilon_{t} \text { is } \\
\beta & =\frac{\operatorname{cov}\left(\Delta s p_{t}, \Delta p_{t}\right)}{\operatorname{var}\left(\Delta p_{t}\right)}
\end{aligned}
$$

\footnotetext{
${ }^{7}$ See Blanchard and Quah (1989) for why the long-run effect is equal to the sum of VMA coefficients.
} 


$$
=\frac{\operatorname{cov}\left(\Delta s p_{t}^{s}+\Delta s p_{t}^{m}, \Delta p_{t}^{s}+\Delta p_{t}^{m}\right)}{\operatorname{var}\left(\Delta p_{t}\right)}
$$

Since the structural shocks are uncorrelated and mutually orthogonal, we have

$$
\begin{aligned}
\beta & =\frac{\operatorname{cov}\left(\Delta s p_{t}^{s}, \Delta p_{t}^{s}\right)+\operatorname{cov}\left(\Delta s p_{t}^{m}, \Delta p_{t}^{m}\right)}{\operatorname{var}\left(\Delta p_{t}\right)} \\
& =\frac{\operatorname{var}\left(\Delta p_{t}^{s}\right)}{\operatorname{var}\left(\Delta p_{t}\right)} \frac{\operatorname{cov}\left(\Delta s p_{t}^{s}, \Delta p_{t}^{s}\right)}{\operatorname{var}\left(\Delta p_{t}^{s}\right)}+\frac{\operatorname{var}\left(\Delta p_{t}^{m}\right)}{\operatorname{var}\left(\Delta p_{t}\right)} \frac{\operatorname{cov}\left(\Delta s p_{t}^{m}, \Delta p_{t}^{m}\right)}{\operatorname{var}\left(\Delta p_{t}^{m}\right)} \\
& =s_{s} \beta_{s}+s_{m} \beta_{m}
\end{aligned}
$$

where $\beta_{\mathrm{s}}$ represents the least squares coefficient of the supply component of inflation in a regression such as $\Delta s p_{t}{ }^{s}=\alpha_{s}+\beta_{s} \Delta p_{t}{ }^{s}+\varepsilon_{t}^{s}, \beta_{\mathrm{m}}$ represents the least squares coefficient of the money supply component of inflation in a regression such as $\Delta s p_{t}^{m}=\alpha_{m}+\beta_{n} \Delta p_{t}^{m}+$ $\varepsilon_{t}^{m}, s_{s}$ represents the percentage of the inflation rate's variance explained by the supply shock, and $s_{m}$ represents the percentage of the inflation rate's variance explained by the money supply shock. Therefore, changes in the relative importance of structural shocks, $s_{s}$ and $s_{m}$, can cause changes in the stock return-inflation relation. This is the point that Hess and Lee (1999) among others make. But the following analysis will show that this is not the only factor that can cause changes in the stock return-inflation relation.

Consider the least squares coefficient of the supply component of the inflation rate,

$$
\begin{aligned}
\beta_{s} & =\frac{\operatorname{cov}\left(\Delta s p_{t}^{s}, \Delta p_{t}^{s}\right)}{\operatorname{var}\left(\Delta p_{t}^{s}\right)} \\
& =\frac{\sum_{j} c_{11}(j) c_{21}(j)}{\sum_{j} c_{21}(j)^{2}}
\end{aligned}
$$

Notice that the discount factor, $\rho$, is very close to one. We obtain 
$\beta_{s} \approx(\lambda-1)(1+\alpha \rho) /(1+\alpha)^{2}$

Proposition 2: Supply components of real stock returns and inflation are insignificantly or positively correlated if monetary policy is strongly pro-cyclical $(\lambda \geq 1)$; but negatively correlated if monetary policy is weakly pro-cyclical, or neutral, or counter-cyclical $(\lambda<1)$.

Proposition 2 implies that monetary policy can affect the stock return-inflation relation indirectly, through its effect on the relation between the supply components of stock returns and inflation, $\beta_{\mathrm{s}}$. Thus, it is very different from what Kaul (1987) and Boyle and Peterson (1995) (Proposition 3) find that monetary policy directly affects the relationship between stock returns and inflation. This difference is due to that the model in this chapter allows that demand shocks affect the stock return-inflation relation, as it is easy to verify that $\beta_{m}=\alpha(1-\rho)(1-\alpha) /(1+\alpha)^{2}>0$, while the models in Kaul (1987) and Boyle and Peterson (1995) do not, or $\beta_{m}=0$.

The model in this chapter suggests that both changes in the monetary policy regime, which can cause changes in $\beta_{\mathrm{s}}$, and changes in the relative importance of structural shocks, $s_{s}$ and $s_{m}$, can cause changes in the stock return-inflation relation. Because there are two factors that can cause changes in the stock return-inflation relation, it is not appropriate to determine the structural break in the stock return-inflation relation only according to the change in one factor, the monetary policy regime as in Kaul (1987). To develop a sense of the shortcoming, suppose the true process is such that $s_{s}=0.0\left(s_{m}=\right.$ 
1.0) for the pre-1945 period and $s_{s}=1.0\left(s_{m}=0.0\right)$ thereafter, while $\beta_{\mathrm{s}}>0.0$ for the pre1940 period due to strongly pro-cyclical monetary policy and $\beta_{\mathrm{s}}<0.0$ thereafter due to counter-cyclical monetary policy. Equation 11 then suggests that the stock returninflation relation has one single break in 1945. The relation is positive in the pre-1945 period and negative thereafter. However, if the break were determined according to the change in the monetary policy regime, it would be 1940. The empirical evidence would also be consistent with the hypothesis that the change in the stock return-inflation relation is due to the change in the monetary policy regime, although it is clear from Equation 11 that the change in the relation is entirely due to the change in the relative importance of demand and supply shocks. Therefore, to analytically determine the structure break in the stock return-inflation relation, one should simultaneously consider changes in the monetary policy regime and changes in the relative importance of demand and supply shocks. This clearly is difficult. This difficulty motivates me to use a data-dependent econometric procedure developed by Bai and Perron $(1998,2000,2001)$ to search endogenously for structural breaks in the stock return-inflation relation.

Estimates of $\beta_{\mathrm{s}}, s_{s}$ and $s_{m}$ over the periods during which the stock return-inflation relation is different then can be used to directly assess the relative importance of these two factors in determining changes in stock return-inflation relation. For instance, insignificantly different estimates of $s_{s}$ and $s_{m}$ but significantly different estimates of $\beta_{s}$ over different periods would suggest that the change in the stock return-inflation is mainly due to the change in the monetary policy regime. To obtain estimates of $\beta_{\mathrm{s}}, s_{s}$ and $s_{m}$, the structural VMA model of $\left[\Delta \mathrm{sp}_{\mathrm{t}}, \Delta \mathrm{p}_{\mathrm{t}}\right]$ needs to be estimated. The methodology 
introduced by Blanchard and Quah (1989) (described in the appendix) can recover such a structural VMA model from the reduced VAR representation.

Alternatively, one may consider directly estimating the exact rational expectations model. However, because the model is mainly set up to show that both changes in the monetary policy regime and changes in the relative importance of structural shocks can cause changes in the stock return-inflation relation, it is highly simplified and may not be appropriate to estimate. For instance, there do not seem to be clear theoretical grounds for ruling out a specification of the monetary reaction function such that the money supply can also react to lagged supply shocks.

\subsection{Data and Empirical Results}

\subsubsection{Data}

The empirical analysis is conducted using US quarterly data during the 1926 to 2001 period. Quarterly returns are constructed by compounding monthly value-weighted returns with dividends obtained from the CRSP data file. The price level is the seasonally unadjusted U.S. Consumer Price Index (CPI) from the Bureau of Labor Statistics. The quarterly real stock returns are computed as nominal returns deflated by consumer price inflation.

\subsubsection{Unit Root Tests}

To econometrically justify a VAR model of $\left[\Delta \mathrm{sp}_{\mathrm{t}}, \Delta \mathrm{p}_{\mathrm{t}}\right]$, which is essential to estimate the structural VMA model, the unit root tests of the levels and the firstdifferences of the variables are conducted. 
Dufour and King (1991), Elliott, Rothenberg, and Stock (1996), and Ng and Perron (2001) find that local GLS detrending of the data yields substantial power gains in unit root tests. Ng and Perron (2001) further suggest a class of modified information criteria that leads to significant size improvements when the unit root process has a negative moving-average root. Hence, I (1) implement GLS detrending and (2) use the modified information criteria of $\mathrm{Ng}$ and Perron (2001) to select the autoregressive truncation lag when the time series has a negative moving-average root.

Following Ng and Perron (2001), I first estimate the simple ARMA $(1,1)$ model for each series, the inflation rate, nominal stock returns, and real stock returns. The results show: (1) the autoregressive root for the inflation rate is close to one (0.88) and the MA coefficient is negative $(-0.52)$; (2) the autoregressive roots and the MA coefficients for stock returns are close to zero (ranging from -0.00 to -0.08 ). This suggests that the modified information criteria of $\mathrm{Ng}$ and Perron (2001) is appropriate for choosing the truncation lag in testing the unit root in the inflation rate. I then follow the procedure in $\mathrm{Ng}$ and Perron (2001) to construct the various tests assuming inflation and stock returns are nontrending. ${ }^{8}$ Table 2-1 reports the results. Although the unit root tests do not show strong rejections for the inflation rate, ${ }^{9}$ this may merely due to the low power of the tests, because there is strong evidence in favor of stationarity of nominal and real stock returns (all tests are significant at the 5\% level), the inflation rate, as the difference between two stationary time series (nominal and real stock returns), should be

\footnotetext{
${ }^{8}$ The Gauss program is downloaded from Pierre Perron's homw page, http://econ.bu.edu/perron/.

${ }^{9}$ Only the Phillips-Perron $Z_{\alpha}$ test shows a rejection. However, it is shown in $\mathrm{Ng}$ and Perron (2001) that the Phillips-Perron $Z_{\alpha}$ test has high size distortions even when constructed using the modified information criteria.
} 
stationary too. Therefore, the results suggest that both the inflation rate and real stock returns are stationary.

The additional tests also show that logged stock price and CPI series are nonstationary but not cointegrated. To gether, the results justify a bivariate VAR model of the first differences of logged stock prices and the price level, i.e., stock returns and inflation.

\subsubsection{Searching for Endogenous Structural Breaks}

Due to the difficulty in determining the structural break in the stock returninflation relation analytically (one has to simultaneously consider changes in the monetary policy regime and changes in the relative importance of demand and supply shocks), I employ a data-dependent econometric procedure developed by Bai and Perron $(1998,2000,2001)$ to search endogenously for structural breaks in the stock returninflation relation. ${ }^{10}$ Specifically, I estimate the following regression model with $m$ breaks $(m+1$ regimes $)$

$$
\Delta s p_{t}=\alpha+\beta_{j} \Delta p_{t}+\varepsilon_{t}
$$

where $\mathrm{j}=1, \ldots, \mathrm{m}+1$. I allow up to 5 breaks and uses a trimming of 0.15 . Different moments of the regressor across segments and serial correlation and heterogeneity in the residuals are also allowed. ${ }^{11}$ Table $2-2$ presents the results. First, the significance of the sup $\mathrm{F}_{\mathrm{T}}(\mathrm{k})$ tests (for $k$ between 1 and 5) and the double maximum tests (UDmax and

\footnotetext{
${ }^{10}$ Although many studies of stock returns and inflation decompose the inflation rate into expected and unexpected components, the ex post inflation rate is used as the single inflation variable in this paper. This is done because, as Aarstol (2000) points out, the additional insight gained by decomposing inflation into expected and unexpected components is small, and does not justify the econometric problem created.

${ }^{11}$ The Gauss program is downloaded from Pierre Perron's home page, http://econ.bu.edu/perron/.
} 
WDmax) suggests that at least one break is present. Second, the insignificance of the sup $\mathrm{F}_{\mathrm{T}}(2 \mid 1)$ test (the statistic is equal to 3.28 ) indicates that there is only one break in the regression model. Third, the break date is estimated at 1939:IV. The difference in the estimated slopes over two periods, obtained under global minimization, is significant. In the 1920s and 1930s there is a positive correlation between inflation and real stock returns, the estimated slope is 1.77 ; since 1940 , the stock return-inflation correlation has been negative, the estimated slope is -2.18 .

\subsubsection{Variance Decomposition and Impulse Response Functions}

To assess the relative importance of changes in the monetary policy regime compared to changes in the composition of structural shocks in explaining the change in the stock return-inflation relation, estimates of $\beta_{\mathrm{s}}, s_{s}$ and $s_{m}$ over these two periods are needed. Insignificantly different estimates of $s_{s}$ and $s_{m}$ but significantly different estimates of $\beta_{\mathrm{s}}$ over these two periods would suggest that the change in the stock returninflation is mainly due to the change in the monetary policy regime. To obtain estimates of $\beta_{\mathrm{s}}, s_{s}$ and $s_{m}$, the structural VMA model of $\left[\Delta \mathrm{sp}_{\mathrm{t}}, \Delta \mathrm{p}_{\mathrm{t}}\right]$ needs to be estimated. I employ the methodology introduced by Blanchard and Quah (1989) to recover the structural VMA model over these two periods from the reduced VAR model with 4 lags for the 1926:I - 1939:IV period and 6 lags for the 1940:I - 2001:IV period. The lag lengths are based on the Akaike criteria. ${ }^{12}$

I first examine whether the relative importance of the two structural shocks, $s_{s}$ and $s_{m}$, changes in these two periods. Following Hess and Lee (1999), the percentage of the

\footnotetext{
${ }^{12}$ A Rats program written by Norman Morin is downloaded from the Rats home page, www.estima.com.
} 
forecast error variance in inflation that is explained by either supply or demand shocks is estimated. The results are reported in Table 2-3. The 95\% standard error bands are presented in parentheses. Both point estimates and interval estimates are very close. This suggests that the relative importance of these structural shocks, $s_{s}$ and $s_{m}$, is about the same in both periods. Hence, the significant change in the stock return-inflation relation must be due mainly to different correlations between the components of real stock returns and inflation in the two periods as indicated by Equation 11.

Formal evidence is found in Table 2-4. In the 1926:I-1939:IV period, the supply components $\left(\Delta s p^{s}\right.$ and $\left.\Delta p^{s}\right)$ are insignificantly correlated (-1.94), and the money supply components $\left(\Delta s p^{m}\right.$ and $\left.\Delta p^{m}\right)$ are positively correlated (1.72). As a result, real stock returns $(\Delta s p)$ and inflation $(\Delta p)$ are positively correlated. In the 1940:I-2001:IV period, the supply components $\left(\Delta s p^{s}\right.$ and $\left.\Delta p^{s}\right)$ are strongly negatively correlated (-7.82), and the money supply components $\left(\Delta s p^{m}\right.$ and $\left.\Delta p^{m}\right)$ are positively correlated (2.16). Thus, real stock returns $(\Delta s p)$ and inflation $(\Delta p)$ are negatively correlated. The money supply shock components have a similar correlation pattern in both periods. The significantly different stock return-inflation relation is mainly due to different correlation between supply shock components of real stock returns and inflation.

Suggested by the model outlined in the Section 2.2, the insignificant correlation between supply components of real stock returns and inflation results from strongly procyclical monetary policy, which shows up as the positive long-run effect of supply shocks on the price level; the negative correlation between supply components of real stock returns and inflation is due to weakly pro-cyclical, neutral, or counter-cyclical monetary policy, which shows up as the negative long-run effect of supply shocks on the price 
level. Hence, the change in the long-run effect of supply shocks on the price level from positive to negative during these periods would suggest that the change in the stock return-inflation relation is mainly due to the change in the monetary policy regime.

Supporting evidence is found in Figure 2-1. Panel A shows the long-run effects of the structural shocks in the 1926:I-1939:IV period. Supply shocks have a positive longrun effect on real stock prices and the price level. This is consistent with the implication of the model and suggests that the insignificant correlation between the supply components of real stock returns and inflation is caused by the strongly pro-cyclical monetary policy. Money supply shocks as implied by the model only have a positive long-run effect on the price level. Panel B shows the long-run effects of the structural shocks in the 1940:I-2001:IV period. Supply shocks have a positive long-run effect on real stock prices but a negative effect on the price level. This is consistent with the implication of the model and suggests that the negative correlation between the supply components of real stock returns and inflation in this period is due to the weakly procyclical, neutral, or counter-cyclical monetary policy. Money supply shocks once again have the long-run effects on real stock prices and the price level implied by the model.

The change in the long-run effect of supply shocks on the price level, due to the change in the monetary policy regime, should also lead to a structural change in the VAR model of $\left[\Delta s p_{t}, \Delta p_{t}\right]$ (see the appendix). Therefore, I conduct a test on whether 1939:IV is a structural break for each equation in the VAR model of $\left[\Delta s p_{t}, \Delta p_{t}\right]$. The F-statistic of the Chow test for the stock return equation takes the value 2.90 and that for the inflation equation is equal to 2.14 . Each is significant at the $5 \%$ level. 
Therefore, the empirical evidence suggests that the change in the stock returninflation relation is mainly due to the change in the monetary policy regime and does not appear to be related to a change in the composition of demand versus supply shocks.

\subsection{Conclusion}

Different from Kaul (1987) and Hess and Lee (1999), I show that both changes in the monetary policy regime and changes in the relative importance of the structural shocks can contribute to the time-varying stock return-inflation relation. Because of the difficulty in determining the structural break in the stock return-inflation relation analytically, I use a data-dependent econometric procedure developed by Bai and Perron $(1998,2000,2001)$ to search endogenously for structural breaks in the relation. The (only) break identified endogenously by the data is 1939:IV. Utilizing the model outlined in this chapter, it is found that the change in monetary policy regime is quantitatively more important than the change in the relative importance of demand and supply shocks in explaining the observed time-varying stock return-inflation relation in the US. 
Table 2-1 Tests for unit roots 1926:I - 2001:IV

\begin{tabular}{|c|c|c|c|}
\hline & Inflation & Nominal Stock Returns & Real Stock Returns \\
\hline $\operatorname{AR}(\alpha)$ & 0.88 & -0.06 & -0.08 \\
\hline $\operatorname{MA}(\theta)$ & -0.52 & -0.03 & -0.00 \\
\hline$k$ & 15 & 2 & 2 \\
\hline $\mathrm{Z}$ & $-11.97 *$ & $-69.10^{*}$ & $-85.32 *$ \\
\hline $\mathrm{MZ}$ & -2.61 & $-22.01 *$ & $-26.13^{*}$ \\
\hline $\mathrm{DF}$ & -1.23 & $-4.02 *$ & $-4.49 *$ \\
\hline $\mathrm{P}$ & 9.82 & $1.47 *$ & $1.27 *$ \\
\hline MP & 9.33 & $1.34^{*}$ & $1.17 *$ \\
\hline
\end{tabular}

Note: $\mathrm{k}$ : the truncation lag; $\mathrm{Z}$ : the Phillips-Perron $\mathrm{Z}_{\alpha}$ test; $\mathrm{MZ}$ : the modified Phillips-Perron $\mathrm{Z}_{\alpha}$ test; DF: the augmented Dickey-Fuller test; P: Elliott, Rothemberg and Stock feasible point optimal test; MP: the modified point optimal test. * denotes a statistic significance at the $5 \%$ level.

Table 2-2 Structural breaks in the stock return-inflation relation: 1926:1 - 2001:IV

\begin{tabular}{|c|c|c|c|c|c|c|}
\hline $\operatorname{SupF}_{\mathrm{T}}(1)$ & $\operatorname{SupF}_{\mathrm{T}}(2)$ & $\operatorname{SupF}_{\mathrm{T}}(3)$ & $\begin{array}{r}\text { Tests } \\
\operatorname{SupF}_{\mathrm{T}}(4)\end{array}$ & $\operatorname{SupF}_{\mathrm{T}}(5)$ & UDmax & WDmax \\
\hline $11.43^{*}$ & $8.03 *$ & $8.59^{*}$ & $9.00 *$ & $14.46^{*}$ & $14.46^{*}$ & $31.73^{*}$ \\
\hline $\operatorname{SupF}_{\mathrm{T}}(2 \mid 1)$ & $\operatorname{SupF}_{\mathrm{T}}(3 \mid 2)$ & $\operatorname{SupF}_{\mathrm{T}}(4 \mid 3)$ & $\operatorname{SupF}_{\mathrm{T}}(5 \mid 4)$ & & & \\
\hline 3.28 & $11.22 *$ & 6.19 & 0.01 & & & \\
\hline \multicolumn{7}{|c|}{ Estimates with One Break } \\
\hline$\hat{\beta_{1}}$ & $\hat{\beta_{2}}$ & & & & & \\
\hline $1.77 *$ & $-2.18^{*}$ & & & & & \\
\hline$(0.84)$ & $(0.57)$ & & & & & \\
\hline
\end{tabular}


Table 2-3 Variance decomposition: percentage of forecast error variance explained by supply and money supply shocks

\begin{tabular}{|c|c|c|c|c|}
\hline & \multicolumn{2}{|c|}{ 1926:I - 1939:IV } & \multicolumn{2}{|c|}{ 1940:I - 2001:IV } \\
\hline & $\mathrm{S}_{\mathrm{S}}$ & $\mathrm{s}_{\mathrm{m}}$ & $\mathrm{S}_{\mathrm{S}}$ & $\mathrm{S}_{\mathrm{m}}$ \\
\hline \multicolumn{5}{|c|}{ Horizon (quarters) } \\
\hline 1 & $0.14(0.03,0.49)$ & $0.86(0.51,0.97)$ & $0.52(0.11,0.87)$ & $0.48(0.13,0.89)$ \\
\hline 4 & $0.39(0.21,0.64)$ & $0.61(0.36,0.79)$ & $0.48(0.09,0.82)$ & $0.52(0.18,0.91)$ \\
\hline 8 & $0.42(0.22,0.66)$ & $0.58(0.34,0.78)$ & $0.47(0.09,0.79)$ & $0.53(0.21,0.91)$ \\
\hline 12 & $0.42(0.21,0.67)$ & $0.58(0.33,0.79)$ & $0.47(0.09,0.79)$ & $0.53(0.21,0.91)$ \\
\hline 16 & $0.42(0.21,0.68)$ & $0.58(0.32,0.79)$ & $0.47(0.09,0.79)$ & $0.53(0.21,0.91)$ \\
\hline 20 & $0.42(0.21,0.68)$ & $0.58(0.32,0.79)$ & $0.47(0.09,0.79)$ & $0.53(0.21,0.91)$ \\
\hline
\end{tabular}

Note: $\mathrm{s}_{\mathrm{s}}$ and $\mathrm{s}_{\mathrm{m}}$ represent relative importance of supply and money supply shocks. Numbers in parentheses are simulated $95 \%$ standard error bands.

Table 2-4 Component regressions 1926:I - 2001:IV

\begin{tabular}{cc}
\hline \multicolumn{1}{c}{$1926: \mathrm{I}-1939: \mathrm{IV}$} \\
\hline$\Delta \mathrm{sp}_{\mathrm{t}}{ }^{\mathrm{s}}=$ & $0.02-1.94 \Delta \mathrm{p}_{\mathrm{t}}{ }^{\mathrm{s}}$ \\
$(0.55)(-0.57)$ & $\Delta \mathrm{sp}_{\mathrm{t}}{ }^{\mathrm{m}}=-0.01+1.72 \Delta \mathrm{p}_{\mathrm{t}}{ }^{\mathrm{m}}$ \\
& $(-1.41)(3.60)$ \\
& $1940: \mathrm{I}-2001: \mathrm{IV}$ \\
\hline$\Delta \mathrm{sp}_{\mathrm{t}}{ }^{\mathrm{s}}=0.00-7.82 \Delta \mathrm{p}_{\mathrm{t}}{ }^{\mathrm{s}}$ & $\Delta \mathrm{sp}_{\mathrm{t}}{ }^{\mathrm{m}}=-0.00+2.16 \Delta \mathrm{p}_{\mathrm{t}}{ }^{\mathrm{m}}$ \\
$(0.31)(-19.33)$ & $(-0.48)(3.69)$ \\
\hline Note: & 0
\end{tabular}

Note: The numbers in parentheses are t-statistics, which use Newey-West consistent covariance estimates. 
Figure 2-1 Cumulative Impulse Responses to One Standard-Deviation Structural Shocks

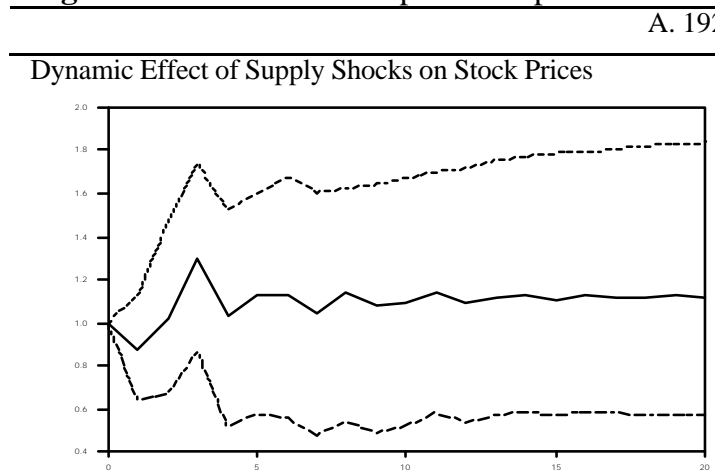

Dynamic Effect of Supply Shocks on the Price Level

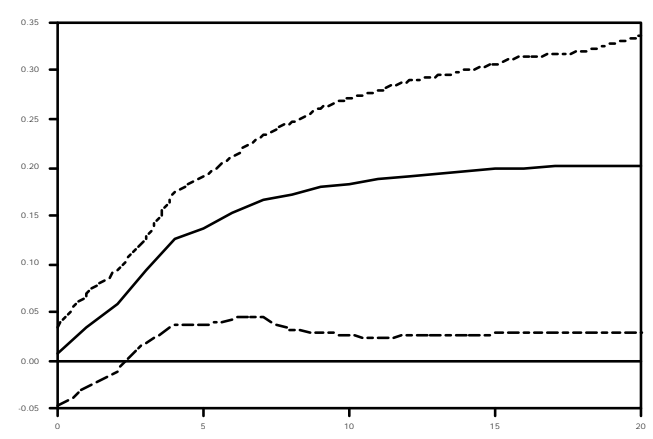

Dynamic Effect of Money Supply Shocks on Stock Prices

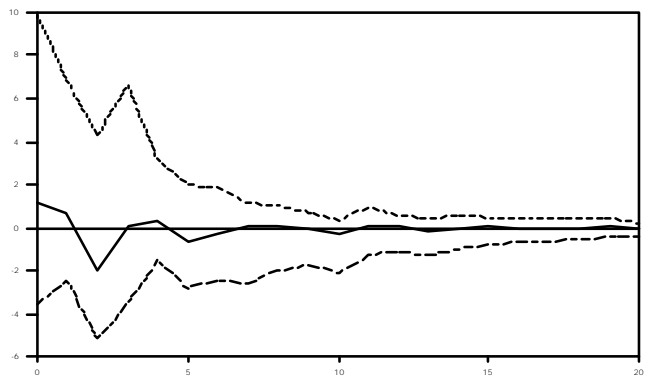

Dynamic Effect of Money Supply Shocks on the Price Level

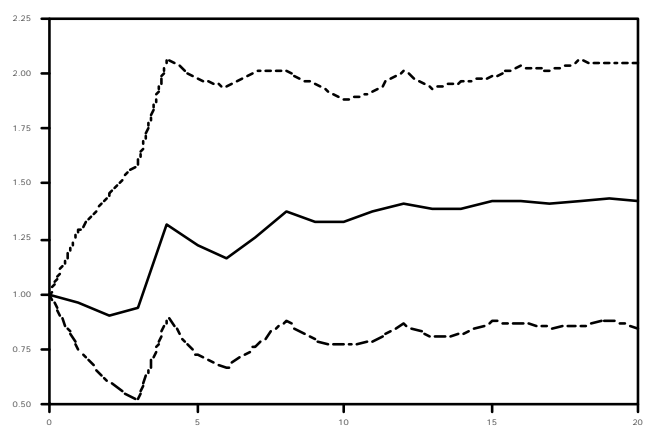

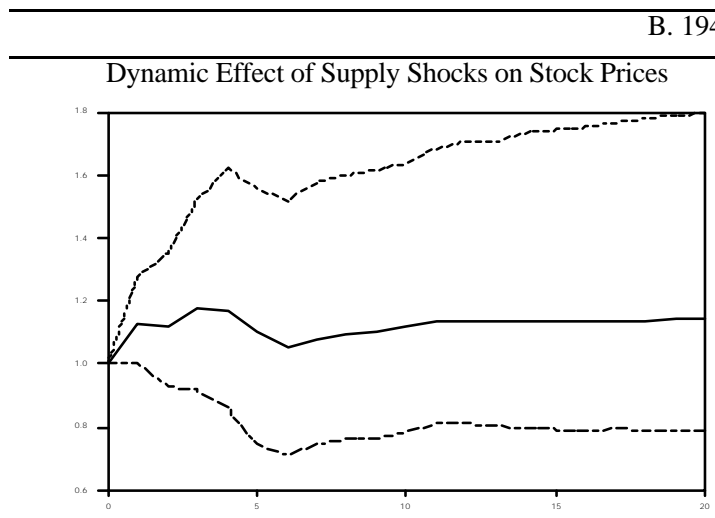

Dynamic Effect of Supply Shocks on the Price Level

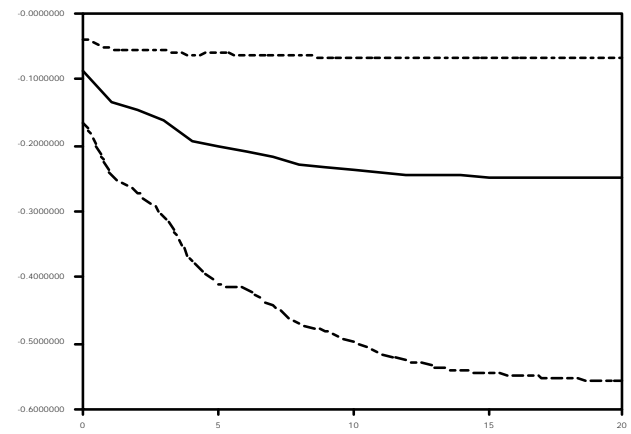

1940:I-2001:IV

Dynamic Effect of Money Supply Shocks on Stock Prices

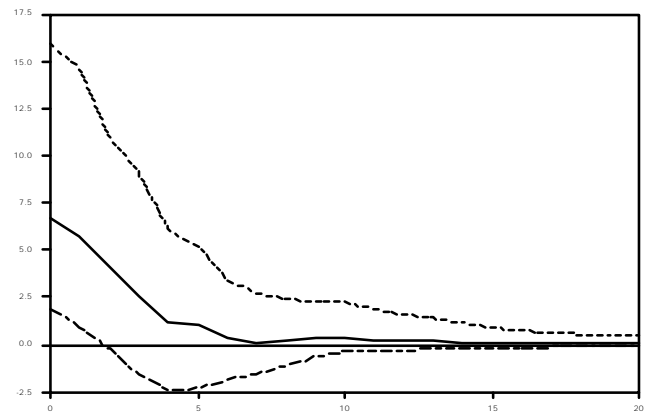

Dynamic Effect of Money Supply Shocks on the Price Level

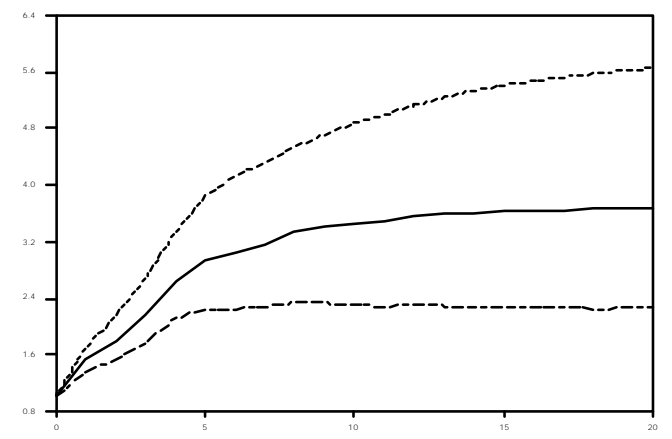

Note: Dashed lines delineate standard-error bands. 


\subsection{Appendix: Identification}

I describe how to recover the structural model outlined in Section 2.2 from the reduced VAR representation. Write the structural VMA representation of the theoretical model as follows (recall equation (6), and (9)):

$$
\begin{aligned}
& {\left[\begin{array}{c}
\Delta s p_{t} \\
\Delta p_{t}
\end{array}\right]=\left[\begin{array}{ll}
C_{11}(L) & C_{12}(L) \\
C_{21}(L) & C_{22}(L)
\end{array}\right]\left[\begin{array}{c}
e_{t}^{s} \\
e_{t}^{m}
\end{array}\right]} \\
& x_{t}=\left[\Delta s p_{t}, \Delta p_{t}\right]=C(L) e_{t}
\end{aligned}
$$

where $L$ is the lag operator, $\mathrm{C}_{\mathrm{ij}}(\mathrm{L})$ for $\mathrm{i}, \mathrm{j}=1,2$ is a polynomial in the lag operator $L$ (i.e. $\left.\mathrm{C}_{\mathrm{ij}}(\mathrm{L})=\Sigma_{\mathrm{k}} \mathrm{c}_{\mathrm{ij}}(\mathrm{k}) \mathrm{L}^{\mathrm{k}}\right)$. Section 2.2 shows that money supply shocks do not have long run effects on real stock prices as can be represented by:

$$
\left.C_{12}(L)\right|_{L=1}=C_{12}(1)=\Sigma_{k} c_{12}(k)=0
$$

To estimate $\mathrm{C}(\mathrm{L})$ in equation (15), we first estimate a VAR of $x_{t}$ :

$$
x_{t}=\left[\Delta s p_{t}, \Delta p_{t}\right]=A(L) x_{t-1}+u_{t}
$$

where $A(L)=\left[A_{i j}(L)\right]=\left[\Sigma_{k} a_{i j}(k) L^{k-1}\right]$ for $i, j=1,2, u=\left[u_{1 t}, u_{2 t}\right]$ with $\operatorname{var}\left(u_{t}\right)=\Omega$. We obtain estimates of $\mathrm{A}(\mathrm{L})$ and $\Omega$. By inverting this VAR of $\mathrm{x}_{\mathrm{t}}$, we obtain a reduced form VMA of $x_{t}$ :

$$
x_{t}=[I-A(L) L]^{-1} u_{t}
$$

where $I$ is the identity matrix of rank 2 .

Estimates of $\mathrm{C}(\mathrm{L})$ can be obtained by noticing that:

$$
C_{0} e_{t}=u_{t}
$$

and that

$$
x_{t}=C(L) e_{t}=[I-A(L) L]^{-1} u_{t}
$$

Using equation (18), equation (19) implies that 


$$
C(L)=[I-A(L) L]^{-1} C_{0}
$$

To calculate $\mathrm{C}(\mathrm{L})$, we only need an estimate of $C_{0}$. This can be obtained by taking the variance of each side of equation (18):

$$
C_{0} C_{0}^{\prime}=\Omega
$$

Here we obtain three restrictions for the four elements of $C_{o}$. Section 2.2 provides the identifying restrictions:

$$
\left.C_{12}(L)\right|_{L=1}=C_{12}(1)=\Sigma_{k} c_{12}(k)=0
$$

Thus, we can recover the structural dynamics of the structural model (15) and the structural shocks from the reduced VAR model (16). ${ }^{13}$

\footnotetext{
${ }^{13}$ Malliaropulos (1999), Rapach (2001), and Gallagher and Taylor (2002) also apply this methodology to study the US stock return-inflation relation after WWII. The difference between this chapter and theirs is that the focus of this chapter is to explain the time-varying stock return-inflation relation, not the negative relation observed mainly after WWII.
} 


\title{
Chapter 3 Behavioral Finance and Mean Reversion: Evidence from a
}

\author{
New Specification Test
}

\subsection{Introduction}

Market efficiency with constant expected returns implies that stock prices follow random walks, and returns are serially independent and unpredictable from past returns. A voluminous literature has developed to test this hypothesis for its important implications for many of the paradigms used in financial economics. Contrary to the early supporting evidence surveyed in Fama (1970), Shiller's (1981) research on the excess volatility issue suggests a rejection of the market efficiency hypothesis. Motivated by the psychological evidence that individuals tend to overreact, Shiller (1981) and Summers (1986) propose the fads model, in which stock prices have a mean reverting component due to overreaction and stock returns are negatively serially correlated.

Fama and French (1988) and Poterba and Summers (1988) first provide statistical evidence of mean reversion in stock prices. ${ }^{14}$ Others are critical of their results: Kim, Nelson, and Startz (1991) argue that mean reversion is only detectable in prewar data; Richardson and Stock (1990) and Richardson (1993) point out that the significance of the Fama and French (1988) and Poterba and Summers (1988) results may be overstated, because of the inadequacy of the asymptotic distribution in the presence of overlapping observations and failure of including joint tests over multiple horizons; Richardson and

\footnotetext{
${ }^{14}$ McQueen and Thornley (1991) uses a Markov chain model to test the random walk hypothesis of stock prices and find annual real returns exhibit significant nonrandom walk behavior. Balvers, Wu, and Gilliland (2000) detect mean reversion across national stock markets by assuming common stochastic trends and identical reversion speeds. The profitability of the contrarian investment strategy [DeBondt and Thaler (1985, 1987), Chopra, Lakonishok, and Ritter (1992), and Richards (1995,1997)] may also suggest that stock returns are negatively serially correlated at long horizons. Finally, Lee (1995) and Gallagher, Sarno, and Taylor (1997) provide supporting evidence by estimating the stationary components in stock prices.
} 
Smith (1991), McQueen (1992), and Chow and Denning (1993) incorporate the inclusion of joint tests and all find evidence supporting lack of mean reversion in stock prices. Richardson and Smith (1994) summarize the empirical results concisely: "most researchers now agree that the mean-reversion evidence is statistically quite weak"(p379).

Furthermore, Conrad and Kaul (1988) and Lo and MacKinlay (1988) find statistical evidence that stock returns are positively serially correlated in the short run (one week to one month). ${ }^{15}$ "The patterns of rejections indicate that the stationary mean reverting models of Shiller and Perron (1985), Summers (1986), Poterba and Summers (1988), and Fama and French (1988) cannot account for the departures of weekly returns from the random walk." [Lo and MacKinlay (1988), p61]

Recently, Barberis, Shleifer, and Vishny (1998) (hereafter, "BSV"), Daniel, Hirshleifer, and Subrahmanyam (1998) ("DHS"), and Hong and Stein (1999) ("HS") have proposed new alternative models against the market efficiency, in which stock prices undereact (delayed overreact) in the short run and overreact in the long run, consequently, stock returns are positively serially correlated at short horizons and negatively serially correlated at longer horizons.

BSV build a model that incorporates two biases: conservatism, the tendency to underweight new (public) information relative to priors, and representativeness (the law of small numbers), whereby people expect even short samples to be indicative of the

\footnotetext{
${ }^{15}$ The profitability of the momentum investment strategy [Jegadeesh and Titman (1993), Chan, Jegadeesh, and Lakonishok (1996), Rouwenhorst (1998), Chan, Hameed and Tong (2000), Grundy and Martin (2001), Jegadeesh and Titman (2001), and Balvers and Wu (2002)] may also suggest that the autocorrelation is positive at horizons on the order of three to twelve months. However, Lehmann (1990) and Jegadeesh (1990) provide evidence of short-term reversals in weekly and monthly returns.
} 
properties of the parent population. Conservatism generates short-run underreaction, while representativeness eventually causes long-run overreaction.

DHS stress investor biases in the interpretation of private, rather than public information. Investors are overconfident about private information. Furthermore, investors react to public information that is consistent with their private signal by increasing their overconfidence but react to inconsistent public information by a smaller reduction in overconfidence (self-attribution bias). Thus, private information triggers short-run overreaction, which continually increases as investors react in a biased way to subsequent public information. But future public information will eventually correct misvaluation.

HS model a market populated by two groups of boundedly rational agents, "newswatchers", who make forecasts based on private information but do not condition on past prices, and "momentum traders", who condition only on the most recent price change. They also assume that private information diffuses slowly through the newswatchers population, which generates short-run underreaction. By buying, momentum traders hope to profit from the continued diffusion of information. But since they cannot observe the extent of information diffusion, they will eventually push the price above the fundamental and create overreaction. HS also show that the cumulative impulse response function may not be monotonic. "After the peak, prices eventually converge back to 1.00 , although not in a monotonic fashion - rather, there are a series of damped oscillations as the momentum-trading effects gradually wring themselves out" [HS, p2156]. 
The models of BSV and DHS emphasize investor cognitive biases. So their models generally predict that the misvaluation should be stronger among firms about which there is high uncertainty/poor information. ${ }^{16}$ In contrast, HS emphasize gradual information diffusion, and predict that slower information diffusion generates more misvaluation.

It is important to note that the alternatives proposed by BSV, DHS, and HS are very different from that proposed by Shiller (1981) and Summers (1986). First, the autocorrelation in BSV, DHS, and HS has different signs across lags (positive at short horizons and negative at longer horizons), while the autocorrelation is always negative in Shiller (1981) and Summers (1986). Second, the autocorrelation in HS may even alter sign multiple times because the cumulative impulse response function may not be monotonic. For instance, in their Table AI, when momentum traders' horizon is six months, the autocorrelation changes its sign three times for lags from 1 to 25 . In contrast, the autocorrelation in the fads model is thought to be persistent. These differences make the commonly used statistical tests lack power against this type of alternative, in particular detecting negative long-horizon autocorrelation for they are not able to differentiate autocorrelations at different horizons. This may in part explain why the literature so far has found little evidence in support of mean reversion even in the long run.

\footnotetext{
16 "More generally, greater uncertainty about a set of stocks, and a lack of accurate feedback about their fundamentals, leaves more room for psychological biases" [Hirshleifer (2001), p1575].
} 
A commonly used test is the variance ratio test of Lo and MacKinlay (1988). ${ }^{17}$ It is motivated by the fact that if stock returns are serially independent, then the variance ratio, which is defined as the ratio of $(1 / q)$ th of the variance of $q$-period return to that of one-period return minus one, should be zero for all $q$, where $q$ is any integer greater than one. 18 The variance ratio is shown to be asymptotically equivalent to a linear combination of the first $q-1$ autocorrelation coefficient estimators of the stock return with arithmetically declining weights. To examine the long-run autocorrelation, one has to compute the variance ratios with large aggregate values, $q$. However, since variance ratios include all first $q-1$ autocorrelations, even the variance ratios computed with large aggregate values still contain short-run autocorrelations. Moreover, since the weights are arithmetically declining, even the variance ratios computed with large aggregate values may be dominated by short-run autocorrelations. Therefore, if autocorrelations are positive at short horizons and negative at longer horizons as BSV, DHS, and HS suggest, the variance ratios computed with large aggregate values would greatly understate the extent of negative long-run autocorrelation because the positive short-run autocorrelations would heavily offset negative long-run autocorrelations. Moreover, if the autocorrelation alters sign multiple times as HS suggest, the test will have even lower power. $^{19}$

17 Campbell and Mankiw (1987), Cochrane (1988, 1994), French and Roll (1986), and Poterba and Summers (1988) all compute variance ratios in a variety of contexts. Lo and MacKinlay (1988) develop the formal sampling theory for the individual variance ratio statistic under nonnormality and heterogeneity.

${ }^{18} q$ is called the aggregate value [Lo and MacKinlay (1988)].

${ }^{19}$ Two other commonly used tests are the regression test of Fama and French (1988) and the $J$-statistic of Jegadeesh (1991). In particular, the test in Fama and French (1988) regresses multiperiod $(k)$ returns on lagged multiperiod $(k)$ returns. The regression coefficient "applies negative weight to autocorrelations up to order $2 k / 3$, followed by increasing positive weight up to lag $k$, followed by decaying positive weights" [Poterba and Summers (1988), p31]. It appears that this test can be powerful against the alternatives in 
Therefore, I propose a new test that is particularly powerful against this type of alternative, the "covariance-variance ratio" test. The covariance-variance ratio, defined as the ratio of the covariance between a one-period return and a p-lagged $(q-p)$--period return to the variance of a one-period return, where $q$ and $p$ are integers and $q>p$, is shown to be asymptotically equal to the sum of sample autocorrelations for lags from $p$ to $q-1$. Its limiting distribution under the random walk/market efficiency hypothesis that allows heteroskedasticity and nonnormality then is derived along the lines of Lo and MacKinlay (1988). The null hypothesis accordingly can be tested by examining jointly a set of covariance-variance ratios corresponding to a set of pre-specified non-overlapping ranges. The overall test size is controlled by the multiple comparison procedure of Chow and Denning (1993). Using non-overlapping ranges makes it possible to differentiate autocorrelations at different horizons. Using the pre-specified ranges and the multiple comparison procedure can effectively deal with data snooping. Monte Carlo experiments indicate that the test is reliable and significantly more powerful than the variance ratio test against this type of alternative, particularly in detecting negative long-horizon autocorrelations. The empirical power of a 5 percent covariance-variance ratio test in detecting the negative long-run autocorrelation is nearly 30 percent, while that of the variance ratio test is close to 0 percent.

The use of non-overlapping ranges to measure autocorrelations is, of course, not new. Cutler, Poterba, and Summers $(1990,1991)$ compute "the average autocorrelation

BSV, DHS, and HS. Unfortunately, this may not be true. Suppose one regresses three-year returns on lagged three-year returns. The regression coefficient will apply negative weight to autocorrelations up to a two-year lag, followed by increasing positive weight up to a three-year lag, followed by declining positive weight up to a six-year lag. Positive autocorrelations within one-year lag and negative autocorrelations from a one-year lag to a two-year lag may cancel out. So unless the negative autocorrelation is more prominent around a three-year lag, the test will still have low power. Also when one regresses a higher order of multiperiod returns on lagged multiperiod returns, more negative autocorrelations will be assigned negative weights, which will clearly reduce the power of the test. 
over several distinct twelve month intervals" [Cutler, Poterba, and Summers (1991), p532]. However, their test has several important drawbacks. First, the sampling distribution of their statistics is derived under the IID Gaussian random walk. But "there is mounting evidence that financial time series often possess time-varying volatilities and deviate from normality. Since it is the unforecastability, or uncorrelatedness, of price changes that is of interest, a rejection of the i.i.d. Gaussian random walk because of heteroskedasticity or nonnormality would be of less import than a rejection that is robust to these two aspects of the data." [Lo and MacKinlay (1988), p44]. Second, the overall test size is not controlled. So their results are overstated. Third, the discussion in Section 3.3.1 of this chapter also shows that the test could have large size distortion if longer intervals were used. In contrast, the test proposed in this chapter is robust to heteroskedasticity and nonnormality. The overall test size is properly controlled. The test is also reliable and without size distortion.

It is important to point out that it is not likely to have a test that is powerful against both the alternative proposed by Shiller (1981) and Summers (1986) and those proposed by BSV, DHS, and HS. To be powerful against the fads model of Shiller (1981) and Summers (1986), a test has to sum up many autocorrelations because autocorrelations are thought to be small in magnitude and persistent. In contrast, to be powerful against the alternatives of BSV, DHS, and HS, a test cannot sum up many autocorrelations because autocorrelations have different signs over different horizons. So again, we have to "face the reality that a statistical test has power to reject the null against only certain classes of alternatives - a uniformly powerful test is the exception rather than the rule" [Stambaugh (1986), p601]. 
When this test is applied to examine four sets of portfolios, industry, size, bookto-market, and size and book-to-market portfolios, there is reliable statistical evidence in support of the behavioral models in that prices of stocks with more uncertainty and slower information diffusion (small size, high book-to-market, or cyclical stocks) tend to have both short-run continuation and long-run reversion. Size, book-to-market, and industry are distinct in determining the autocorrelation patterns. The evidence that value stocks have more misvaluation seems to be more consistent with HS instead of BSV and DHS. Furthermore, the three-factor model cannot absorb autocorrelations in industry portfolios, which lends more support to the behavioral models. The autocorrelation patterns show up in different sets of portfolios (industry, size, book-to-market, and size and book-to-market portfolios), different stock markets (15 international stock markets), different sample periods (1871-1946 and 1947-2001), and even for different nonoverlapping intervals (1 year, 2 years, 3 years, and 6 years) used to measure autocorrelations. So the results are not likely due to data mining.

The remainder of this chapter is organized as follows. Section 3.2 presents the covariance-variance ratio test. Section 3.3 compares the size and power of the covariance-variance ratio test against that of alternative tests. Section 3.4 describes the data and presents the empirical results. Section 3.5 discusses the data-mining issue. Section 3.6 concludes the chapter with a brief summary. 


\subsection{The Covariance-Variance Ratio Statistic}

\subsubsection{The Variance Ratio Test}

The formal sampling theory for an individual variance ratio statistic is developed by Lo and MacKinlay (1988). What follows is a brief summary of their main result. Denote by $p_{t}$ the log stock price at time $t$. The random walk/market efficiency null hypothesis is given by the following recursive relation:

$$
p_{t}=\mu+p_{t-1}+\varepsilon_{t}
$$

where $\mu$ is an arbitrary drift parameter and $\varepsilon_{\mathrm{t}}$ is the random disturbance term. $\varepsilon_{\mathrm{t}}$ (i) has a zero mean, (ii) is serially uncorrelated, and (iii) satisfies some mixing and moment conditions which allows for quite general forms of heteroskedasticity. ${ }^{20}$ Suppose that there are $n q+1$ observations $p_{0}, p_{1}, \ldots \ldots, p_{n q}$, where $q$ is any integer greater than 1 . The variance ratio statistic, $\bar{M}_{r}(q)$, is defined as:

$$
\bar{M}_{r}(q) \equiv \frac{\overline{\boldsymbol{\sigma}}_{c}^{2}(q)}{\overline{\boldsymbol{\sigma}}_{a}^{2}}-1
$$

where

$$
\begin{aligned}
& \overline{\boldsymbol{\sigma}}_{a}^{2}=\frac{1}{n q-1} \sum_{k=1}^{n q}\left(p_{k}-p_{k-1}-\hat{\mu}\right)^{2} \\
& \overline{\boldsymbol{\sigma}}_{c}^{2}(q)=\frac{1}{m} \sum_{k=q}^{n q}\left(p_{k}-p_{k-q}-q \hat{\mu}\right)^{2}
\end{aligned}
$$

with $m=q(n q-q+1)\left(1-\frac{q}{n q}\right)$, and where $\hat{\mu}=\frac{1}{n q} \sum_{k=1}^{n q}\left(p_{k}-p_{k-1}\right)$. The variance ratio computed with an aggregate value $q$ is shown to be asymptotically equivalent to a linear

\footnotetext{
${ }^{20}$ For detail, see Lo and MacKinlay (1988).
} 
combination of the first $q-1$ autocorrelation coefficient estimators of the stock return with arithmetically declining weights:

$$
\bar{M}_{r}(q) \stackrel{a}{=} \frac{2(q-1)}{q} \hat{\boldsymbol{\rho}}(1)+\frac{2(q-2)}{q} \hat{\boldsymbol{\rho}}(2)+\ldots+\frac{2}{q} \hat{\boldsymbol{\rho}}(q-1)
$$

where $\hat{\rho}(k)$ denotes the $k$ th-order autocorrelation coefficient estimator, Based on this equality, the asymptotic distribution for $\bar{M}_{r}(q)$ is shown to be

$$
\begin{aligned}
& \sqrt{n q} \bar{M}_{r}(q) \stackrel{a}{\sim} N(0, V(q)) \\
& V(q)=\sum_{j=1}^{q-1}\left[\frac{2(q-j)}{q}\right]^{2} \boldsymbol{\delta}(j) \quad \hat{V}(q)=\sum_{j=1}^{q-1}\left[\frac{2(q-j)}{q}\right]^{2} \hat{\boldsymbol{\delta}}(j) \\
& \hat{\boldsymbol{\delta}}(j)=\frac{n q \sum_{k=j+1}^{n q}\left(p_{k}-p_{k-1}-\hat{\mu}\right)^{2}\left(p_{k-j}-p_{k-j-1}-\hat{\mu}\right)^{2}}{\left[\sum_{k=1}^{n q}\left(p_{k}-p_{k-1}-\hat{\mu}\right)^{2}\right]^{2}}
\end{aligned}
$$

where $\stackrel{a}{\sim}$ indicates that the distributional equivalence is aymptotic, and $\hat{\boldsymbol{\delta}}(j)$ are the heteroskedasticity-consistent estimators of $\delta(j)$. The test statistic $z^{*}(q)=\sqrt{n q} \bar{M}_{r}(q) / \sqrt{\hat{V}(q)}$ is asymptotically standard normal.

Chow and Denning (1993) argue that since the random walk hypothesis requires that all selected $\bar{M}_{r}(q)$ must equal zero, a multiple comparison of all selected $\bar{M}_{r}(q)$ with zero is a natural way to test the null hypothesis. The asymptotic joint confidence interval of at least $100(1-\alpha)$ percent for a set of $\bar{M}_{r}(q)$ is shown to be:

$$
z^{*}(q) \pm \operatorname{SMM}(\boldsymbol{\alpha}, m)
$$

where $\operatorname{SMM}(\alpha, \mathrm{m})$ is the asymptotic critical value of the $\alpha$-point of the studentized maximum modulus (SMM) distribution with $m$ degrees of freedom. The asymptotic 
$\operatorname{SMM}(\alpha, \mathrm{m})$ can be calculated as the upper $\alpha^{*} / 2$ point of the standard normal distribution, $z_{\alpha^{*} / 2}$, where $\alpha^{*}=1-(1-\alpha)^{1 / m}$

\subsubsection{The Covariance-Variance Ratio Test}

Empirical applications of the variance ratio test usually employ multiple variance ratio estimates to examine the random walk hypothesis. Whether there is short-run or long-run autocorrelation is inferred by inspecting the pattern of the significance of the variance ratio estimates. Significant variance ratio estimates for large aggregate values are interpreted as evidence to support long-run autocorrelation, while those for small aggregate values are used to support short-run autocorrelation. ${ }^{21}$ However, since variance ratios computed with an aggregate value $q$ sum all first $q-1$ autocorrelations (see Equation 3), even the variance ratios computed with large aggregate values still contain short-run autocorrelations. Furthermore, the arithmetically declining weights (see Equation 3) make the variance ratios computed with large aggregate values be dominated by short-run autocorrelations. Thus, if negative long-run autocorrelation co-exists with positive short-run autocorrelation, as suggested by the behavioral theories of BSV, DHS, and HS, the variance ratios computed with large aggregate values would greatly understate the negative long-run autocorrelation, because positive short-run autocorrelations could heavily offset negative long-run autocorrelations.

To develop a sense of this shortcoming, consider the following monthly stock price-generating process, which is a generalization of the Summers (1986) and Lo and MacKinlay (1989) model.

\footnotetext{
${ }^{21}$ See, for instance, Lo and MacKinlay (1988) and Poterba and Summers (1988).
} 


$$
p_{t}=\phi p_{t-1}+\sum_{i=1}^{k} \rho\left(p_{t-j}-p_{t-j-1}\right)+\varepsilon_{t} \quad \varepsilon_{t} \sim N(0,1)
$$

where $\phi$ and $\rho$ are positive and less than unity. Assign the values $(0.979,0.026,12)$ as obtained by Balvers and $\mathrm{Wu}$ (2002) for international data to the parameters $(\phi, \rho, k)$. The theoretical autocorrelation of stock returns is shown in figure 3-1. There are positive short-run autocorrelations up to 16 lags, and then negative long-run autocorrelations up to 100 lags. Since the variance ratios are (approximately) equal to the weighted sum of first $q-1$ autocorrelations, a simple calculation can show the theoretical variance ratios computed with various aggregate values, which can be found in the column headed by $V R$ in Table 3-1. Not surprisingly, even though there are negative autocorrelations from lag 17, the variance ratios computed with large aggregate values are all positive and indicate positive autocorrelations even in the long run.

The autocorrelation of stock returns for the price-generating process in Equation 6 is still persistent in the sense that autocorrelations are all positive below 16 lags and then negative. Suppose the autocorrelation is not persistent and changes sign multiple times as HS suggest, it is easy to see that the variance ratio test will have even lower power to detect negative autocorrelations at some long horizons.

A natural way to test the behavioral models is to examine a set of estimates of sums of sample autocorrelations corresponding to a set of pre-specified non-overlapping ranges, for instance, from lag 1 to 12 , from lag 13 to $24, \ldots$, for monthly data. This set of non-overlapping ranges corresponds to one year, two years, ..., which is natural and used by Cutler, Poterba, and Summers (1990, 1991). Since estimates correspond to nonoverlapping ranges, the estimates of autocorrelations at one horizon would not be affected by autocorrelations at other horizons. The test therefore will have more power 
against the alternatives in BSV, DHS, and HS, particularly in detecting negative autocorrelations at some long horizons.

The random walk null hypothesis can be tested by examining jointly this set of estimates. If at least one estimate is significantly different from zero, then the null hypothesis can be rejected. Furthermore, whether the rejection is due to the short-run or the long-run autocorrelation can be inferred by inspecting the pattern of the significance of the estimates. Specifically, long-run autocorrelation is supported by significant estimates corresponding to higher order ranges, while significant estimates corresponding to lower order ranges would suggest short-run autocorrelation. Positive estimates at short horizons and negative estimates at some longer horizons are broadly consistent with all three behavioral models (BSV, DHS, and HS). The corresponding theoretical estimates for the same price generating process, Equation 6, can be found in the column headed by $C V$ in Table 3-1. All estimates for ranges beyond lag 12 are negative and indicate negative autocorrelations in the long run.

Furthermore, the models in BSV and DHS emphasize cognitive biases that investors have. So their models generally predict that the misvaluation should be stronger among growth firms about which there is high uncertainty. "To the extent that lower book-to-market firms have more growth options, they should exhibit stronger overconfidence effects" [Daniel and Titman (2000), p8]. In contrast, HS emphasize gradual information diffusion, and predict that value firms should have more misvaluation, because (1) value firms have a persistently low ratio of earnings to book equity (bad news) ${ }^{22}$ and (2) bad news travels slowly [see Hong, Lim, and Stein (2000)].

\footnotetext{
22 "Low-BE/ME stocks are on average more profitable than high-BE/ME stocks for four years before and at least five years after portfolio formation" [Fama and French (1995), p135]
} 
So autocorrelation patterns of value and growth stocks may be used to distinguish three behavioral models.

The approach in this chapter to obtain estimates of sums of sample autocorrelations over non-overlapping ranges is based on the fact that the covariance between a one-period return and a $p$-lagged $(q-p)$-period return is equal to the sum of autocovariances for lags from $p$ to $q-1$, where $q>p$. Specifically, I consider the following covariance and variance estimator and the corresponding covariance-variance ratio statistic:

$$
\begin{aligned}
& \hat{\boldsymbol{\sigma}}(p, q)=\frac{1}{n q} \sum_{k=q}^{n q}\left(p_{k}-p_{k-1}-\hat{\boldsymbol{\mu}}\right)\left[p_{k-p}-p_{k-q}-(q-p) \hat{\boldsymbol{\mu}}\right] \\
& \hat{\boldsymbol{\sigma}}_{a}^{2}=\frac{1}{n q} \sum_{k=1}^{n q}\left(p_{k}-p_{k-1}-\hat{\boldsymbol{\mu}}\right)^{2} \\
& C V(p, q) \equiv \frac{\hat{\boldsymbol{\sigma}}(p, q)}{\hat{\boldsymbol{\sigma}}_{a}^{2}}
\end{aligned}
$$

The $C V(p, q)$-statistic may be re-expressed as

$$
\begin{gathered}
C V(p, q)=\frac{(1 / n q) \sum_{k=q}^{n q}\left(p_{k}-p_{k-1}-\hat{\mu}\right)\left[p_{k-p}-p_{k-q}-(q-p) \hat{\mu}\right]}{(1 / n q) \sum_{k=1}^{n q}\left(p_{k}-p_{k-1}-\hat{\mu}\right)^{2}} \\
=\frac{(1 / n q) \sum_{k=q}^{n q}\left[\left(p_{k}-p_{k-1}-\hat{\mu}\right) \sum_{j=p+1}^{q}\left(p_{k-j+1}-p_{k-j}-\hat{\mu}\right)\right]}{(1 / n q) \sum_{k=1}^{n q}\left(p_{k}-p_{k-1}-\hat{\mu}\right)^{2}} \\
=\frac{(1 / n q) \sum_{j=p+1}^{q}\left[\sum_{k=q}^{n q}\left(p_{k}-p_{k-1}-\hat{\mu}\right)\left(p_{k-j+1}-p_{k-j}-\hat{\mu}\right)\right]}{(1 / n q) \sum_{k=1}^{n q}\left(p_{k}-p_{k-1}-\hat{\mu}\right)^{2}}
\end{gathered}
$$




$$
\begin{aligned}
& =\sum_{j=p}^{q-1} \hat{\mathbf{\rho}}(j)+o_{p}\left(n^{-1 / 2}\right) \\
& \approx \sum_{j=p}^{q-1} \hat{\boldsymbol{\rho}}(j)
\end{aligned}
$$

where $o_{p}\left(n^{-1 / 2}\right)$ denote terms which are of order smaller than $n^{-1 / 2}$ in probability. Therefore, the covariance-variance ratio computed with aggregate values, $q$ and $p$, is approximately a linear combination of sample autocorrelations with all the weights set identically equal to unity for the lags from $p$ to $q-1$. Under the random walk/market efficiency hypothesis, the covariance-variance ratios for any $p$ and $q$ should be equal to zero.

Please note the similarity between the covariance-variance ratio statistic and the Box-Pierce (1970) Q-statistic, which is the sum of squared autocorrelations. The advantage of the covariance-variance ratio statistic is that it is able to distinguish between positive and negative autocorrelation. Thus, it provides more information and is particularly useful for detecting negative long-run autocorrelation. Moreover, it is important to control the size of a joint test when simultaneously examining a set of statistics. In the next part, the limiting distribution of individual covariance-variance ratio statistic is found to be Gaussian and the multiple comparison procedure developed by Chow and Denning (1993) can be readily employed to construct the joint confidence interval for a set of covariance-variance ratio statistics. In contrast, the Q-statistic is asymptotically distributed as $\chi^{2}$ and the procedure to construct the joint confidence interval for a set of Q-statistics is not known.

To derive the limiting distribution of $C V(p, q)$ under the same null hypothesis as Lo and MacKinlay (1988), define the $[(q-p) \times 1]$ vector $\hat{\rho} \equiv[\hat{\rho}(p) \hat{\rho}(p+1)$ 
$\ldots \hat{\rho}(q-1)]^{\prime}$. By considering the regression of increments $\Delta p_{t}$ on a constant term and the $j$ th lagged increments $\Delta p_{t-j}$, the limiting distribution of sample autocorrelation coefficient $\hat{\boldsymbol{\rho}}(j)$, which is the estimated slope coefficient, then is ${ }^{23}$ :

$$
\sqrt{n q} \hat{\boldsymbol{\rho}} \sim N\left(0, \boldsymbol{\delta}(j) I_{q-p}\right)
$$

where $I_{q-p}$ is the identity matrix of order $q-p$ (recall Equation $4 \mathrm{a}, 4 \mathrm{~b}$, and $4 \mathrm{c}$ ). Returning to the quantity $\sqrt{n q} C V(p, q)$, we have

$$
\sqrt{n q} C V(p, q)=\sqrt{n q}[\hat{\boldsymbol{\rho}}(p)+\hat{\boldsymbol{\rho}}(p+1)+\ldots+\hat{\boldsymbol{\rho}}(q-1)]+\sqrt{n q} o_{p}\left(n^{-1 / 2}\right)
$$

Combining equation (11) and (12) then yields the following results:

$$
\sqrt{n q} C V(p, q) \stackrel{a}{\sim} N\left(0, \sum_{j=p}^{q-1} \delta(j)\right)
$$

More formally, we have:

Lemma 1. Under the random walk null hypothesis (Equation 1):

$$
\text { 1. } \sqrt{n q} C V(p, q) \stackrel{a}{\sim} N\left(0, \sum_{j=p}^{q-1} \delta(j)\right)
$$

2. The following is a heteroskedasticity-consistent estimator of $\delta(j)$ :

$$
\hat{\boldsymbol{\delta}}(j)=\frac{n q \sum_{k=j+1}^{n q}\left(p_{k}-p_{k-1}-\hat{\boldsymbol{\mu}}\right)^{2}\left(p_{k-j}-p_{k-j-1}-\hat{\boldsymbol{\mu}}\right)^{2}}{\left[\sum_{k=1}^{n q}\left(p_{k}-p_{k-1}-\hat{\boldsymbol{\mu}}\right)^{2}\right]^{2}}
$$

The test statistic $z(p, q)=\sqrt{n q} C V(p, q) / \sqrt{\sum_{j=p}^{q-1} \hat{\boldsymbol{\delta}}(j)}$ is asymptotically standard normal.

\footnotetext{
${ }^{23}$ This follows directly from White and Domowitz (1984) and Lo and MacKinlay (1988).
} 
The random walk null hypothesis can be tested by examining jointly a set of $C V(p, q)$ estimates, such as $[C V(1,12), C V(13,24), C V(25,37), \ldots]$ for monthly data. If at least one $C V(p, q)$ estimate is significant, then the null hypothesis can be rejected. Furthermore, whether the rejection is due to the short-run or long-run autocorrelation can be inferred by inspecting the pattern of significance of the $C V(p, q)$ estimates. Long-run autocorrelation is supported by significant $C V(p, q)$ estimates for large values of $p$ and $q$, while significant $C V(p, q)$ estimates for small values of $p$ and $q$ would suggest short-run autocorrelation. Positive $C V(p, q)$ estimates at short horizons and negative $C V(p, q)$ estimates at some longer horizons are broadly consistent with the behavioral models in BSV, DHS, and HS. Furthermore, cross-sectional differences in the $C V(p, q)$ estimates may be used to distinguish the behavioral models. If value stocks had more significantly positive $C V(p, q)$ estimates at short horizons and negative $C V(p, q)$ estimates at longer horizons, the evidence would favor HS in that bad news diffuses slower.

Clearly, it is important to control the size of a joint test when simultaneously examining a set of $C V(p, q)$ estimates. That is a nominal $100 \alpha \%$ critical value is not appropriate for each $C V(p, q)$ estimate; instead an overall size of $100 \alpha \%$ is necessary. I adjust the critical value for each individual $z(p, q)$ test statistic by following the multiple comparison procedure developed by Chow and Denning (1993).

Lemma 2. Under the random walk null hypothesis, the asymptotic joint 100(1$\alpha) \%$ confidence interval for a set of $z(p, q)$ statistics can be calculated as:

$$
\left[z\left(p_{i}, q_{i}\right)\right] \pm S M M(\alpha, m) \text { for } i=1, \ldots, m
$$




\subsection{The Size and Power of the Covariance-Variance Ratio Test}

\subsubsection{Two Alternative Tests}

In this section, the size and power of the covariance-variance ratio test are investigated. For comparison, I also employ two alternative tests. The first one is the simple sum of sample autocorrelations $(S A)$, which is effectively used by Cutler, Poterba, and Summers (1990, 1991):

$$
S A(p, q) \equiv \sum_{j=p}^{q-1} \hat{\mathbf{\rho}}(j)
$$

The limiting distribution under the null hypothesis (Equation 1) is:

$$
\sqrt{n q} S A(p, q) \sim N\left(0, \sum_{j=p}^{q-1} \delta(j)\right)
$$

The test statistic $z_{S A}(p, q)=\sqrt{n q} S A(p, q) / \sqrt{\sum_{j=p}^{q-1} \hat{\boldsymbol{\delta}}(j)}$ is asymptotically standard normal.

Note that this statistic is asymptotically equivalent to the covariance-variance ratio statistic. However, to calculate one such statistic, many individual autocorrelations are required to be first estimated using the same sample, this can induce sampling error into the estimation process. To develop a sense, a random walk process with 660 observations is simulated for 10,000 replications. $^{24}$ The variance of the sum of autocorrelations, $\quad V=\operatorname{Var}\left(\sum_{j=1}^{q-1} \hat{\rho}(j)\right.$, and the sum of variances of autocorrelations, $V^{\prime}=\sum_{j=1}^{q-1}[\operatorname{Var} \hat{\rho}(j)]$, are computed and shown in Table 3-2 for various aggregate values.

Under the random walk null hypothe sis, autocorrelations are asymptotically independent,

\footnotetext{
${ }^{24}$ See Section 3.3.2 for a description of the random walk process being used.
} 
and $V$ and $V^{\prime}$ are equivalent. But in the finite sample, using the same sample to estimate many autocorrelations could induce sampling error. Let $S E=\frac{V^{\prime}-V}{V}$ measure the sampling error. Table 3-2 shows that it is always positive and increases with the number of autocorrelations estimated. For instance, $S E$ is equal to 3.8 percent if $q-1=12$, but 16.2 percent if $q-1=48$ ! In contrast, the covariance-variance ratio test directly estimates the sum of autocorrelations and would not induce this type of sampling error.

The second alternative test is the rescaled variance ratio test $(R V R)$ of Chow, Pan and Sakano (1996):

$$
R V R(p, q)=\frac{\bar{M}_{r}(q)+1}{\bar{M}_{r}(p)+1}-1
$$

The limiting distribution under the null hypothesis (Equation 1) is:

$$
\begin{aligned}
& \sqrt{n q} \operatorname{RVR}(p, q) \stackrel{a}{\sim} N(0, V(p, q)) \\
& V(p, q)=\sum_{j=1}^{q-1}\left[\frac{2(q-j)}{q}\right]^{2} \delta(j)-\sum_{j=1}^{p-1}\left[\frac{2(p-j)}{p}\right]^{2} \delta(j)
\end{aligned}
$$

The test statistic $z_{R V R}(p, q)=\sqrt{n q} R V R(p, q) / \sqrt{\hat{V}(p, q)}$ is asymptotically standard normal.

However, (1) the rescaled variance ratios are not asymptotically equivalent to sums of autocorrelations corresponding to a set of non-overlapping ranges. They are still linear combinations of the first $q-1$ autocorrelations but with increasing weight up to lag $p-1$ and declining weight thereafter. Therefore, this statistic may not be able to effectively differentiate autocorrelations at different horizons; (2) the test statistic is not well defined in some cases, because the variance of the statistic is the difference between 
two terms, which could be zero or negative. For instance, it is found that the statistic computed with aggregate values $(p, q)=(73,85)$ for a sample of 660 observations is not defined 46 times for 10,000 Monte Carlo simulations under the null hypothesis. ${ }^{25}$ In contrast, the covariance-variance ratios are asymptotically equivalent to sums of autocorrelations corresponding to a set of non-overlapping ranges and are always well defined.

Under the null hypothesis, the asymptotic joint $100(1-\alpha) \%$ confidence interval for a set of $\mathrm{ZSA}_{\mathrm{SA}}(p, q)$ and $\mathrm{ZRVR}_{\mathrm{R}}(p, q)$ statistics can be calculated as:

$$
\begin{aligned}
& {\left[z_{S A}\left(p_{i}, q_{i}\right)\right] \pm \operatorname{SMM}(\alpha, m) \text { for } i=1, \ldots, m} \\
& {\left[z_{R V R}\left(p_{i}, q_{i}\right)\right] \pm \operatorname{SMM}(\boldsymbol{\alpha}, m) \text { for } i=1, \ldots, m}
\end{aligned}
$$

All size and power tests are based on 10,000 replications. To be useful for the empirical study of monthly stock returns in Section 3.4, the sample size is chosen to be 660, which is the sample size for the empirical study, and the non-overlapping ranges, $(p$, $q-1)$ are chosen to be $(1,1),(2,12),(13,24),(25,36),(37,48),(49,60),(61,72)$, and $(73,84)$. Correspondingly, the aggregate values for the variance ratio test, $q$, are 2,13 , $25,37,49,61,73$, and 85 .

\subsubsection{The Size of the Covariance-Variance Ratio Test}

The sampling theory in the second section is based on standard asymptotic approximations. To gauge the quality of those approximations, following Lo and MacKinlay (1989), I perform simulation experiments under the null hypothesis that the disturbance $\varepsilon_{t}$ in Equation (1) is serially uncorrelated but heteroskedastic. Specifically, let

\footnotetext{
${ }^{25}$ See Section 3.3.2 for a description of the random walk process being used.
} 
the random walk disturbance $\varepsilon_{t}$ satisfy the relation $\varepsilon_{\mathrm{t}}=\sigma_{\mathrm{t}} \lambda_{\mathrm{t}}$, where $\lambda_{\mathrm{t}}$ is IID N $(0,1)$ and $\sigma_{\mathrm{t}}$ satisfies

$$
\ln \sigma_{t}^{2}=0.5 \ln \sigma_{t-1}^{2}+\xi_{t}, \xi_{t} \sim N(0,1)
$$

$\lambda_{\mathrm{t}}$ and $\xi_{\mathrm{t}}$ are assumed to be independent. The test size is estimated by calculating the percentage of rejections of the null hypothesis from 10,000 random samples generated from the above random walk population.

Table 3-3 reports simulation results for the $z^{*}(q), z(p, q), z_{S A}(p, q)$, and $z_{R V R}(p, q)$ statistics. The four tests have similar empirical size. However, it can be seen that the size distortion of the $z_{S A}(p, q)$ statistic is always higher than that of the $z(p, q)$ statistic. The difference is small because the number of estimated autocorrelations used in computing one $z_{S A}(p, q)$ statistic (the non-overlapping interval) in the simulation is only one year and the sampling error associated with this interval is small (recall Table 3-2). If a longer non-overlapping interval has to be used or weekly/daily returns are being examined and more estimated autocorrelations are needed to compute one $z_{S A}(p, q)$ statistic, the sampling error will increase and the size distortion of the $z_{S A}(p, q)$ will increase. More extensive experiments confirm this conclusion. For instance, in a 2500-replication simulation with a sample size of 2000 and the interval of 50, which corresponds to the weekly data scenario, it is found that the empirical sizes of the 1,5 , and 10 percent $z_{S A}(p$, q) statistic are 3.2, 9.4 and 15.5 percent, while those of the $z(p, q)$ statistic are 1.3, 4.7, and 8.6 percent. Thus, the covariance-variance ratio test is more reliable than the simple sum of sample autocorrelations. 


\subsubsection{The Power of the Covariance-Variance Ratio Test}

BSV, DHS, and HS suggest that autocorrelations are positive at short horizons and negative at some longer horizons. But they do not propose a specification fr their models. I therefore consider a stock-price-generating process, which is a generalization of the Summers (1986) and Lo and MacKinlay (1989) models and obtained by Balvers and $\mathrm{Wu}$ (2002) for international data.

$$
p_{t}=0.979 p_{t-1}+\sum_{i=1}^{12} 0.026\left(p_{t-j}-p_{t-j-1}\right)+\varepsilon_{t} \quad \varepsilon_{t} \sim N(0,1)
$$

The critical values of all four tests are empirically determined by simulation under the heteroskedastic null hypothesis. Table 3-4 reports the empirical critical values.

Table 3-5 reports the empirical power of the $z^{*}(q), z(p, q), z_{S A}(p, q)$, and $z_{R V R}(p, q)$ statistics. The rejection rates are broken down into upper and lower tail rejections to display the power of detecting positive and negative autocorrelations. The empirical power of the 1,5 , and 10 percent $z(p, q)$ statistic in detecting (long-run) negative autocorrelations are $13.5,28.5$, and 38.3 percent, while those of the $z^{*}(q)$ statistic are only $0.1,0.6$, and 1.7 percent. Interestingly, for this particular alternative process, the covariance-variance ratio test is also more powerful than the variance ratio test in detecting the (short-run) positive autocorrelation. The power of the 1,5 , and 10 percent $z(p, q)$ statistic in detecting positive autocorrelations are 9.9, 20.8, and 29.8 percent, while those of the $z^{*}(q)$ statistic are 3.6, 15.8, and 25.5 percent. This is because the positive autocorrelation in the alternative process first increases and then decreases, and the

variance ratio test applies arithmetically declining weights. The simulation results therefore confirm that the covariance-variance ratio test is significantly more powerful 
than the variance ratio test against the type of alternatives in BSV, DHS, and HS, particularly in detecting the negative long-horizon autocorrelations.

The empirical power of the 1,5 , and 10 percent $z_{R V R}(p, q)$ statistic in detecting (long-run) negative autocorrelations are $0.0,1.5$, and 4.7 percent, which are all significantly lower than the corresponding power of the $z(p, q)$ statistic. Those of the $z_{S A}(p, q)$ statistic are $13.4,30.0$, and 39.5 percent, which are similar to the corresponding power of the $z(p, q)$ statistic.

\subsection{Data and Empirical Results}

\subsubsection{Data}

To test for random walks in stock market prices (with dividends reinvested), I focus on the 660-month time span from January 1947 to December 2001. Monthly sampling yields a large number of observations while minimizing the biases inherent in daily and weekly data, the nonsynchronous trading effect [Fisher (1966)] and the bid-ask effect [Roll (1984)]. The pre-WWII period is excluded, because of possible structural changes in the time series properties of stock returns as suggested by Kim, Nelson, and Startz (1991). Four sets of portfolios are used for empirical investigation, 10 industry portfolios, 10 size portfolios, 10 book-to-market portfolios, and 25 size and book-tomarket portfolios. The equal-weighted monthly returns of four sets of portfolios, the three Fama and French factors, and the risk free rate are all downloaded from Kenneth French's website. ${ }^{26}$ In addition, the empirical critical values from Table 2-4 are used for the empirical study.

\footnotetext{
${ }^{26}$ http://mba.tuck.dartmouth.edu/pages/faculty/ken.french/
} 


\subsubsection{Empirical Results}

\subsubsection{Industry Portfolios}

Panel A of Table 3-6 reports the variance ratios $\left[\bar{M}_{r}(q)\right]$ and the test statistics $z^{*}(q)$ for the excess returns of industry portfolios using a base observation period of one month. The values reported in the main rows are the actual variance ratios, and the entries enclosed in parentheses are the $z^{*}(q)$ statistics. The variance ratio test does not support the alternatives proposed by BSV, DHS, and HS: there are only positive short-run autocorrelations (in eight out of ten portfolios) but no negative long-run autocorrelations (none of $\mathrm{Z}^{*}(q)$ statistics for $q-1>12$ is negatively significant).

However, one may suspect the long-run autocorrelation results obtained from examining the $z^{*}(q)$ statistics computed with large aggregate values since they may be dominated by short-run autocorrelation. The insignificant $z^{*}(q)$ statistics with large aggregate values are not necessarily consistent with no higher order autocorrelations, because it may be due to the positive autocorrelations at small lags offsetting the negative autocorrelations at large lags. I therefore compute the $C V(p, q)$ and the test statistics $z(p$, q) for the same industry portfolios over the same sample period. Panel B of Table 3-6 reports the results. The values reported in the main rows are the actual values of $C V(p, q)$, and the entries enclosed in parentheses are the $z(p, q)$ statistics.

Strikingly, the covariance-variance ratio test finds that the returns of six industry portfolios exhibit the autocorrelation patterns predicted by BSV, DHS, and HS: (1) positive short-horizon autocorrelations co-exist with negative long-horizon autocorrelations; (2) the autocorrelation is not persistent. Negative autocorrelations only show up in two intervals, 1 to 2 year and 5 to 6 year intervals. In Cutler, Poterba, and 
Summers (1991), negative autocorrelations also only show up in these two intervals. The insignificant estimates between these two intervals may be due to positive autocorrelations at some horizons offsetting negative autocorrelations at adjacent horizons. Or autocorrelations are too small to be detected [see Summers (1986) for an example)]. Although returns of chemicals, telephones and television, and finance industries only show positive short-horizon autocorrelations but no negative long-horizon autocorrelations, this may be due to the low power of the test. The utilities industry is the only industry whose returns do not have any significant autocorrelations. These results are consistent with the behavioral models of BSV, DHS, and HS, because the utilities industry has little uncertainty, while the other industries are all cyclical in nature and have quite significant uncertainty.

Interestingly, the positive short-run autocorrelation found in this chapter (only for one month) as in Conrad and Kaul (1988) and Lo and MacKinlay (1988) is not as persistent as the literature believes. The literature generally believes that "returns tend to exhibit unconditional positive serial correlation at horizons on the order of three to twelve months" [HS, p2146].

\subsubsection{Size Portfolios}

Panel A of Table 3-7 reports the variance ratios $\left[\bar{M}_{r}(q)\right]$ and the test statistics $z^{*}(q)$ for the excess returns of 10 size-sorted portfolios. The values reported in the main rows are the actual variance ratios, and the entries enclosed in parentheses are the $z^{*}(q)$ statistics. Again, the variance ratio test does not support the alternatives proposed by $\mathrm{BSV}, \mathrm{DHS}$, and HS in that there is no evidence of the presence of negative long-run 
autocorrelations. Panel B of Table 3-7 reports the $C V(p, q)$ and the test statistics $z(p, q)$ for the same size portfolios. The values reported in the main rows are the actual values of $C V(p, q)$, and the entries enclosed in parentheses are the $z(p, q)$ statistics. Once autocorrelations at different horizons are differentiated there is evidence that the returns of the smallest portfolio are positively serially correlated at short horizons and negatively serially correlated at some longer horizon (again the 5 to 6 year interval). Small firms have more uncertainty/poor information and slower information diffusion [see Hong, Lim, and Stein (2000)], they ought to have the sort of misvaluation predicted by the behavioral models. On the other hand, large firms have less uncertainty/good information and faster information diffusion. So they don't exhibit either short-run under- or longerrun overreaction to information.

\subsubsection{Book-to-market Portfolios}

Panel A of Table 3-8 reports the variance ratios $\left[\bar{M}_{r}(q)\right]$ and the test statistics $z^{*}(q)$ for the excess returns of book-to-market portfolios. The values reported in the main rows are the actual variance ratios and the entries enclosed in parentheses are the $z^{*}(q)$ statistics. Similarly, the variance ratio test suggests that there are only positive short-run autocorrelations but no negative long-run autocorrelation in these portfolio returns. Panel B of Table 3-8 reports the $C V(p, q)$ and the test statistics $z(p, q)$ for the same portfolio returns. The values reported in the main rows are the actual values of $C V(p, q)$ and the entries enclosed in parentheses are the $z(p, q)$ statistics. The covariance-variance ratio test, in contrast, finds that the returns of the three highest book-to-market-ratio portfolios 
have not only positive short-run autocorrelations but also negative long-run autocorrelations at the same two horizons, the 1 to 2 year and 5 to 6 year intervals.

The evidence that high book-to-market-ratio portfolios have stronger positive short-run and negative long-run autocorrelations supports the HS model more than the BSV and DHS models. This is because BSV and DHS emphasize investor psychological biases and predict that the misvaluation should be stronger among low book-to-marketratio firms about which there is high uncertainty. In contrast, HS emphasize gradual information diffusion and predict that high book-to-market-ratio firms have more misvaluation, because (1) they have more bad news (poor earnings) and (2) bad news travels slowly.

\subsubsection{Size and Book-to-market Portfolios}

The evidence so far shows that small size and high book-to-market-ratio firms tend to have the misvaluation predicted by the behavioral models. It is natural to see whether size and book-to-market-ratio are two distinct factors in determining the misvaluation. Therefore, the 25 size and book-to-market portfolios are examined using both the variance ratio test and the covariance-variance ratio test.

Table 3-9 reports the variance ratios $\left[\bar{M}_{r}(q)\right]$ and the test statistics $z^{*}(q)$ for excess returns of size and book-to-market portfolios. Not surprisingly, the variance ratio test shows no support to the behavioral models. Table 3-10 reports the $C V(p, q)$ and the test statistics $z(p, q)$ for the same portfolio returns. It can be seen that the size and bookto-market-ratio are distinct but the size factor seems more important: (1) large firms, regardless of book-to-market-ratio, have no autocorrelations; (2) within the smallest firm 
group, the firms with high book-to-market-ratio tend to have stronger positive short-run and negative long-run autocorrelations. Again, negative autocorrelations only show up at the two horizons, 1 to 2 year and 5 to 6 year intervals.

\subsubsection{The Three-factor model and Autocorrelations in Stock Returns}

By separating autocorrelations at different horizons, the test proposed in this chapter has found statistical evidence in support of the behavioral models, particularly the presence of negative long-horizon autocorrelations (mean reversion) in returns of stocks with more uncertainty or slower information diffusion. One may wonder at this point whether the evidence is also consistent with rational asset-pricing models such as the three-factor model of Fama and French (1993). I address this issue in the same fashion as that used by Fama and French (1988) to investigate whether mean reversion in stock prices is due to common factors. That is the residuals of stock returns obtained from the three-factor model are examined. Absence autocorrelations in the residuals would support the three-factor model. Otherwise, the behavioral models are supported. Tables 3-11, 312, and 3-13 report the $C V(p, q)$ and the test statistics $z(p, q)$ for the residuals of returns of size, book-to-market, and industry portfolios. Although (not surprisingly) the threefactor model can absorb autocorrelations in size and book-to-market portfolio returns, it cannot absorb autocorrelations in industry portfolio returns. The residuals of industry portfolio returns still exhibit strong autocorrelations. Therefore, the empirical evidence in this chapter supports more the behavioral models instead of the three-factor model. It also suggests that industry, size, and book-to-market are distinct factors in determining the 
misvaluation: cyclical industries, regardless of size and book-to-market-ratio, have more uncertainty and therefore more misvaluation.

\subsection{Data Mining}

Over the past 20 years, financial economists have looked at autocorrelations every which way. With so much searching, it is likely, purely by chance, that someone will uncover what looks to be patterns. Thus, apparent autocorrelation patterns, uncovered in this way, must be interpreted skeptically.

There are several ways of addressing the data-mining issue. Perhaps the most robust is to examine some other samples that have not been studied much. Two such samples are considered in this chapter: (1) a monthly time series of the Standard and Poor Composite Stock Price Index starting in $1871^{27}$; (2) 14 international stock markets during the period 1957 to $2003^{28}$. The monthly stock index data in these two samples are time average of daily index values. Working (1960) shows that the first difference of a timeaveraged random walk would exhibit positive autocorrelation, with a first-order autocorrelation coefficient of 0.25 as the number of observations in the average becomes large. This will bias the covariance-variance ratio estimates upward.

Returns in these two samples correspond to capital gains alone. Although the dividend-inclusive data are superior to the returns being used in this section, they are typically much shorter. For instance, Morgan Stanley Capital International inc. publishes the dividend-inclusive price data for international stock markets. But the sample period is

\footnotetext{
${ }^{27}$ The data is downloaded from Robert Shiller's web page, http://aida.econ.yale.edu/ shiller/data.htm.

${ }^{28}$ They are Austria, Canada, Columbia, Finland, France, India, Israel, Italy, Japan, Netherlands, Norway, Philippines, Spain, and UK. Monthly returns are based on stock price indices in the International Monetary Fund's International Financial Statistics.
} 
much shorter. The sample period for developed markets is no more than 30 years and that for developing markets is often shorter than 10 years. In contrast, the data being used in this section has a sample period of 45 years! Since the hypothesis that this chapter wants to test is whether negative long-horizon autocorrelations co-exist with positive shorthorizon autocorrelations, short samples will have no power to test this hypothesis. Moreover, Poterba and Summers (1988) show that the omission of dividends does not seem to be crucial.

Table 3-14 reports the $C V(p, q)$ and the test statistics $z(p, q)$ for the real returns of S\&P Index. The whole sample period is divided into two subperiods 1871-1946 and 1947-2001 for two considerations: (1) omitting dividends may be potentially dangerous over such a long period (more than 100 years) because dividend policy can change, which may look like the stock price has a mean-reverting component; (2) it is more informative to compare early years with recent decades. In early years, information should diffuse slower and investors should have more cognitive biases. Thus, the sort of misvaluation predicted by the behavioral models should be stronger in early years. The empirical evidence confirms this intuition in that the 1871-1946 period has stronger positive short-run and negative long-run autocorrelations.

Table 3-15 reports the $C V(p, q)$ and the test statistics $z(p, q)$ for the real returns of 14 international stock markets. Small markets should have more uncertainty and may also have slower information diffusion. Thus, they are expected to have the autocorrelation patterns predicted by the behavioral models: autocorrelations are positive at short horizons and negative at some longer horizons. The evidence indeed suggests that four 
small markets, Austria, Columbia, Finland, and the Netherlands have such autocorrelation patterns.

Since the estimates of covariance-variance ratios are biased upward (because the monthly data are time averages of daily values), the evidence in Table 3-14 and 3-15 regarding mean reversion in stock prices may be quite strong in some sense.

As one additional robustness check, different non-overlapping ranges are used to re-examine the size, book-to-market, and industry portfolios. The non-overlapping interval used in Section 3.4 is one year. Although it is the most natural choice and used by Cutler, Poterba, and Summers $(1990,1991)$, there do not seem to be clear theoretical grounds for ruling out other intervals such as 2 years, 3 years, and so on. When the nonoverlapping interval increases, on the one hand, if the autocorrelation is more persistent, the test will gain power; on the other hand, if the autocorrelation is not persistent and alters sign frequently as HS suggest, the test will lose power. Tables 3-16, 3-17 and 3-18 report the $C V(p, q)$ and the test statistics $z(p, q)$ for the same size, industry, and book-tomarket portfolios over the same sample period of 1947-2001 using the intervals of 2 years, 3 years, and 6 years. The results suggest that the autocorrelation is not persistent. As the interval increases, fewer portfolios exhibit positive and then negative autocorrelations. Nevertheless, the smallest size portfolio and the Finance industry still show robust positive and then negative autocorrelations regardless of the intervals being used.

Therefore, the robust evidence for other samples and other intervals suggest that the evidence obtained in this chapter is not likely due to data mining. Stocks with more 
uncertainty and slower information diffusion tend to have positive autocorrelations at short horizons and negative autocorrelations at some longer horizons.

\subsection{Conclusion}

What does this chapter add to the literature? First, I propose a new test that is particularly powerful to test the recent behavioral models. Since they are so different from the traditional fads model, the commonly used statistical tests such as the variance ratio test have little power to test them, particularly in detecting negative long-horizon autocorrelations. The same reason also makes the test proposed in this chapter have less power to test the fads model. But a uniformly powerful test seems to be not likely. Second, applying this new test, I find reliable statistical evidence in support of the behavioral models in that prices of stocks with more uncertainty and slower information diffusion (small size, high book-to-market, or cyclical stocks) tend to have both short-run continuation and long-run reversion, while the literature has so far found little statistical evidence of long-run mean reversion. Short-run continuation and long-run reversal show up in different sets of portfolios (industry, size, book-to-market, and size and book-tomarket portfolios), different stock markets (15 international stock markets), different sample periods (1871-1946 and 1947-2001), and even for different non-overlapping intervals used to estimate autocorrelations (1 year, 2 years, 3 years, and 6 years). So the results are not likely due to data mining. Furthermore, the fact that the three-factor model cannot absorb autocorrelations in industry portfolios lends more support to the behavioral models. Third, the evidence that value stocks have more misvaluation seems to shed some light on distinguishing three behavioral models. Specifically, it more supports HS 
instead of BSV and DHS because value stocks have more bad news and bad news travels slowly. 
Figure 3-1 The theoretical autocorrelation structure

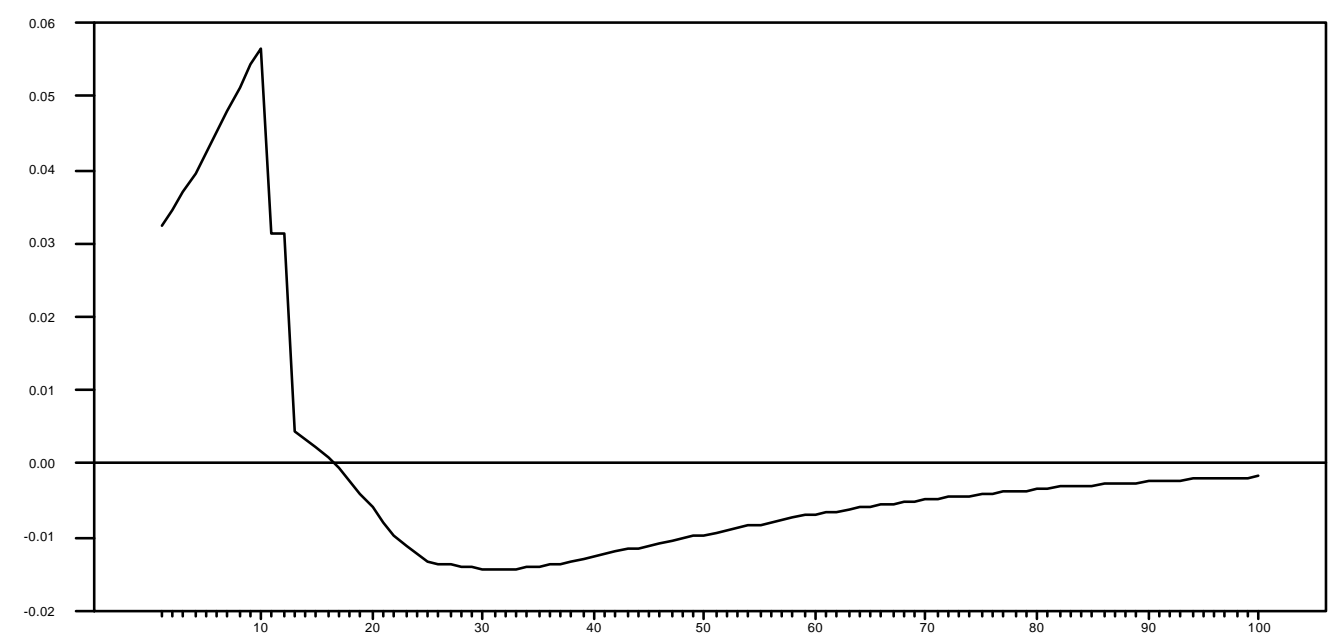

The theoretical autocorrelation structure for the following stock price generating process

$$
p_{t}=0.979 p_{t-1}+\sum_{i=1}^{12} 0.026\left(p_{t-j}-p_{t-j-1}\right)+\varepsilon_{t} \quad \varepsilon_{t} \sim N(0,1)
$$

Table 3-1 The theoretical values of variance ratios and covariance-variance ratios

\begin{tabular}{cccc}
\hline$q-1$ & VR & $(p, q-1)$ & $\mathrm{CV}$ \\
\hline 12 & 0.488 & $(1,12)$ & 0.503 \\
24 & 0.733 & $(13,24)$ & -0.043 \\
36 & 0.736 & $(25,36)$ & -0.167 \\
48 & 0.660 & $(37,48)$ & -0.142 \\
60 & 0.567 & $(48,60)$ & -0.100 \\
72 & 0.478 & $(61,72)$ & -0.067 \\
84 & 0.399 & $(73,84)$ & -0.044 \\
96 & 0.331 & $(85,96)$ & -0.029 \\
\hline
\end{tabular}

The theoretical values of variance ratios and covariance-variance ratios for the following specifications of the stock price process:

$$
p_{t}=0.979 p_{t-1}+\sum_{i=1}^{12} 0.026\left(p_{t-j}-p_{t-j-1}\right)+\varepsilon_{t} \boldsymbol{\varepsilon}_{t} \sim N(0,1)
$$


Table 3-2 Sampling error of the $S A$ test

\begin{tabular}{cccc}
\hline$q-1$ & $\mathrm{~V}$ & $\mathrm{~V}$ & $\mathrm{SE}$ \\
\hline 12 & 0.019423 & 0.020166 & 0.038 \\
24 & 0.035034 & 0.038515 & 0.099 \\
36 & 0.050564 & 0.057309 & 0.133 \\
48 & 0.065642 & 0.076288 & 0.162 \\
\hline
\end{tabular}

Sampling error of the $S A$ test. $V=\operatorname{Var}\left(\sum_{j=1}^{g-1} \hat{\rho}(j){ }^{\prime}, V^{\prime}=\sum_{j=1}^{q-1}[\operatorname{Var} \hat{\rho}(j)]\right.$, and $S E=\frac{V^{\prime}-V}{V}$. The specific form of heteroscadasticity is given by $\varepsilon_{\mathrm{t}}=\sigma_{\mathrm{t}} \lambda_{\mathrm{t}}$, where $\lambda_{\mathrm{t}}$ is IID N(0,1) and $\sigma_{\mathrm{t}}$ satisfies $\ln \sigma_{\mathrm{t}}^{2}=0.5 \ln \sigma_{\mathrm{t}-1}{ }^{2}+\xi_{\mathrm{t}}, \xi_{\mathrm{t}} \sim \mathrm{N}(0,1), \lambda_{\mathrm{t}}$ and $\xi_{\mathrm{t}}$ are assumed to be independent. The experiment is based on 10,000 replications.

Table 3-3 Empirical sizes of the nominal 1, 5, 10 percent variance ratio tests, covariance-variance ratio tests, rescaled variance ratio tests, and SA tests of the random walk null hypothesis with heteroskedastic distribution

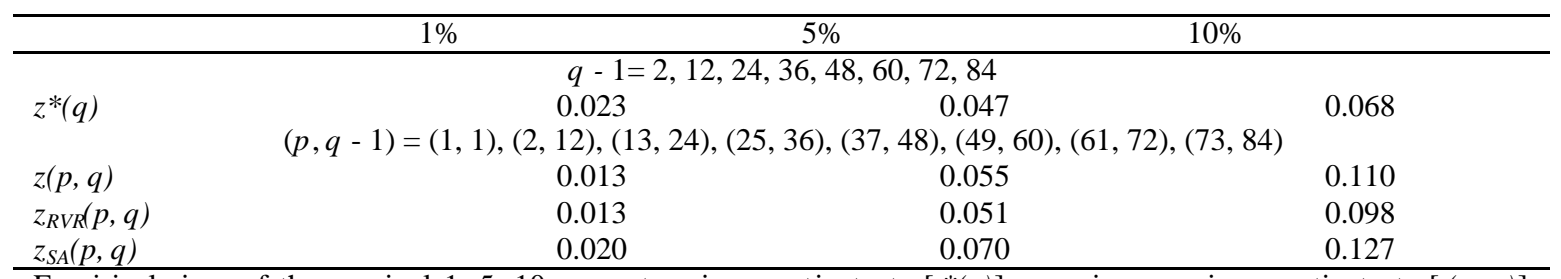

Empirical sizes of the nominal 1, 5, 10 percent variance ratio tests $\left[z^{*}(q)\right]$, covariance-variance ratio tests $[z(p, q)]$, rescaled variance ratio tests $\left.£_{R V R}(p, q)\right]$, and $\mathrm{SA}$ tests $\left.E_{S A}(p, q)\right]$ of the random walk null hypothesis with heteroskedastic distribution. The specific form of heteroscadasticity is given by $\varepsilon_{\mathrm{t}}=\sigma_{\mathrm{t}} \lambda_{\mathrm{t}}$, where $\lambda_{\mathrm{t}}$ is IID N $(0,1)$ and $\sigma_{\mathrm{t}}$ satisfies $\ln \sigma_{\mathrm{t}}^{2}=0.5 \ln \sigma_{\mathrm{t}-1}{ }^{2}+\xi_{\mathrm{t}}, \xi_{\mathrm{t}} \sim \mathrm{N}(0,1), \lambda_{\mathrm{t}}$ and $\xi_{\mathrm{t}}$ are assumed to be independent. The experiment is based on 10,000 replications. 
Table 3-4 Empirical critical values of the 1, 5, 10 percent variance ratio tests, covariance-variance ratio tests, rescaled variance ratio tests, and SA tests of the random walk null hypothesis with heteroskedastic distribution

\begin{tabular}{lccc}
\hline & \multicolumn{4}{c}{$5 \%$} & $10 \%$ \\
\hline \multirow{4}{*}{$z^{*}(q)$} & \multicolumn{1}{c}{$q-1=2,12,24,36,48,60,72,84$} & $(-1.87,2.65)$ \\
& $(-2.55,4.49)$ & $(-2.08,3.15)$ & $(-2.56,2.33)$ \\
$z(p, q)$ & $(p, q-1)=(1,1),(2,12),(13,24),(25,36),(37,48),(49,60),(61,72),(73,84)$ \\
$z_{R V R}(p, q)$ & $(-3.34,3.26)$ & $(-2.80,2.64)$ & $(-2.17,2.18)$ \\
$z_{S A}(p, q)$ & $(-3.47,4.02)$ & $(-2.53,2.62)$ & $(-2.68,2.45)$ \\
\hline
\end{tabular}

Empirical critical values of the $1,5,10$ percent variance ratio tests $\left[z^{*}(q)\right]$, covariance-variance ratio tests $[z(p, q)]$, rescaled variance ratio tests $\left.E_{R V R}(p, q)\right]$, and SA tests $\left.E_{S A}(p, q)\right]$ of the random walk null hypothesis with heteroskedastic distribution. The specific form of heteroscadasticity is given by $\varepsilon_{t}=\sigma_{t} \lambda_{t}$, where $\lambda_{t}$ is IID N $(0,1)$ and $\sigma_{t}$ satisfies $\ln \sigma_{\mathrm{t}}^{2}=0.5 \ln \sigma_{\mathrm{t}-1}^{2}+\xi_{\mathrm{t}}, \xi_{\mathrm{t}} \sim \mathrm{N}(0,1), \lambda_{\mathrm{t}}$ and $\xi_{\mathrm{t}}$ are assumed to be independent. The experiment is based on 10,000 replications.

Table 3-5 Power of the two-sided variance ratio test, covariance-variance ratio test, rescaled variance ratio test, and SA test

\begin{tabular}{lcccccc}
\hline & \multicolumn{3}{c}{$1 \%$} & \multicolumn{2}{c}{$5 \%$} & \multicolumn{2}{c}{$10 \%$} \\
\cline { 2 - 7 } & Upper & Lower & Upper & Lower & Upper & Lower \\
\hline$z_{*}^{*}(q)$ & 0.036 & 0.001 & 0.158 & 0.006 & 0.255 & 0.017 \\
$z(p, q)$ & 0.099 & 0.135 & 0.208 & 0.285 & 0.298 & 0.383 \\
$z_{R V R}(p, q)$ & 0.029 & 0.000 & 0.191 & 0.015 & 0.307 & 0.047 \\
$z_{S A}(p, q)$ & 0.085 & 0.134 & 0.193 & 0.300 & 0.272 & 0.395 \\
\hline
\end{tabular}

Power of the two -sided variance ratio test $\left[z^{*}(q)\right]$, covariance-variance ratio test $[z(p, q)]$, rescaled variance ratio test $\left[z_{R V R}(p, q)\right]$, and SA test $\left[z_{S A}(p, q)\right]$ against the following alternative process:

$$
p_{t}=0.979 p_{t-1}+\sum_{i=1}^{12} 0.026\left(p_{t-j}-p_{t-j-1}\right)+\varepsilon_{t} \quad \varepsilon_{t} \sim N(0,1)
$$

The experiment is based on 10,000 replications. 
Table 3-6 Tests for excess returns of industry portfolios: 1947:01-2001:12

\begin{tabular}{|c|c|c|c|c|c|c|c|c|}
\hline \multicolumn{9}{|c|}{ A Variance ratio tests } \\
\hline$q-1$ & 1 & 12 & 24 & 36 & 48 & 60 & 72 & 84 \\
\hline \multirow[t]{2}{*}{ NoDur } & 0.24 & 0.43 & 0.26 & 0.10 & 0.07 & 0.17 & 0.10 & 0.09 \\
\hline & $(4.93)^{*}$ & $(2.48)$ & (1.07) & $(0.32)$ & $(0.19)$ & $(0.42)$ & $(0.24)$ & $(0.20)$ \\
\hline \multirow[t]{2}{*}{ Durbl } & 0.21 & 0.35 & 0.19 & 0.02 & -0.05 & 0.00 & -0.03 & -0.09 \\
\hline & $(4.92)^{*}$ & $(2.10)$ & $(0.79)$ & $(0.05)$ & $(-0.16)$ & $(0.01)$ & $(-0.06)$ & $(-0.20)$ \\
\hline \multirow[t]{2}{*}{ Oil } & 0.13 & 0.58 & 0.61 & 0.50 & 0.58 & 0.77 & 0.74 & 0.70 \\
\hline & $(2.93)$ & $(3.21)^{*}$ & $(2.39)$ & $(1.56)$ & $(1.60)$ & $(1.91)$ & $(1.77)$ & (1.48) \\
\hline \multirow[t]{2}{*}{ Chems } & 0.16 & 0.09 & -0.19 & -0.40 & -0.54 & -0.49 & -0.48 & -0.50 \\
\hline & (3.09) & $(0.47)$ & $(-0.73)$ & $(-1.27)$ & $(-1.53)$ & $(-1.23)$ & $(-1.16)$ & $(-1.09)$ \\
\hline \multirow[t]{2}{*}{ Manuf } & 0.20 & 0.19 & 0.00 & -0.05 & -0.06 & -0.01 & 0.03 & -0.11 \\
\hline & $(4.51)^{*}$ & (1.10) & $(0.01)$ & $(-0.16)$ & $(-0.17)$ & $(-0.02)$ & $(0.07)$ & $(-0.25)$ \\
\hline \multirow[t]{2}{*}{ Telcm } & 0.18 & 0.38 & 0.04 & -0.09 & -0.24 & -0.20 & -0.21 & -0.21 \\
\hline & $(3.21)^{*}$ & (1.68) & (0.13) & $(-0.24)$ & $(-0.60)$ & $(-0.45)$ & $(-0.47)$ & $(-0.41)$ \\
\hline \multirow[t]{2}{*}{ Utils } & 0.10 & 0.24 & 0.23 & 0.27 & 0.37 & 0.42 & 0.58 & 0.53 \\
\hline & $(2.24)$ & (1.36) & $(0.91)$ & $(0.87)$ & (1.07) & (1.07) & (1.45) & (1.15) \\
\hline \multirow[t]{2}{*}{ Shop } & 0.23 & 0.35 & 0.18 & 0.07 & 0.07 & 0.14 & 0.01 & -0.07 \\
\hline & $(4.59) *$ & (1.83) & (0.68) & $(0.23)$ & $(0.19)$ & $(0.34)$ & $(0.02)$ & $(-0.14)$ \\
\hline \multirow[t]{2}{*}{ Money } & 0.25 & 0.78 & 0.89 & 0.85 & 0.83 & 0.81 & 0.79 & 0.52 \\
\hline & $(5.02)^{*}$ & $(4.34)^{*}$ & $(3.49)^{*}$ & $(2.71)$ & $(2.34)$ & $(2.02)$ & (1.89) & (1.09) \\
\hline \multirow[t]{2}{*}{ Other } & 0.23 & 0.31 & 0.11 & 0.09 & 0.12 & 0.19 & 0.19 & 0.11 \\
\hline & $(5.58)^{*}$ & (1.97) & $(0.51)$ & $(0.33)$ & $(0.37)$ & $(0.53)$ & $(0.50)$ & $(0.25)$ \\
\hline \multicolumn{9}{|c|}{ B Covariance-variance ratio tests } \\
\hline$(p, q-1)$ & $(1,1)$ & $(2,12)$ & $(13,24)$ & $(25,36)$ & $(37,48)$ & $(49,60)$ & $(61,72)$ & $(73,84)$ \\
\hline \multirow[t]{2}{*}{ NoDur } & 0.23 & 0.08 & -0.53 & 0.08 & 0.12 & 0.04 & -0.32 & 0.01 \\
\hline & $(4.87)^{*}$ & $(0.56)$ & $(-3.66)^{*}$ & $(0.55)$ & $(0.82)$ & $(0.25)$ & $(-2.34)$ & $(0.08)$ \\
\hline \multirow[t]{2}{*}{ Durbl } & 0.21 & 0.03 & -0.41 & -0.04 & 0.09 & 0.12 & -0.34 & -0.05 \\
\hline & $(4.87)^{*}$ & $(0.19)$ & $(-2.94)^{*}$ & $(-0.28)$ & $(0.65)$ & $(0.81)$ & $(-2.68)$ & $(-0.38)$ \\
\hline \multirow[t]{2}{*}{ Oil } & 0.13 & 0.30 & -0.33 & -0.06 & 0.28 & 0.07 & -0.51 & -0.06 \\
\hline & $(2.87)^{*}$ & (1.98) & $(-2.23)$ & $(-0.43)$ & $(2.10)$ & $(0.53)$ & $(-3.89)^{*}$ & $(-0.45)$ \\
\hline \multirow[t]{2}{*}{ Chems } & 0.16 & -0.17 & -0.37 & -0.02 & -0.01 & 0.26 & -0.22 & -0.01 \\
\hline & $(3.03)^{*}$ & $(-1.16)$ & $(-2.48)$ & $(-0.19)$ & $(-0.09)$ & (1.96) & $(-1.91)$ & $(-0.05)$ \\
\hline \multirow[t]{2}{*}{ Manuf } & 0.20 & -0.10 & -0.29 & 0.14 & -0.03 & 0.12 & -0.34 & -0.11 \\
\hline & $(4.44)^{*}$ & $(-0.73)$ & $(-2.13)$ & $(1.02)$ & $(-0.22)$ & $(0.83)$ & $(-2.81)^{*}$ & $(-0.89)$ \\
\hline \multirow[t]{2}{*}{ Telcm } & 0.18 & 0.04 & -0.32 & -0.10 & -0.10 & 0.12 & -0.12 & 0.16 \\
\hline & $(3.18)^{*}$ & $(0.23)$ & $(-2.20)$ & $(-0.68)$ & $(-0.83)$ & $(0.97)$ & $(-1.14)$ & $(1.40)$ \\
\hline \multirow[t]{2}{*}{ Utils } & 0.10 & 0.11 & -0.08 & 0.05 & 0.08 & 0.14 & -0.12 & 0.21 \\
\hline & (2.18) & $(0.71)$ & $(-0.57)$ & $(0.39)$ & $(0.57)$ & $(0.95)$ & $(-0.87)$ & $(1.52)$ \\
\hline \multirow[t]{2}{*}{ Shop } & 0.23 & 0.01 & -0.43 & 0.12 & 0.07 & -0.10 & -0.39 & 0.06 \\
\hline & $(4.55)^{*}$ & $(0.05)$ & $(-3.00)^{*}$ & $(0.80)$ & $(0.50)$ & $(-0.74)$ & $(-3.25)^{*}$ & $(0.46)$ \\
\hline \multirow[t]{2}{*}{ Money } & 0.24 & 0.36 & -0.36 & -0.02 & 0.02 & -0.07 & -0.35 & -0.20 \\
\hline & $(4.95)^{*}$ & $(2.40)$ & $(-2.52)$ & $(-0.17)$ & $(0.13)$ & $(-0.45)$ & $(-2.46)$ & $(-1.40)$ \\
\hline \multirow[t]{2}{*}{ Other } & 0.22 & -0.07 & -0.31 & 0.20 & -0.04 & 0.09 & -0.38 & -0.15 \\
\hline & $(5.53) *$ & $(-0.54)$ & $(-2.38)$ & $(1.52)$ & $(-0.28)$ & $(0.61)$ & $(-3.11)^{*}$ & $(-1.15)$ \\
\hline
\end{tabular}

Panel A: variance ratio test of the random walk hypothesis for industry portfo lios using a base observation period of one month, for the sample period from January 1947 to December 2001. The variance ratios $\bar{M}_{r}(q)$ are reported in the main rows, with the heteroscedasticity-robust test statistics $z^{*}(q)$ given in parentheses immediately below each main row. Panel B: covariance-variance ratio test of the random walk hypothesis for same industry portfolios over the same sample period. The covariance-variance ratios $C V(p, q)$ are reported in the main rows, with the heteroscedasticityrobust test statistics $z(p, q)$ given in parentheses immediately below each main row. The critical values corresponding to an overall size of $100 \alpha \%$ are empirically determined by simulation under the heteroskedastic null hypothesis. * denotes significance at the $5 \%$ level.

NoDur: Consumer Non-Durables; Durbl: Consumer Durables; Oil: Oil, Gas, and Coal Extraction and Products; Chems: Chemicals and Allied Products; Manuf: Manufacturing; Telcm: Telephones and Television; Utils: Utilities; Shops: Wholes ale, Retail, and Some Services; Money: Finance; Other: Everything Else. 
Table 3-7 Tests for excess returns of size portfolios: 1947:01-2001:12

\begin{tabular}{|c|c|c|c|c|c|c|c|c|}
\hline \multicolumn{9}{|c|}{ A Variance ratio tests } \\
\hline$q-1$ & 1 & 12 & 24 & 36 & 48 & 60 & 72 & 84 \\
\hline \multirow[t]{2}{*}{ Small 1} & 0.24 & 0.39 & 0.27 & 0.21 & 0.21 & 0.34 & 0.20 & 0.17 \\
\hline & $(5.32)^{*}$ & $(2.33)$ & (1.14) & $(0.72)$ & $(0.62)$ & $(0.88)$ & $(0.51)$ & $(0.38)$ \\
\hline \multirow[t]{2}{*}{2} & 0.18 & 0.21 & 0.09 & 0.02 & 0.02 & 0.11 & 0.10 & 0.03 \\
\hline & $(4.00)^{*}$ & $(1.24)$ & $(0.36)$ & $(0.06)$ & $(0.05)$ & $(0.30)$ & $(0.25)$ & $(0.07)$ \\
\hline \multirow[t]{2}{*}{3} & 0.15 & 0.05 & -0.11 & -0.19 & -0.20 & -0.14 & -0.13 & -0.21 \\
\hline & $(3.56)^{*}$ & $(0.27)$ & $(-0.47)$ & $(-0.64)$ & $(-0.62)$ & $(-0.38)$ & $(-0.32)$ & $(-0.46)$ \\
\hline \multirow[t]{2}{*}{4} & 0.17 & 0.11 & -0.06 & -0.17 & -0.21 & -0.18 & -0.14 & -0.24 \\
\hline & $(3.70)^{*}$ & $(0.66)$ & $(-0.27)$ & $(-0.59)$ & $(-0.64)$ & $(-0.47)$ & $(-0.35)$ & $(-0.53)$ \\
\hline \multirow[t]{2}{*}{5} & 0.14 & 0.09 & -0.10 & -0.19 & -0.22 & -0.19 & -0.14 & -0.26 \\
\hline & (3.10) & $(0.54)$ & $(-0.42)$ & $(-0.64)$ & $(-0.67)$ & $(-0.52)$ & $(-0.37)$ & $(-0.59)$ \\
\hline \multirow[t]{2}{*}{6} & 0.14 & 0.07 & -0.11 & -0.21 & -0.25 & -0.20 & -0.14 & -0.21 \\
\hline & (3.10) & $(0.41)$ & $(-0.46)$ & $(-0.70)$ & $(-0.76)$ & $(-0.53)$ & $(-0.35)$ & $(-0.47)$ \\
\hline \multirow[t]{2}{*}{7} & 0.12 & 0.05 & -0.16 & -0.28 & -0.31 & -0.26 & -0.15 & -0.23 \\
\hline & $(2.74)$ & $(0.31)$ & $(-0.66)$ & $(-0.93)$ & $(-0.93)$ & $(-0.67)$ & $(-0.38)$ & $(-0.52)$ \\
\hline \multirow{2}{*}{8} & 0.09 & -0.02 & -0.24 & -0.36 & -0.39 & -0.37 & -0.23 & -0.35 \\
\hline & (2.03) & $(-0.12)$ & $(-0.99)$ & $(-1.19)$ & $(-1.15)$ & $(-0.96)$ & $(-0.59)$ & $(-0.79)$ \\
\hline \multirow[t]{2}{*}{9} & 0.08 & -0.01 & -0.15 & -0.24 & -0.22 & -0.19 & 0.00 & -0.14 \\
\hline & (1.76) & $(-0.06)$ & $(-0.62)$ & $(-0.79)$ & $(-0.66)$ & $(-0.51)$ & $(0.01)$ & $(-0.30)$ \\
\hline \multirow[t]{2}{*}{ Big10 } & 0.03 & 0.07 & -0.06 & -0.16 & -0.12 & -0.05 & 0.14 & 0.02 \\
\hline & $(0.55)$ & $(0.37)$ & $(-0.26)$ & $(-0.52)$ & $(-0.36)$ & $(-0.14)$ & $(0.35)$ & $(0.04)$ \\
\hline \multicolumn{9}{|c|}{ B Covariance-variance ratio tests } \\
\hline$(p, q-1)$ & $(1,1)$ & $(2,12)$ & $(13,24)$ & $(25,36)$ & $(37,48)$ & $(49,60)$ & $(61,72)$ & $(73,84)$ \\
\hline \multirow[t]{2}{*}{ Small 1} & 0.23 & 0.06 & -0.38 & 0.10 & 0.05 & -0.01 & -0.46 & -0.14 \\
\hline & $(5.27)^{*}$ & $(0.44)$ & $(-2.75)$ & $(0.76)$ & $(0.34)$ & $(-0.09)$ & $(-3.78)^{*}$ & $(-1.08)$ \\
\hline \multirow[t]{2}{*}{2} & 0.17 & -0.03 & -0.31 & 0.06 & 0.08 & 0.04 & -0.31 & -0.07 \\
\hline & $(3.96)^{*}$ & $(-0.21)$ & $(-2.25)$ & $(0.45)$ & $(0.61)$ & $(0.30)$ & $(-2.53)$ & $(-0.53)$ \\
\hline \multirow[t]{2}{*}{3} & 0.15 & -0.14 & -0.27 & 0.10 & 0.01 & 0.10 & -0.26 & -0.06 \\
\hline & $(3.51)^{*}$ & $(-0.98)$ & $(-2.02)$ & $(0.71)$ & $(0.08)$ & $(0.70)$ & $(-2.07)$ & $(-0.50)$ \\
\hline \multirow[t]{2}{*}{4} & 0.16 & -0.13 & -0.29 & 0.07 & 0.01 & 0.10 & -0.25 & -0.01 \\
\hline & $(3.65)^{*}$ & $(-0.89)$ & $(-2.21)$ & $(0.49)$ & $(0.10)$ & $(0.75)$ & $(-2.00)$ & $(-0.08)$ \\
\hline \multirow[t]{2}{*}{5} & 0.14 & -0.13 & -0.28 & 0.11 & -0.01 & 0.09 & -0.22 & 0.00 \\
\hline & $(3.04)^{*}$ & $(-0.95)$ & $(-2.19)$ & $(0.79)$ & $(-0.06)$ & $(0.68)$ & $(-1.81)$ & $(-0.02)$ \\
\hline \multirow[t]{2}{*}{6} & 0.14 & -0.14 & -0.29 & 0.08 & 0.02 & 0.14 & -0.19 & 0.05 \\
\hline & $(3.05)^{*}$ & $(-1.01)$ & $(-2.18)$ & $(0.59)$ & $(0.12)$ & (1.05) & $(-1.59)$ & $(0.38)$ \\
\hline \multirow[t]{2}{*}{7} & 0.12 & -0.15 & -0.31 & 0.09 & 0.06 & 0.21 & -0.20 & 0.03 \\
\hline & $(2.69)^{*}$ & $(-1.06)$ & $(-2.31)$ & (0.63) & $(0.45)$ & (1.54) & $(-1.61)$ & $(0.20)$ \\
\hline \multirow[t]{2}{*}{8} & 0.09 & -0.18 & -0.27 & 0.09 & 0.02 & 0.20 & -0.16 & 0.10 \\
\hline & (1.97) & $(-1.27)$ & $(-2.00)$ & (0.68) & $(0.16)$ & (1.51) & $(-1.31)$ & $(0.77)$ \\
\hline \multirow[t]{2}{*}{9} & 0.08 & -0.13 & -0.22 & 0.12 & 0.05 & 0.20 & -0.10 & 0.05 \\
\hline & (1.69) & $(-0.90)$ & $(-1.62)$ & $(0.87)$ & $(0.41)$ & (1.44) & $(-0.85)$ & $(0.41)$ \\
\hline \multirow[t]{2}{*}{ Big10 } & 0.03 & 0.02 & -0.23 & 0.10 & 0.07 & 0.17 & -0.12 & 0.08 \\
\hline & $(0.49)$ & $(0.13)$ & $(-1.75)$ & $(0.74)$ & $(0.55)$ & $(1.28)$ & $(-1.03)$ & $(0.66)$ \\
\hline
\end{tabular}

Panel A: variance ratio test of the random walk hypothesis for size portfolios using a base observation period of one month, for the sample period from January 1947 to December 2001. The variance ratios $\bar{M}_{r}(q)$ are reported in the main rows, with the heteroscedasticity-robust test statistics $z^{*}(q)$ given in parentheses immediately below each main row. Panel B: covariance-variance ratio test of the random walk hypothesis for same size portfolios over the same sample period. The covariance-variance ratios $C V(p, q)$ are reported in the main rows, with the heteroscedasticityrobust test statistics $z(p, q)$ given in parentheses immediately below each main row. The critical values corresponding to an overall size of $100 \alpha \%$ are empiric ally determined by simulation under the heteroskedastic null hypothesis. * denotes significance at the $5 \%$ level. 
Table 3-8 Tests for excess returns of book-to-market portfolios: 1947:01-2001:12

\begin{tabular}{|c|c|c|c|c|c|c|c|c|}
\hline \multicolumn{9}{|c|}{ A Variance ratio tests } \\
\hline$q-1$ & 1 & 12 & 24 & 36 & 48 & 60 & 72 & 84 \\
\hline \multirow[t]{2}{*}{ Low 1} & 0.18 & 0.21 & -0.05 & -0.15 & -0.15 & -0.09 & -0.02 & -0.19 \\
\hline & $(3.27)^{*}$ & $(1.00)$ & $(-0.17)$ & $(-0.44)$ & $(-0.40)$ & $(-0.22)$ & $(-0.05)$ & $(-0.40)$ \\
\hline \multirow[t]{2}{*}{2} & 0.17 & 0.08 & -0.09 & -0.15 & -0.13 & -0.05 & -0.01 & -0.09 \\
\hline & $(3.70)^{*}$ & $(0.44)$ & $(-0.36)$ & $(-0.48)$ & $(-0.37)$ & $(-0.14)$ & $(-0.03)$ & $(-0.19)$ \\
\hline \multirow[t]{2}{*}{3} & 0.18 & 0.10 & -0.07 & -0.17 & -0.17 & -0.08 & -0.05 & -0.11 \\
\hline & $(4.08)^{*}$ & $(0.58)$ & $(-0.27)$ & $(-0.56)$ & $(-0.49)$ & $(-0.22)$ & $(-0.11)$ & $(-0.24)$ \\
\hline \multirow[t]{2}{*}{4} & 0.20 & 0.17 & 0.00 & -0.08 & -0.09 & -0.01 & 0.01 & -0.07 \\
\hline & $(4.80)^{*}$ & $(0.97)$ & $(0.01)$ & $(-0.26)$ & $(-0.26)$ & $(-0.03)$ & $(0.02)$ & $(-0.14)$ \\
\hline \multirow[t]{2}{*}{5} & 0.19 & 0.20 & 0.04 & -0.02 & -0.01 & 0.07 & 0.11 & 0.05 \\
\hline & $(4.33)^{*}$ & (1.18) & $(0.16)$ & $(-0.08)$ & $(-0.02)$ & $(0.18)$ & $(0.27)$ & $(0.11)$ \\
\hline \multirow[t]{2}{*}{6} & 0.18 & 0.21 & 0.03 & -0.07 & -0.09 & -0.02 & -0.01 & -0.09 \\
\hline & $(4.27)^{*}$ & $(1.30)$ & $(0.12)$ & $(-0.25)$ & $(-0.27)$ & $(-0.05)$ & $(-0.02)$ & $(-0.21)$ \\
\hline \multirow[t]{2}{*}{7} & 0.19 & 0.24 & 0.01 & -0.09 & -0.17 & -0.11 & -0.16 & -0.19 \\
\hline & $(4.43)^{*}$ & $(1.45)$ & $(0.06)$ & $(-0.32)$ & $(-0.53)$ & $(-0.29)$ & $(-0.41)$ & $(-0.42)$ \\
\hline \multirow[t]{2}{*}{8} & 0.19 & 0.25 & 0.08 & -0.07 & -0.18 & -0.13 & -0.19 & -0.26 \\
\hline & $(4.15)^{*}$ & $(1.52)$ & $(0.36)$ & $(-0.25)$ & $(-0.54)$ & $(-0.33)$ & $(-0.49)$ & $(-0.57)$ \\
\hline \multirow[t]{2}{*}{9} & 0.20 & 0.21 & 0.05 & -0.06 & -0.13 & -0.05 & -0.13 & -0.16 \\
\hline & $(4.53)^{*}$ & $(1.25)$ & $(0.20)$ & $(-0.22)$ & $(-0.40)$ & $(-0.14)$ & $(-0.33)$ & $(-0.35)$ \\
\hline \multirow[t]{2}{*}{ High 10} & 0.20 & 0.22 & 0.07 & -0.03 & -0.11 & -0.04 & -0.13 & -0.19 \\
\hline & $(4.32)^{*}$ & $(1.33)$ & $(0.29)$ & $(-0.11)$ & $(-0.32)$ & $(-0.09)$ & $(-0.34)$ & $(-0.42)$ \\
\hline \multicolumn{9}{|c|}{ B Covariance-variance ratio tests } \\
\hline$(p, q-1)$ & $(1,1)$ & $(2,12)$ & $(13,24)$ & $(25,36)$ & $(37,48)$ & $(49,60)$ & $(61,72)$ & $(73,84)$ \\
\hline \multirow[t]{2}{*}{ Low 1} & 0.17 & -0.12 & -0.35 & 0.18 & 0.00 & 0.12 & -0.24 & -0.06 \\
\hline & $(3.21)^{*}$ & $(-0.71)$ & $(-2.49)$ & $(1.34)$ & $(-0.02)$ & $(0.90)$ & $(-2.06)$ & $(-0.50)$ \\
\hline \multirow[t]{2}{*}{2} & 0.17 & -0.16 & -0.27 & 0.16 & 0.03 & 0.09 & -0.25 & -0.08 \\
\hline & $(3.66)^{*}$ & $(-1.09)$ & $(-1.87)$ & $(1.17)$ & $(0.20)$ & $(0.65)$ & $(-2.00)$ & $(-0.65)$ \\
\hline \multirow[t]{2}{*}{3} & 0.18 & -0.16 & -0.29 & 0.13 & 0.05 & 0.11 & -0.25 & -0.06 \\
\hline & $(4.01)^{*}$ & $(-1.10)$ & $(-2.07)$ & $(0.93)$ & $(0.32)$ & $(0.78)$ & $(-1.92)$ & $(-0.43)$ \\
\hline \multirow[t]{2}{*}{4} & 0.20 & -0.13 & -0.30 & 0.10 & 0.06 & 0.09 & -0.30 & -0.08 \\
\hline & $(4.74)^{*}$ & $(-0.87)$ & $(-2.17)$ & $(0.69)$ & $(0.40)$ & $(0.64)$ & $(-2.37)$ & $(-0.58)$ \\
\hline \multirow[t]{2}{*}{5} & 0.19 & -0.09 & -0.29 & 0.13 & 0.00 & 0.13 & -0.25 & -0.08 \\
\hline & $(4.27)^{*}$ & $(-0.62)$ & $(-2.07)$ & $(0.90)$ & $(0.03)$ & (0.89) & $(-1.92)$ & $(-0.58)$ \\
\hline \multirow[t]{2}{*}{6} & 0.18 & -0.05 & -0.36 & 0.07 & 0.07 & 0.10 & -0.31 & -0.05 \\
\hline & $(4.22)^{*}$ & $(-0.39)$ & $(-2.61)$ & $(0.52)$ & $(0.51)$ & $(0.64)$ & $(-2.38)$ & $(-0.40)$ \\
\hline \multirow[t]{2}{*}{7} & 0.18 & -0.07 & -0.34 & 0.01 & -0.02 & 0.15 & -0.32 & -0.06 \\
\hline & $(4.36)^{*}$ & $(-0.47)$ & $(-2.51)$ & $(0.10)$ & $(-0.14)$ & (1.03) & $(-2.55)$ & $(-0.46)$ \\
\hline \multirow[t]{2}{*}{8} & 0.18 & 0.01 & -0.42 & -0.08 & 0.04 & 0.13 & -0.36 & -0.08 \\
\hline & $(4.08)^{*}$ & $(0.08)$ & $(-2.99)^{*}$ & $(-0.59)$ & $(0.30)$ & $(0.86)$ & $(-2.77)$ & $(-0.58)$ \\
\hline \multirow[t]{2}{*}{9} & 0.20 & -0.01 & -0.40 & -0.01 & 0.01 & 0.12 & -0.35 & -0.08 \\
\hline & $(4.46)^{*}$ & $(-0.08)$ & $(-2.83)^{*}$ & $(-0.09)$ & $(0.08)$ & $(0.79)$ & $(-2.80)^{*}$ & $(-0.64)$ \\
\hline \multirow[t]{2}{*}{ High 10} & 0.20 & 0.00 & -0.37 & -0.01 & 0.01 & 0.07 & -0.42 & -0.07 \\
\hline & $(4.26)^{*}$ & $(0.01)$ & $(-2.73)$ & $(-0.04)$ & $(0.08)$ & $(0.48)$ & $(-3.41)^{*}$ & $(-0.53)$ \\
\hline
\end{tabular}

Panel A: variance ratio test of the random walk hypothesis for book-to-market portfolios using a base observation period of one month, for the sample period from January 1947 to December 2001. The variance ratios $\bar{M}_{r}(q)$ are reported in the main rows, with the heteroscedasticity-robust test statistics $z *(q)$ given in parentheses immediately below each main row. Panel B: covariance-variance ratio test of the random walk hypothesis for same book-to-market portfolios over the same sample period. The covariance-variance ratios $C V(p, q)$ are reported in the main rows, with the heteroscedasticity-robust test statistics $z(p, q)$ given in parentheses immediately below each main row. The critical values corresponding to an overall size of $100 \alpha \%$ are empirically determined by simulation under the heteroskedastic null hypothesis. * denotes significance at the $5 \%$ level. 
Table 3-9 Variance ratio tests for excess returns of size and book-to-market portfolios: 1947:01-2001:12

\begin{tabular}{|c|c|c|c|c|c|c|c|c|c|}
\hline & $q-1$ & 1 & 12 & 24 & 36 & 48 & 60 & 72 & 84 \\
\hline \multirow[t]{9}{*}{ Small 1} & Low 1 & $\begin{array}{c}0.17 \\
(3.41)^{*}\end{array}$ & $\begin{array}{c}0.20 \\
(1.03)\end{array}$ & $\begin{array}{c}0.03 \\
(0.10)\end{array}$ & $\begin{array}{c}0.02 \\
(0.07)\end{array}$ & $\begin{array}{c}0.05 \\
(0.15)\end{array}$ & $\begin{array}{c}0.21 \\
(0.51)\end{array}$ & $\begin{array}{c}0.08 \\
(0.19)\end{array}$ & $\begin{array}{c}0.09 \\
(0.20)\end{array}$ \\
\hline & 2 & 0.19 & 0.23 & 0.11 & 0.01 & 0.00 & 0.06 & -0.04 & -0.10 \\
\hline & & $(4.27)^{*}$ & $(1.34)$ & $(0.45)$ & $(0.03)$ & $(-0.01)$ & $(0.17)$ & $(-0.11)$ & $(-0.22)$ \\
\hline & 3 & 0.21 & 0.32 & 0.17 & 0.11 & 0.10 & 0.22 & 0.11 & 0.09 \\
\hline & & $(4.79)^{*}$ & $(1.90)$ & $(0.70)$ & $(0.36)$ & $(0.29)$ & $(0.56)$ & $(0.27)$ & $(0.20)$ \\
\hline & 4 & 0.22 & 0.33 & 0.21 & 0.12 & 0.06 & 0.15 & 0.03 & -0.01 \\
\hline & & $(4.88)^{*}$ & (1.98) & $(0.86)$ & $(0.39)$ & $(0.17)$ & $(0.39)$ & $(0.08)$ & $(-0.02)$ \\
\hline & High 5 & 0.22 & 0.27 & 0.14 & 0.05 & -0.02 & 0.07 & -0.05 & -0.09 \\
\hline & & $(4.76)^{*}$ & $(1.62)$ & $(0.60)$ & $(0.17)$ & $(-0.05)$ & $(0.19)$ & $(-0.13)$ & $(-0.19)$ \\
\hline \multirow[t]{10}{*}{2} & Low 1 & 0.16 & 0.08 & -0.09 & -0.20 & -0.22 & -0.20 & -0.22 & -0.33 \\
\hline & & $(3.17)^{*}$ & $(0.40)$ & $(-0.35)$ & $(-0.63)$ & $(-0.63)$ & $(-0.51)$ & $(-0.53)$ & $(-0.73)$ \\
\hline & 2 & 0.16 & 0.02 & -0.13 & -0.22 & -0.25 & -0.17 & -0.14 & -0.19 \\
\hline & & $(3.49)^{*}$ & $(0.13)$ & $(-0.54)$ & $(-0.75)$ & $(-0.72)$ & $(-0.45)$ & $(-0.36)$ & $(-0.43)$ \\
\hline & 3 & 0.16 & 0.12 & -0.04 & -0.19 & -0.26 & -0.22 & -0.21 & -0.30 \\
\hline & & $(3.60)^{*}$ & $(0.73)$ & $(-0.19)$ & $(-0.65)$ & $(-0.76)$ & $(-0.57)$ & $(-0.53)$ & $(-0.66)$ \\
\hline & 4 & 0.16 & 0.17 & 0.01 & -0.09 & -0.18 & -0.15 & -0.19 & -0.21 \\
\hline & & $(3.71)^{*}$ & (1.02) & $(0.06)$ & $(-0.32)$ & $(-0.56)$ & $(-0.40)$ & $(-0.50)$ & $(-0.47)$ \\
\hline & High 5 & 0.15 & 0.05 & -0.09 & -0.19 & -0.28 & -0.22 & -0.24 & -0.26 \\
\hline & & $(3.53)^{*}$ & $(0.28)$ & $(-0.41)$ & $(-0.69)$ & $(-0.86)$ & $(-0.61)$ & $(-0.62)$ & $(-0.60)$ \\
\hline \multirow[t]{10}{*}{3} & Low 1 & 0.12 & 0.04 & -0.15 & -0.21 & -0.23 & -0.18 & -0.11 & -0.24 \\
\hline & & $(2.20)$ & $(0.20)$ & $(-0.54)$ & $(-0.66)$ & $(-0.62)$ & $(-0.44)$ & $(-0.27)$ & $(-0.51)$ \\
\hline & 2 & 0.16 & 0.08 & -0.09 & -0.19 & -0.24 & -0.22 & -0.18 & -0.24 \\
\hline & & $(3.66)^{*}$ & $(0.50)$ & $(-0.36)$ & $(-0.64)$ & $(-0.74)$ & $(-0.57)$ & $(-0.45)$ & $(-0.53)$ \\
\hline & 3 & 0.15 & 0.15 & 0.02 & -0.08 & -0.11 & -0.07 & -0.01 & -0.11 \\
\hline & & $(3.39)^{*}$ & $(0.90)$ & $(0.07)$ & $(-0.27)$ & $(-0.33)$ & $(-0.18)$ & $(-0.03)$ & $(-0.26)$ \\
\hline & 4 & 0.14 & 0.20 & -0.02 & -0.19 & -0.32 & -0.30 & -0.29 & -0.37 \\
\hline & & $(3.16)^{*}$ & $(1.22)$ & $(-0.08)$ & $(-0.68)$ & $(-1.02)$ & $(-0.82)$ & $(-0.77)$ & $(-0.87)$ \\
\hline & High 5 & 0.13 & 0.14 & -0.07 & -0.25 & -0.29 & -0.23 & -0.25 & -0.30 \\
\hline & & (3.14) & $(0.83)$ & $(-0.31)$ & $(-0.90)$ & $(-0.89)$ & $(-0.64)$ & $(-0.64)$ & $(-0.68)$ \\
\hline \multirow[t]{10}{*}{$\overline{4}$} & Low 1 & 0.12 & 0.06 & -0.17 & -0.29 & -0.33 & -0.28 & -0.16 & -0.23 \\
\hline & & $(2.25)$ & $(0.30)$ & $(-0.65)$ & $(-0.88)$ & $(-0.90)$ & $(-0.68)$ & $(-0.39)$ & $(-0.50)$ \\
\hline & 2 & 0.13 & 0.11 & 0.02 & -0.07 & -0.05 & 0.05 & 0.21 & 0.15 \\
\hline & & (3.05) & $(0.62)$ & $(0.09)$ & $(-0.22)$ & $(-0.15)$ & $(0.13)$ & $(0.52)$ & $(0.33)$ \\
\hline & 3 & 0.12 & 0.06 & -0.14 & -0.24 & -0.26 & -0.25 & -0.08 & -0.24 \\
\hline & & $(2.65)$ & $(0.35)$ & $(-0.60)$ & $(-0.84)$ & $(-0.79)$ & $(-0.67)$ & $(-0.19)$ & $(-0.55)$ \\
\hline & 4 & 0.06 & 0.09 & -0.20 & -0.42 & -0.55 & -0.52 & -0.50 & -0.56 \\
\hline & & (1.53) & $(0.55)$ & $(-0.85)$ & $(-1.49)$ & $(-1.71)$ & $(-1.42)$ & $(-1.31)$ & $(-1.29)$ \\
\hline & High 5 & 0.08 & 0.03 & -0.17 & -0.38 & -0.46 & -0.49 & -0.43 & -0.60 \\
\hline & & (1.94) & $(0.18)$ & $(-0.72)$ & $(-1.32)$ & $(-1.40)$ & $(-1.31)$ & $(-1.10)$ & $(-1.33)$ \\
\hline \multirow[t]{10}{*}{ Big 5} & Low 1 & 0.07 & 0.06 & -0.10 & -0.22 & -0.22 & -0.17 & 0.00 & -0.08 \\
\hline & & $(1.31)$ & $(0.29)$ & $(-0.39)$ & $(-0.69)$ & $(-0.64)$ & $(-0.44)$ & $(0.00)$ & $(0.17)$ \\
\hline & 2 & 0.05 & -0.09 & -0.22 & -0.30 & -0.28 & -0.23 & -0.08 & -0.18 \\
\hline & & (1.25) & $(-0.55)$ & $(-0.90)$ & $(-0.98)$ & $(-0.82)$ & $(-0.58)$ & $(-0.21)$ & $(-0.40)$ \\
\hline & 3 & 0.04 & -0.01 & -0.10 & -0.16 & -0.09 & -0.07 & 0.14 & -0.05 \\
\hline & & $(0.92)$ & $(-0.03)$ & $(-0.43)$ & $(-0.53)$ & $(-0.26)$ & $(-0.17)$ & $(0.36)$ & $(-0.10)$ \\
\hline & 4 & 0.03 & 0.18 & -0.02 & -0.16 & -0.17 & -0.22 & 0.04 & -0.28 \\
\hline & & $(0.82)$ & (1.12) & $(-0.08)$ & $(-0.56)$ & $(-0.53)$ & $(-0.61)$ & $(0.10)$ & $(-0.66)$ \\
\hline & High 5 & 0.07 & 0.11 & -0.10 & -0.25 & -0.31 & -0.30 & -0.16 & -0.30 \\
\hline & & (1.62) & $(0.68)$ & $(-0.45)$ & $(-0.92)$ & $(-0.97)$ & $(-0.85)$ & $(-0.42)$ & $(-0.71)$ \\
\hline
\end{tabular}

Variance ratio test of the random walk hypothesis for size and book-to-market portfolios using a base observation period of one month, for the sample period from January 1947 to December 2001. The variance ratios $\bar{M}_{r}(q)$ are reported in the main rows, with the heteroscedasticity-robust test statistics $z^{*}(q)$ given in parentheses immediately below each main row. $*$ denotes significance at the $5 \%$ level. 
Table 3-10 Covariance-variance ratio tests for excess returns of size and book-to-market portfolios: 1947:01-2001:12

\begin{tabular}{|c|c|c|c|c|c|c|c|c|c|}
\hline \multicolumn{2}{|c|}{$(p, q-1)$} & $(1,1)$ & $(2,12)$ & $(13,24)$ & $(25,36)$ & $(37,48)$ & $(49,60)$ & $(61,72)$ & $(73,84)$ \\
\hline \multirow[t]{10}{*}{ Small 1} & \multirow[t]{2}{*}{ Low 1} & 0.16 & -0.06 & -0.28 & 0.18 & 0.05 & -0.01 & -0.34 & -0.20 \\
\hline & & $(3.38)^{*}$ & $(-0.36)$ & $(-2.02)$ & $(1.42)$ & (0.38) & $(-0.09)$ & $(-3.06)^{*}$ & $(-1.69)$ \\
\hline & \multirow[t]{2}{*}{2} & 0.18 & -0.03 & -0.32 & 0.06 & 0.06 & -0.05 & -0.37 & -0.07 \\
\hline & & $(4.21)^{*}$ & $(-0.20)$ & $(-2.33)$ & $(0.41)$ & $(0.43)$ & $(-0.33)$ & $(-3.07)^{*}$ & $(-0.53)$ \\
\hline & \multirow[t]{2}{*}{3} & 0.20 & 0.05 & -0.39 & 0.10 & 0.07 & -0.01 & -0.40 & -0.09 \\
\hline & & $(4.72)^{*}$ & $(0.34)$ & $(-2.72)$ & (0.73) & $(0.45)$ & $(-0.06)$ & $(-3.12)^{*}$ & $(-0.67)$ \\
\hline & \multirow[t]{2}{*}{4} & 0.21 & 0.05 & -0.37 & 0.00 & 0.04 & 0.01 & -0.42 & -0.09 \\
\hline & & $(4.82)^{*}$ & $(0.33)$ & $(-2.56)$ & $(0.00)$ & $(0.27)$ & $(0.08)$ & $(-3.25)^{*}$ & $(-0.68)$ \\
\hline & \multirow{2}{*}{ High 5} & 0.22 & 0.03 & -0.38 & -0.01 & 0.03 & 0.05 & -0.43 & -0.12 \\
\hline & & $(4.71)^{*}$ & $(0.20)$ & $(-2.73)$ & $(-0.06)$ & $(0.20)$ & $(0.36)$ & $(-3.38)^{*}$ & $(-0.89)$ \\
\hline \multirow[t]{10}{*}{2} & \multirow[t]{2}{*}{ Low 1} & 0.16 & -0.13 & -0.27 & 0.08 & -0.01 & 0.02 & -0.28 & -0.08 \\
\hline & & $(3.12)^{*}$ & $(-0.88)$ & $(-1.94)$ & $(0.61)$ & $(-0.08)$ & $(0.16)$ & $(-2.18)$ & $(-0.61)$ \\
\hline & \multirow[t]{2}{*}{2} & 0.15 & -0.16 & -0.27 & 0.07 & 0.02 & 0.13 & -0.22 & -0.07 \\
\hline & & $(3.43)^{*}$ & $(-1.09)$ & $(-1.95)$ & $(0.51)$ & $(0.17)$ & $(0.88)$ & $(-1.75)$ & $(-0.55)$ \\
\hline & \multirow[t]{2}{*}{3} & 0.15 & -0.09 & -0.32 & -0.05 & 0.07 & 0.12 & -0.27 & -0.06 \\
\hline & & $(3.55)^{*}$ & $(-0.64)$ & $(-2.31)$ & $(-0.36)$ & $(0.51)$ & $(0.79)$ & $(-2.01)$ & $(-0.46)$ \\
\hline & \multirow[t]{2}{*}{4} & 0.16 & -0.04 & -0.31 & -0.08 & 0.00 & 0.14 & -0.25 & -0.07 \\
\hline & & $(3.67)^{*}$ & $(-0.26)$ & $(-2.35)$ & $(-0.57)$ & $(-0.02)$ & $(0.95)$ & $(-1.96)$ & $(-0.52)$ \\
\hline & \multirow[t]{2}{*}{ High 5} & 0.14 & -0.06 & -0.32 & -0.01 & -0.04 & 0.18 & -0.24 & -0.08 \\
\hline & & $(3.51)^{*}$ & $(-0.46)$ & $(-2.47)$ & $(-0.06)$ & $(-0.28)$ & $(1.25)$ & $(-1.98)$ & $(-0.65)$ \\
\hline \multirow[t]{10}{*}{3} & \multirow[t]{2}{*}{ Low 1} & 0.12 & -0.16 & -0.24 & 0.14 & -0.01 & 0.08 & -0.16 & -0.03 \\
\hline & & (2.15) & $(-0.99)$ & $(-1.75)$ & (1.01) & $(-0.07)$ & $(0.62)$ & $(-1.29)$ & $(-0.22)$ \\
\hline & \multirow[t]{2}{*}{2} & 0.15 & -0.18 & -0.24 & 0.06 & -0.01 & 0.12 & -0.19 & 0.01 \\
\hline & & $(3.59)^{*}$ & $(-1.28)$ & $(-1.82)$ & $(0.43)$ & $(-0.05)$ & $(0.86)$ & $(-1.49)$ & $(0.06)$ \\
\hline & \multirow[t]{2}{*}{3} & 0.15 & -0.08 & -0.29 & 0.03 & 0.05 & 0.11 & -0.17 & -0.06 \\
\hline & & $(3.34)^{*}$ & $(-0.56)$ & $(-2.20)$ & $(0.22)$ & (0.33) & $(0.79)$ & $(-1.38)$ & $(-0.46)$ \\
\hline & \multirow[t]{2}{*}{4} & 0.13 & -0.05 & -0.34 & -0.12 & 0.02 & 0.20 & -0.19 & -0.05 \\
\hline & & $(3.10)^{*}$ & $(-0.36)$ & $(-2.69)$ & $(-0.96)$ & $(0.12)$ & (1.43) & $(-1.53)$ & $(-0.40)$ \\
\hline & \multirow[t]{2}{*}{ High 5} & 0.13 & 0.00 & -0.45 & 0.04 & 0.08 & 0.05 & -0.30 & 0.04 \\
\hline & & $(3.08)^{*}$ & $(-0.04)$ & $(-3.43)^{*}$ & $(0.33)$ & $(0.61)$ & $(0.34)$ & $(-2.44)$ & $(0.32)$ \\
\hline 4 & Low 1 & 0.11 & -0.16 & -0.30 & 0.11 & 0.01 & 0.18 & -0.11 & 0.02 \\
\hline & & (2.19) & $(-1.04)$ & $(-2.17)$ & $(0.81)$ & (0.09) & (1.39) & $(-0.89)$ & (0.19) \\
\hline & 2 & 0.13 & -0.12 & -0.20 & 0.06 & 0.12 & 0.19 & -0.14 & 0.00 \\
\hline & & $(2.98) *$ & $(-0.85)$ & $(-1.43)$ & $(0.46)$ & $(0.86)$ & (1.34) & $(-1.06)$ & $(0.01)$ \\
\hline & 3 & 0.11 & -0.15 & -0.27 & 0.10 & 0.03 & 0.21 & -0.13 & 0.02 \\
\hline & & $(2.61)$ & $(-1.07)$ & $(-1.99)$ & $(0.75)$ & $(0.20)$ & $(1.58)$ & $(-1.06)$ & $(0.12)$ \\
\hline & 4 & 0.06 & -0.04 & -0.44 & -0.08 & 0.10 & 0.24 & -0.27 & 0.01 \\
\hline & & (1.47) & $(-0.31)$ & $(-3.39)^{*}$ & $(-0.60)$ & $(0.70)$ & $(1.74)$ & $(-2.17)$ & $(0.08)$ \\
\hline & High 5 & 0.08 & -0.11 & -0.27 & -0.06 & 0.06 & 0.11 & -0.28 & -0.02 \\
\hline & & (1.86) & $(-0.83)$ & $(-2.03)$ & $(-0.40)$ & $(0.45)$ & $(0.76)$ & $(-2.26)$ & $(-0.13)$ \\
\hline Big 5 & Low 1 & 0.07 & -0.07 & -0.25 & 0.08 & 0.00 & 0.17 & -0.02 & 0.09 \\
\hline & & (1.25) & $(-0.43)$ & $(-1.89)$ & $(0.58)$ & $(0.01)$ & $(1.29)$ & $(-0.15)$ & (0.69) \\
\hline & 2 & 0.05 & -0.16 & -0.19 & 0.10 & 0.09 & 0.15 & -0.11 & 0.05 \\
\hline & & (1.18) & $(-1.11)$ & $(-1.36)$ & $(0.70)$ & $(0.62)$ & (1.10) & $(-0.85)$ & $(0.37)$ \\
\hline & 3 & 0.04 & -0.06 & -0.19 & 0.13 & 0.12 & 0.11 & -0.09 & -0.01 \\
\hline & & $(0.85)$ & $(-0.46)$ & $(-1.37)$ & (1.01) & (0.89) & $(0.81)$ & $(-0.78)$ & $(-0.04)$ \\
\hline & 4 & 0.03 & 0.02 & -0.28 & 0.04 & 0.07 & 0.18 & -0.17 & 0.00 \\
\hline & & $(0.75)$ & $(0.15)$ & $(-2.09)$ & (0.33) & $(0.56)$ & (1.33) & $(-1.32)$ & $(0.01)$ \\
\hline & High 5 & 0.07 & -0.06 & -0.35 & 0.03 & 0.12 & 0.17 & -0.23 & -0.04 \\
\hline & & (1.54) & $(-0.46)$ & $(-2.66)$ & $(0.24)$ & $(0.87)$ & $(1.24)$ & $(-1.85)$ & $(-0.33)$ \\
\hline
\end{tabular}

Covariance-variance ratio test of the random walk hypothesis for size and book-to-market portfolios over the sample period from January 1947 to December 2001. The covariance-variance ratios $C V(p, q)$ are reported in the main rows, with the heteroscedasticity-robust test statistics $z(p, q)$ given in parentheses immediately below each main row. The critical values corresponding to an overall size of $100 \alpha \%$ are empirically determined by simulation under the heteroskedastic null hypothesis. * denotes significance at the $5 \%$ level. 
Table 3-11 Covariance-variance ratio tests for residuals of returns of size portfolios: 1947:01-2001:12

\begin{tabular}{|c|c|c|c|c|c|c|c|c|}
\hline$(p, q-1)$ & $(1,1)$ & $(2,12)$ & $(13,24)$ & $(25,36)$ & $(37,48)$ & $(49,60)$ & $(61,72)$ & $(73,84)$ \\
\hline \multirow[t]{2}{*}{ Small 1} & -0.07 & 0.22 & -0.12 & 0.05 & 0.05 & 0.09 & -0.09 & -0.05 \\
\hline & $(-0.87)$ & (1.16) & $(-0.71)$ & $(0.34)$ & $(0.34)$ & $(0.72)$ & $(-0.75)$ & $(-0.44)$ \\
\hline \multirow[t]{2}{*}{2} & -0.14 & 0.24 & 0.03 & 0.12 & 0.10 & 0.08 & 0.11 & -0.02 \\
\hline & $(-1.12)$ & $(0.99)$ & $(0.21)$ & (0.94) & $(0.91)$ & $(0.92)$ & (1.02) & $(-0.19)$ \\
\hline \multirow[t]{2}{*}{3} & -0.08 & 0.05 & -0.04 & 0.10 & -0.08 & -0.05 & -0.02 & -0.02 \\
\hline & $(-0.97)$ & $(0.17)$ & $(-0.23)$ & (0.80) & $(-0.54)$ & $(-0.45)$ & $(-0.19)$ & $(-0.24)$ \\
\hline \multirow[t]{2}{*}{4} & 0.06 & -0.14 & -0.12 & -0.07 & -0.02 & 0.04 & 0.08 & -0.06 \\
\hline & (0.64) & $(-0.50)$ & $(-0.66)$ & $(-0.59)$ & $(-0.14)$ & (0.33) & $(0.83)$ & $(-0.65)$ \\
\hline \multirow[t]{2}{*}{5} & 0.02 & -0.26 & -0.05 & 0.00 & -0.06 & -0.02 & -0.03 & -0.05 \\
\hline & $(0.23)$ & $(-0.89)$ & $(-0.27)$ & $(-0.04)$ & $(-0.54)$ & $(-0.18)$ & $(-0.30)$ & $(-0.49)$ \\
\hline \multirow[t]{2}{*}{6} & 0.08 & -0.21 & 0.13 & -0.10 & -0.18 & -0.03 & -0.04 & -0.02 \\
\hline & $(0.80)$ & $(-0.81)$ & $(0.64)$ & $(-0.69)$ & $(-1.35)$ & $(-0.27)$ & $(-0.39)$ & $(-0.21)$ \\
\hline \multirow[t]{2}{*}{7} & 0.03 & 0.10 & -0.03 & -0.28 & -0.17 & 0.09 & 0.09 & -0.08 \\
\hline & $(0.34)$ & $(0.44)$ & $(-0.15)$ & $(-2.25)$ & $(-1.55)$ & $(0.84)$ & $(0.86)$ & $(-0.76)$ \\
\hline \multirow[t]{2}{*}{8} & 0.02 & 0.21 & -0.10 & -0.40 & -0.19 & -0.02 & 0.00 & 0.03 \\
\hline & $(0.33)$ & (1.08) & $(-0.52)$ & $(-2.82)^{*}$ & $(-1.60)$ & $(-0.17)$ & $(0.02)$ & $(0.25)$ \\
\hline \multirow[t]{2}{*}{9} & 0.01 & -0.04 & -0.03 & -0.52 & 0.02 & 0.12 & 0.12 & -0.03 \\
\hline & $(0.12)$ & $(-0.23)$ & $(-0.21)$ & $(-4.08)^{*}$ & $(0.20)$ & (1.11) & (1.18) & $(-0.25)$ \\
\hline \multirow[t]{2}{*}{ Big10 } & -0.08 & -0.07 & 0.16 & -0.04 & 0.01 & -0.04 & 0.04 & 0.16 \\
\hline & $(-0.84)$ & $(-0.24)$ & $(0.90)$ & $(-0.38)$ & $(0.10)$ & $(-0.51)$ & $(0.44)$ & (1.77) \\
\hline
\end{tabular}

Covariance-variance ratio test of the random walk hypothesis for residuals of size portfolio returns over the sample period from January 1947 to December 2001. The covariance-variance ratios $C V(p, q)$ are reported in the main rows, with the heteroscedasticity-robust test statistics $z(p, q)$ given in parentheses immediately below each main row. The critical values corresponding to an overall size of $100 \alpha \%$ are empirically determined by simulation under the heteroskedastic null hypothesis. * denotes significance at the $5 \%$ level.

Table 3-12 Covariance-variance ratio tests for residuals of returns of book-to-market portfolios: 1947:012001:12

\begin{tabular}{lcccccccc}
\hline$(p, q-1)$ & $(1,1)$ & $(2,12)$ & $(13,24)$ & $(25,36)$ & $(37,48)$ & $(49,60)$ & $(61,72)$ & $(73,84)$ \\
\hline Low 1 & -0.10 & 0.36 & 0.23 & 0.15 & 0.20 & 0.02 & -0.04 & -0.04 \\
& $(-1.08)$ & $(1.53)$ & $(1.47)$ & $(1.09)$ & $(1.42)$ & $(0.13)$ & $(-0.34)$ & $(-0.29)$ \\
2 & -0.10 & 0.49 & 0.22 & -0.03 & -0.22 & -0.08 & -0.16 & -0.29 \\
& $(-1.39)$ & $(2.38)$ & $(1.43)$ & $(-0.18)$ & $(-1.63)$ & $(-0.64)$ & $(-1.27)$ & $(-2.58)$ \\
3 & -0.04 & 0.24 & -0.05 & -0.10 & -0.18 & -0.03 & -0.10 & -0.05 \\
& $(-0.59)$ & $(1.10)$ & $(-0.32)$ & $(-0.72)$ & $(-1.39)$ & $(-0.26)$ & $(-0.86)$ & $(-0.40)$ \\
4 & -0.05 & 0.17 & -0.03 & -0.11 & -0.19 & -0.07 & 0.00 & 0.00 \\
& $(-0.65)$ & $(0.84)$ & $(-0.21)$ & $(-0.80)$ & $(-1.47)$ & $(-0.59)$ & $(-0.02)$ & $(-0.02)$ \\
5 & -0.02 & 0.40 & 0.12 & 0.01 & -0.10 & 0.18 & 0.11 & -0.10 \\
& $(-0.19)$ & $(1.90)$ & $(0.74)$ & $(0.09)$ & $(-0.78)$ & $(1.52)$ & $(0.93)$ & $(-0.88)$ \\
6 & -0.02 & 0.44 & 0.03 & 0.10 & -0.02 & 0.15 & 0.02 & -0.02 \\
& $(-0.30)$ & $(2.05)$ & $(0.19)$ & $(0.84)$ & $(-0.19)$ & $(1.23)$ & $(0.19)$ & $(-0.16)$ \\
7 & -0.05 & 0.33 & -0.05 & -0.04 & 0.00 & 0.22 & 0.23 & -0.11 \\
& $(-0.67)$ & $(1.57)$ & $(-0.29)$ & $(-0.33)$ & $(-0.02)$ & $(1.94)$ & $(2.09)$ & $(-0.90)$ \\
8 & -0.05 & 0.39 & -0.02 & -0.13 & -0.05 & 0.15 & 0.06 & -0.12 \\
& $(-0.73)$ & $(1.94)$ & $(-0.15)$ & $(-1.02)$ & $(-0.37)$ & $(1.26)$ & $(0.55)$ & $(-1.00)$ \\
9 & -0.09 & 0.17 & -0.01 & 0.09 & 0.12 & 0.21 & 0.10 & -0.04 \\
& $(-1.11)$ & $(0.80)$ & $(-0.04)$ & $(0.66)$ & $(0.93)$ & $(1.66)$ & $(0.74)$ & $(-0.30)$ \\
High 10 & -0.01 & 0.25 & -0.01 & 0.04 & 0.06 & 0.21 & -0.07 & 0.13 \\
& $(-0.12)$ & $(1.39)$ & $(-0.09)$ & $(0.26)$ & $(0.45)$ & $(1.62)$ & $(-0.57)$ & $(1.06)$ \\
\hline
\end{tabular}

Covariance-variance ratio test of the random walk hypothesis for residuals of book-to-market portfolio returns over the sample period from January 1947 to December 2001. The covariance-variance ratios $C V(p, q)$ are reported in the main rows, with the heteroscedasticity-robust test statistics $z(p, q)$ given in parentheses immediately below each main row. The critical values corresponding to an overall size of $100 \alpha \%$ are empirically determined by simulation under the heteroskedastic null hypothesis. * denotes significance at the $5 \%$ level. 
Table 3-13 Covariance-variance ratio tests for residuals of returns of industry portfolios: 1947:01-2001:12

\begin{tabular}{lcccccccc}
\hline \multicolumn{1}{c}{$(p, q-1)$} & $(1,1)$ & $(2,12)$ & $(13,24)$ & $(25,36)$ & $(37,48)$ & $(49,60)$ & $(61,72)$ & $(73,84)$ \\
\hline NoDur & 0.03 & 0.44 & -0.47 & 0.09 & 0.18 & 0.03 & -0.25 & 0.05 \\
& $(0.34)$ & $(2.11)$ & $(-2.92)^{*}$ & $(0.66)$ & $(1.48)$ & $(0.28)$ & $(-2.25)$ & $(0.44)$ \\
Durbl & 0.10 & 0.04 & -0.28 & 0.03 & -0.10 & 0.09 & -0.15 & 0.33 \\
& $(1.28)$ & $(0.21)$ & $(-1.99)$ & $(0.25)$ & $(-0.84)$ & $(0.70)$ & $(-1.29)$ & $(2.77)^{*}$ \\
Oil & 0.25 & 1.02 & -0.37 & -0.16 & 0.44 & -0.19 & -0.39 & 0.33 \\
& $(4.84)^{*}$ & $(5.92)^{*}$ & $(-2.14)$ & $(-1.05)$ & $(3.16)^{*}$ & $(-1.42)$ & $(-2.90)^{*}$ & $(2.42)$ \\
Chems & 0.16 & 0.74 & -0.19 & -0.80 & -0.17 & 0.51 & -0.18 & -0.54 \\
& $(1.59)$ & $(4.12)^{*}$ & $(-1.12)$ & $(-4.76)^{*}$ & $(-1.09)$ & $(3.21)^{*}$ & $(-1.22)$ & $(-3.98)^{*}$ \\
Manuf & 0.02 & 0.73 & 0.02 & -0.04 & 0.04 & 0.14 & -0.34 & -0.28 \\
& $(0.25)$ & $(3.17)^{*}$ & $(0.11)$ & $(-0.27)$ & $(0.29)$ & $(1.13)$ & $(-2.78)$ & $(-2.29)$ \\
Telcm & 0.10 & 0.38 & -0.31 & -0.56 & -0.27 & 0.23 & 0.36 & 0.19 \\
& $(1.44)$ & $(2.05)$ & $(-2.16)$ & $(-4.63)^{*}$ & $(-2.52)$ & $(2.03)$ & $(3.18)^{*}$ & $(1.62)$ \\
Utils & 0.18 & 0.11 & -0.01 & -0.06 & -0.17 & 0.08 & -0.29 & 0.11 \\
& $(4.17)^{*}$ & $(0.77)$ & $(-0.08)$ & $(-0.48)$ & $(-1.36)$ & $(0.65)$ & $(-2.36)$ & $(0.81)$ \\
Shop & -0.02 & 0.30 & -0.34 & -0.15 & -0.03 & -0.30 & -0.16 & 0.35 \\
& $(0.22)$ & $(1.20)$ & $(-2.06)$ & $(-1.02)$ & $(-0.26)$ & $(-2.51)$ & $(-1.42)$ & $(3.20)^{*}$ \\
Money & 0.16 & 1.17 & -0.19 & -0.35 & -0.29 & -0.58 & -0.23 & -0.25 \\
& $(3.43)^{*}$ & $(7.62)^{*}$ & $(-1.27)$ & $(-2.76)$ & $(-2.45)$ & $(-4.76)^{*}$ & $(-1.91)$ & $(-1.98)$ \\
Other & 0.08 & 0.48 & -0.02 & 0.13 & -0.27 & -0.31 & -0.41 & -0.39 \\
& $(1.56)$ & $(3.18)^{*}$ & $(-0.12)$ & $(1.00)$ & $(-2.14)$ & $(-2.31)$ & $(-3.51)^{*}$ & $(-3.16)^{*}$ \\
\hline
\end{tabular}

Covariance-variance ratio test of the random walk hypothesis for residuals of industry portfolio returns over the sample period from January 1947 to December 2001. The covariance-variance ratios $C V(p, q)$ are reported in the main rows, with the heteroscedasticity-robust test statistics $z(p, q)$ given in parentheses immediately below each main row. The critical values corresponding to an overall size of $100 \alpha \%$ are empirically determined by simulation under the heteroskedastic null hypothesis. * denotes significance at the $5 \%$ level.

NoDur: Consumer Non-Durables; Durbl: Consumer Durables; Oil: Oil, Gas, and Coal Extraction and Products; Chems: Chemicals and Allied Products; Manuf: Manufacturing; Telcm: Telephones and Television; Utils: Utilities; Shops: Wholesale, Retail, and Some Services; Money: Finance; Other: Everything Else.

Table 3-14 Covariance-variance ratio tests for real returns of S\&P Index 1871:02-2001:12

\begin{tabular}{ccccccccc}
\hline$(p, q-1)$ & $(1,1)$ & $(2,12)$ & $(13,24)$ & $(25,36)$ & $(37,48)$ & $(49,60)$ & $(61,72)$ & $(73,84)$ \\
\hline $1947-2001$ & 0.24 & 0.24 & -0.33 & 0.19 & 0.13 & 0.36 & -0.19 & 0.15 \\
& $(4.93)^{*}$ & $(1.73)$ & $(-2.57)$ & $(1.43)$ & $(1.00)$ & $(2.68)$ & $(-1.53)$ & $(1.17)$ \\
& & & & & & & & \\
$1871-1946$ & 0.29 & 0.22 & -0.45 & 0.03 & -0.06 & -0.40 & -0.05 & 0.15 \\
& $(5.27)^{*}$ & $(1.16)$ & $(-2.91)^{*}$ & $(0.19)$ & $(-0.50)$ & $(-3.36)^{*}$ & $(-0.35)$ & $(1.16)$ \\
\hline
\end{tabular}

Covariance-variance ratio test of the random walk hypothesis for real returns of S\&P Index over the sample period from February 1871 to December 2001. The covariance-variance ratios $C V(p, q)$ are reported in the main rows, with the heteroscedasticity-robust test statistics $z(p, q)$ given in parentheses immediately below each main row. The critical value corresponding to an overall size of $5 \%$ is 2.73 . $*$ denotes significance at the $5 \%$ level. 
Table 3-15 Covariance-variance ratio tests for international data on real monthly returns

\begin{tabular}{|c|c|c|c|c|c|c|c|c|}
\hline$(p, q-1)$ & $(1,1)$ & $(2,12)$ & $(13,24)$ & $(25,36)$ & $(37,48)$ & $(49,60)$ & $(61,72)$ & $(73,84)$ \\
\hline Austria & 0.25 & 0.69 & -0.35 & -0.60 & 0.14 & 0.42 & -0.39 & -0.08 \\
\hline $57: 2-99: 1$ & $(3.48)^{*}$ & $(3.59)^{*}$ & $(-2.23)$ & $(-3.79)^{*}$ & (0.99) & (2.33) & $(-2.50)$ & $(-0.57)$ \\
\hline Canada & 0.10 & -0.05 & -0.34 & 0.09 & -0.05 & 0.02 & -0.32 & 0.17 \\
\hline $57: 2-03: 2$ & $(2.30)$ & $(-0.31)$ & $(-2.32)$ & $(0.59)$ & $(-0.39)$ & $(0.14)$ & $(-2.13)$ & (1.26) \\
\hline Colombia & 0.21 & 0.38 & -0.26 & -0.05 & -0.24 & 0.04 & 0.60 & -0.67 \\
\hline $59: 2-03: 3$ & $(2.66)$ & (2.10) & $(-1.65)$ & $(-0.37)$ & $(-1.54)$ & $(0.32)$ & $(4.11)^{*}$ & $(-4.36) *$ \\
\hline Finland & 0.34 & 0.91 & -0.06 & -0.42 & -0.63 & -0.02 & 0.06 & 0.02 \\
\hline $57: 2-03: 2$ & $(5.30) *$ & $(4.73)^{*}$ & $(-0.29)$ & $(-2.28)$ & $(-3.73)^{*}$ & $(-0.12)$ & (0.38) & $(0.11)$ \\
\hline France & 0.01 & 0.18 & -0.06 & 0.12 & -0.09 & -0.25 & -0.05 & 0.06 \\
\hline $57: 2-03: 2$ & $(0.08)$ & (1.19) & $(-0.40)$ & $(0.84)$ & $(-0.66)$ & $(-1.82)$ & $(-0.33)$ & $(0.38)$ \\
\hline India & 0.33 & 0.05 & -0.08 & 0.22 & -0.18 & -0.15 & 0.09 & -0.09 \\
\hline $57: 8-99: 4$ & $(3.34)^{*}$ & $(0.23)$ & $(-0.38)$ & $(1.21)$ & $(-1.02)$ & $(-0.69)$ & $(0.57)$ & $(-0.47)$ \\
\hline Israel & 0.07 & 0.42 & -0.26 & -0.40 & -0.13 & 0.18 & -0.12 & -0.13 \\
\hline $57: 2-03: 2$ & $(1.32)$ & $(2.52)$ & $(-1.84)$ & $(-2.57)$ & $(-0.83)$ & (1.37) & $(-0.73)$ & $(-0.80)$ \\
\hline Italy & 0.26 & 0.78 & -0.19 & -0.12 & -0.31 & -0.03 & -0.01 & -0.29 \\
\hline $57: 2-03: 3$ & $(5.10)^{*}$ & $(5.03)^{*}$ & $(-1.27)$ & $(-0.84)$ & $(-2.22)$ & $(-0.21)$ & $(-0.05)$ & $(-1.94)$ \\
\hline Japan & 0.23 & 0.45 & -0.19 & 0.24 & 0.00 & -0.32 & -0.15 & 0.24 \\
\hline $57: 2-02: 2$ & $(2.53)$ & $(2.90)^{*}$ & $(-1.25)$ & (1.66) & $(0.01)$ & $(-2.61)$ & $(-1.26)$ & $(2.01)$ \\
\hline Netherlands & 0.34 & 0.84 & 0.21 & 0.26 & -0.04 & -0.14 & -0.46 & -0.29 \\
\hline $57: 2-03: 3$ & $(5.61)^{*}$ & $(5.49)^{*}$ & $(1.41)$ & $(1.86)$ & $(-0.28)$ & $(-1.00)$ & $(-3.78)^{*}$ & $(-2.51)$ \\
\hline Norway & 0.02 & 0.15 & -0.29 & 0.07 & 0.14 & 0.02 & 0.05 & -0.04 \\
\hline $57: 2-01: 8$ & $(0.16)$ & $(0.97)$ & $(-1.81)$ & $(0.43)$ & $(0.67)$ & (0.13) & $(0.39)$ & $(-0.25)$ \\
\hline Philippines & -0.04 & 0.29 & -0.15 & 0.03 & -0.18 & 0.06 & 0.05 & -0.07 \\
\hline $57: 2-03: 2$ & $(-0.39)$ & (1.61) & $(-0.73)$ & $(0.19)$ & $(-1.28)$ & $(0.45)$ & $(0.32)$ & $(-0.45)$ \\
\hline Spain & 0.16 & 0.72 & 0.40 & 0.55 & -0.24 & -0.14 & -0.34 & -0.35 \\
\hline $61: 2-03: 3$ & $(2.84)^{*}$ & $(4.39)^{*}$ & (2.39) & $(3.36)^{*}$ & $(-1.51)$ & $(-0.86)$ & $(-2.24)$ & $(-2.28)$ \\
\hline UK & 0.31 & 0.12 & -0.26 & -0.24 & 0.14 & 0.23 & -0.22 & 0.01 \\
\hline $58: 1-99: 3$ & $(4.22)^{*}$ & $(0.65)$ & $(-1.43)$ & $(-1.48)$ & $(0.95)$ & (1.41) & $(-1.46)$ & $(0.06)$ \\
\hline
\end{tabular}

Covariance-variance ratio test of the random walk hypothesis for international data on real monthly returns. The covariance-variance ratios $C V(p, q)$ are reported in the main rows, with the heteroscedasticity-robust test statistics $z(p$, $q)$ given in parentheses immediately below each main row. The critical value corresponding to an overall size of $5 \%$ is 2.73. * denotes significance at the $5 \%$ level. 
Table 3-16 Covariance-variance ratio tests for excess returns of size, industry, and book-to-market portfolios using the interval of 2 years: 1947:01-2001:12

\begin{tabular}{cccc|cccc|cccc}
\hline \multicolumn{4}{c}{ Size } & \multicolumn{5}{c|}{ Industry } & \multicolumn{4}{c}{ Book-to-market } \\
$(1,12)$ & $(13,36)$ & $(37,60)$ & $(61,84)$ & $(1,12)$ & $(13,36)$ & $(37,60)$ & $(61,84)$ & $(1,12)$ & $(13,36)$ & $(37,60)$ & $(61,84)$ \\
\hline 0.29 & -0.25 & 0.03 & -0.61 & 0.31 & -0.44 & 0.16 & -0.30 & 0.06 & -0.18 & 0.10 & -0.32 \\
$(2.00)$ & $(-1.25)$ & $(0.17)$ & $(-3.28)^{*}$ & $(2.05)$ & $(-2.13)$ & $(0.73)$ & $(-1.54)$ & $(0.33)$ & $(-0.91)$ & $(0.51)$ & $(-1.89)$ \\
0.14 & -0.23 & 0.11 & -0.37 & 0.24 & -0.44 & 0.22 & -0.39 & 0.01 & -0.12 & 0.11 & -0.34 \\
$(0.96)$ & $(-1.16)$ & $(0.58)$ & $(-2.03)$ & $(1.61)$ & $(-2.18)$ & $(1.03)$ & $(-2.00)$ & $(0.04)$ & $(-0.60)$ & $(0.52)$ & $(-1.82)$ \\
0.01 & -0.16 & 0.09 & -0.32 & 0.43 & -0.39 & 0.32 & -0.61 & 0.02 & -0.17 & 0.15 & -0.31 \\
$(0.10)$ & $(-0.83)$ & $(0.46)$ & $(-1.72)$ & $(2.69)^{*}$ & $(-1.89)$ & $(1.70)$ & $(-3.11)^{*}$ & $(0.11)$ & $(-0.85)$ & $(0.72)$ & $(-1.62)$ \\
0.04 & -0.22 & 0.09 & -0.25 & -0.01 & -0.39 & 0.23 & -0.20 & 0.07 & -0.22 & 0.13 & -0.37 \\
$(0.26)$ & $(-1.14)$ & $(0.46)$ & $(-1.35)$ & $(-0.07)$ & $(-1.97)$ & $(1.22)$ & $(-1.19)$ & $(0.50)$ & $(-1.09)$ & $(0.64)$ & $(-1.94)$ \\
0.00 & -0.17 & 0.06 & -0.22 & 0.09 & -0.14 & 0.05 & -0.45 & 0.10 & -0.16 & 0.11 & -0.31 \\
$(0.03)$ & $(-0.90)$ & $(0.31)$ & $(-1.22)$ & $(0.62)$ & $(-0.74)$ & $(0.28)$ & $(-2.51)^{*}$ & $(0.66)$ & $(-0.78)$ & $(0.54)$ & $(-1.64)$ \\
0.00 & -0.19 & 0.14 & -0.14 & 0.22 & -0.40 & 0.01 & 0.03 & 0.13 & -0.27 & 0.14 & -0.35 \\
$(0.00)$ & $(-1.01)$ & $(0.70)$ & $(-0.76)$ & $(1.15)$ & $(-1.97)$ & $(0.04)$ & $(0.17)$ & $(0.87)$ & $(-1.37)$ & $(0.68)$ & $(-1.85)$ \\
-0.04 & -0.23 & 0.24 & -0.16 & 0.20 & -0.07 & 0.22 & 0.05 & 0.12 & -0.30 & 0.12 & -0.37 \\
$(-0.25)$ & $(-1.20)$ & $(1.24)$ & $(-0.86)$ & $(1.27)$ & $(-0.39)$ & $(1.07)$ & $(0.23)$ & $(0.80)$ & $(-1.57)$ & $(0.60)$ & $(-1.94)$ \\
-0.09 & -0.19 & 0.19 & -0.05 & 0.24 & -0.32 & -0.04 & -0.34 & 0.19 & -0.47 & 0.16 & -0.41 \\
$(-0.63)$ & $(-0.99)$ & $(0.98)$ & $(-0.29)$ & $(1.45)$ & $(-1.55)$ & $(-0.19)$ & $(-1.96)$ & $(1.31)$ & $(-2.37)$ & $(0.77)$ & $(-2.11)$ \\
-0.05 & -0.12 & 0.21 & -0.05 & 0.60 & -0.43 & -0.08 & -0.57 & 0.19 & -0.36 & 0.12 & -0.41 \\
$(-0.35)$ & $(-0.62)$ & $(1.07)$ & $(-0.26)$ & $(3.82)^{*}$ & $(-2.13)$ & $(-0.39)$ & $(-2.72)^{*}$ & $(1.27)$ & $(-1.82)$ & $(0.58)$ & $(-2.14)$ \\
0.05 & -0.16 & 0.20 & -0.05 & 0.15 & -0.10 & 0.02 & -0.51 & 0.20 & -0.34 & 0.08 & -0.47 \\
$(0.29)$ & $(-0.83)$ & $(1.07)$ & $(-0.26)$ & $(1.10)$ & $(-0.51)$ & $(0.12)$ & $(-2.79)^{*}$ & $(1.38)$ & $(-1.78)$ & $(0.41)$ & $(-2.50)^{*}$ \\
\hline
\end{tabular}

Covariance-variance ratio test of the random walk hypothesis for excess returns of size, industry, and book-to-market portfolios over the sample period from January 1947 to December 2001. The covariance-variance ratios $C V(p, q)$ are reported in the main rows, with the heteroscedasticity-robust test statistics $z(p, q)$ given in parentheses immediately below each main row. The critical value corresponding to an overall size of $5 \%$ is 2.49 . * denotes significance at the $5 \%$ level.

The size and book-to-market-ratio increases as we move down. The ten industries as we move down are Consumer Non-Durables, Consumer Durables, Oil, Gas, and Coal Extraction and Products, Chemicals and Allied Products, Manufacturing, Telephones and Television, Utilities, Wholesale, Retail, and Some Services, Finance, and Everything Else. 
Table 3-17 Covariance-variance ratio tests for excess returns of size, industry, and book-to-market portfolios using the interval of 3 years: 1947:01-2001:12

\begin{tabular}{ccc|ccc|ccc}
\hline & Size & & \multicolumn{3}{c}{ Industry } & \multicolumn{3}{c}{ Book-to-market } \\
$(1,12)$ & $(13,36)$ & $(61,84)$ & $(1,12)$ & $(13,36)$ & $(61,84)$ & $(1,12)$ & $(13,36)$ & $(61,84)$ \\
\hline 0.29 & -0.19 & -0.66 & 0.31 & -0.32 & -0.29 & 0.06 & -0.18 & -0.24 \\
$(2.00)$ & $(-0.80)$ & $(-2.77)^{*}$ & $(2.05)$ & $(-1.25)$ & $(-1.14)$ & $(0.33)$ & $(-0.75)$ & $(-1.10)$ \\
0.14 & -0.14 & -0.37 & 0.24 & -0.35 & -0.32 & 0.01 & -0.09 & -0.27 \\
$(0.96)$ & $(-0.59)$ & $(-1.61)$ & $(1.61)$ & $(-1.41)$ & $(-1.28)$ & $(0.04)$ & $(-0.37)$ & $(-1.16)$ \\
0.01 & -0.15 & -0.25 & 0.43 & -0.10 & -0.56 & 0.02 & -0.13 & -0.22 \\
$(0.10)$ & $(-0.62)$ & $(-1.07)$ & $(2.69)^{*}$ & $(-0.39)$ & $(-2.35)$ & $(0.11)$ & $(-0.51)$ & $(-0.93)$ \\
0.04 & -0.20 & -0.19 & -0.01 & -0.39 & 0.00 & 0.07 & -0.16 & -0.31 \\
$(0.26)$ & $(-0.84)$ & $(-0.81)$ & $(-0.07)$ & $(-1.65)$ & $(0.02)$ & $(0.50)$ & $(-0.65)$ & $(-1.29)$ \\
0.00 & -0.18 & -0.17 & 0.09 & -0.17 & -0.38 & 0.10 & -0.15 & -0.23 \\
$(0.03)$ & $(-0.77)$ & $(-0.74)$ & $(0.62)$ & $(-0.72)$ & $(-1.67)$ & $(0.66)$ & $(-0.61)$ & $(-0.97)$ \\
0.00 & -0.17 & -0.04 & 0.22 & -0.50 & 0.11 & 0.13 & -0.19 & -0.30 \\
$(0.00)$ & $(-0.74)$ & $(-0.18)$ & $(1.15)$ & $(-2.12)$ & $(0.57)$ & $(0.87)$ & $(-0.78)$ & $(-1.22)$ \\
-0.04 & -0.17 & 0.01 & 0.20 & 0.00 & 0.15 & 0.12 & -0.32 & -0.27 \\
$(-0.25)$ & $(-0.70)$ & $(0.04)$ & $(1.27)$ & $(-0.02)$ & $(0.58)$ & $(0.80)$ & $(-1.33)$ & $(-1.10)$ \\
-0.09 & -0.17 & 0.10 & 0.24 & -0.25 & -0.47 & 0.19 & -0.42 & -0.33 \\
$(-0.63)$ & $(-0.71)$ & $(0.43)$ & $(1.45)$ & $(-1.00)$ & $(-2.11)$ & $(1.31)$ & $(-1.71)$ & $(-1.36)$ \\
-0.05 & -0.06 & 0.10 & 0.60 & -0.41 & -0.67 & 0.19 & -0.34 & -0.34 \\
$(-0.35)$ & $(-0.26)$ & $(0.43)$ & $(3.82)^{*}$ & $(-1.64)$ & $(-2.56)^{*}$ & $(1.27)$ & $(-1.40)$ & $(-1.38)$ \\
0.05 & -0.08 & 0.06 & 0.15 & -0.13 & -0.45 & 0.20 & -0.32 & -0.42 \\
$(0.29)$ & $(-0.35)$ & $(0.28)$ & $(1.10)$ & $(-0.57)$ & $(-1.90)$ & $(1.38)$ & $(-1.36)$ & $(-1.75)$ \\
\hline
\end{tabular}

Covariance-variance ratio test of the random walk hypothesis for excess returns of size, industry, and book-to-market portfolios over the sample period from January 1947 to December 2001. The covariance-variance ratios $C V(p, q)$ are reported in the main rows, with the heteroscedasticity-robust test statistics $z(p, q)$ given in parentheses immediately below each main row. The critical value corresponding to an overall size of $5 \%$ is 2.39 . * denotes significance at the $5 \%$ level.

The size and book-to-market-ratio increases as we move down. The ten industries as we move down are Consumer Non-Durables, Consumer Durables, Oil, Gas, and Coal Extraction and Products, Chemicals and Allied Products, Manufacturing, Telephones and Television, Utilities, Wholesale, Retail, and Some Services, Finance, and Everything Else. 
Table 3-18 Covariance-variance ratio tests for excess returns of size, industry, and book-to-market portfolios using the interval of 6 years: 1947:01-2001:12

\begin{tabular}{cc|cc|cc}
\hline & Size & & \multicolumn{2}{|c|}{ Industry } & \multicolumn{2}{c}{ Book-to-market } \\
$(1,12)$ & $(13,84)$ & $(1,12)$ & $(13,84)$ & $(1,12)$ & -0.48 \\
\hline 0.29 & -0.78 & 0.31 & -0.58 & 0.06 & $(-1.48)$ \\
$(2.00)$ & $(-2.27)^{*}$ & $(2.05)$ & $(-1.61)$ & $-0.33)$ & -0.38 \\
0.14 & -0.51 & 0.24 & -0.62 & 0.01 & $(-1.10)$ \\
$(0.96)$ & $(-1.50)$ & $(1.61)$ & $(-1.75)$ & $-0.04)$ & -0.34 \\
0.01 & -0.39 & 0.43 & -0.65 & $(0.11)$ & $(-0.99)$ \\
$(0.10)$ & $(-1.16)$ & $(2.69)^{*}$ & $(-1.86)$ & 0.07 & -0.46 \\
0.04 & -0.39 & -0.01 & -0.35 & $(0.50)$ & $(-1.32)$ \\
$(0.26)$ & $(-1.16)$ & $(-0.07)$ & $(-1.07)$ & 0.10 & -0.36 \\
0.00 & -0.33 & 0.09 & -0.54 & $(0.66)$ & $(-1.03)$ \\
$(0.03)$ & $(-1.01)$ & $(0.62)$ & $(-1.61)$ & 0.13 & -0.47 \\
0.00 & -0.22 & 0.22 & -0.35 & $(0.87)$ & $(-1.34)$ \\
$(0.00)$ & $(-0.65)$ & $(1.15)$ & $(-1.09)$ & 0.12 & -0.51 \\
-0.04 & -0.18 & 0.20 & 0.07 & $(0.80)$ & $(-1.46)$ \\
$(-0.25)$ & $(-0.53)$ & $(1.27)$ & $(0.20)$ & 0.19 & -0.67 \\
-0.09 & -0.07 & 0.24 & -0.70 & $(1.31)$ & $(-1.88)$ \\
$(-0.63)$ & $(-0.22)$ & $(1.45)$ & $(-2.07)$ & 0.19 & -0.59 \\
-0.05 & -0.02 & 0.60 & -1.13 & $(1.27)$ & $(-1.68)$ \\
$(-0.35)$ & $(-0.05)$ & $(3.82)^{*}$ & $(-3.08)^{*}$ & 0.20 & -0.68 \\
0.05 & -0.05 & 0.15 & -0.52 & $(1.38)$ & $(-1.96)$ \\
$(0.29)$ & $(-0.17)$ & $(1.10)$ & $(-1.55)$ & & \\
\hline
\end{tabular}

Covariance-variance ratio test of the random walk hypothesis for excess returns of size, industry, and book-to-market portfolios over the sample period from January 1947 to December 2001. The covariance-variance ratios $C V(p, q)$ are reported in the main rows, with the heteroscedasticity-robust test statistics $z(p, q)$ given in parentheses immediately below each main row. The critical value corresponding to an overall size of $5 \%$ is 2.23 . * denotes significance at the $5 \%$ level.

The size and book-to-market-ratio increases as we move down. The ten industries as we move down are Consumer Non-Durables, Consumer Durables, Oil, Gas, and Coal Extraction and Products, Chemicals and Allied Products, Manufacturing, Telephones and Television, Utilities, Wholesale, Retail, and Some Services, Finance, and Everything Else. 


\section{Chapter 4 Under- and Over-reaction to a Common Factor in Stock}

\section{Markets}

\subsection{Introduction}

Recently, Barberis, Shleifer, and Vishny (1998) (hereafter, "BSV"), Daniel, Hirshleifer, and Subrahmanyam (1998) (“DHS”), and Hong and Stein (1999) (“HS”) have proposed behavioral asset pricing models to explain the anomalies in the stock market. The models in BSV and DHS emphasize cognitive biases of investors. Their models predict that the misvaluation should be stronger among firms about which there is high uncertainty/poor information. In contrast, HS emphasize gradual information diffusion, and predict that slower information diffusion generates more misvaluation. All of these models, as Lewellen (2002) points out, do not differentiate between firm specific and market-wide information, and predict underreaction (delayed overreaction) in the short run and overreaction in the long run. As can be seen from a multifactor model such as that of Jegadeesh and Titman (1995), how stock prices respond to firm-specific information determines in part their serial correlations, while how stock prices react to market-wide information determines not only in part serial correlations but also entirely cross-serial correlations, which can be important for explaining momentum and mean reversion of stock returns [see Lo and MacKinlay (1990)].

Empirically, there is consistent evidence supporting underreaction of stock prices to firm-specific information in the short run and overreaction in the longer run. Bernard and Thomas $(1989,1990)$ and Brown and Pope (1996) find short-run underreaction to 
earnings announcements, ${ }^{29}$ while DeBondt and Thaler (1987) and Lakonishok, Shleifer, and Vishny (1994) find a negative relation between long-horizon returns and past financial performance measures such as earnings or sales growth. Although Chan, Jegadeesh, and Lakonishok (1996) do not reject the null of no such a negative relation, DHS point out that it may be due to a lack of power.

Empirical evidence regarding stock price reaction to market-wide information is contradictory. Lo and MacKinlay (1990) and Jegadeesh and Titman (1995) find that prices of (small) stocks underreact to market-wide information in the short run (one week to one month), which gives rise to a size-related lead-lag relationship in stock returns. In contrast, a recent study by Lewellen (2002) documents a negative average of cross-serial correlations across lags and suggests that stock prices overreact to market-wide information at all horizons, The evidence is indeed interpreted as a rejection of the recent behavioral models of DHS, BSV, and HS, because in these models short-run underreaction (delayed overreaction) must coexist with long-run overreaction. ${ }^{30}$ In other words, in these models, the misperceptions that drive short-run underreaction are also drivers of long-run overreaction. So there cannot be only overreaction.

However, it is important to note that the empirical methodology of Lewellen (2002), calculating the average of cross-serial correlations, has several drawbacks. First, it masks changes in the cross-serial correlations across lags. If there exist short-run underand long-run overreaction to market-wide information, which show up as positive cross-

\footnotetext{
${ }^{29}$ Stocks are also found to under-react to other evens such as stock splits, tender offer and open market repurchases, analyst recommendations, dividend imitations and omissions, and seasoned issues of common stock. See Daniel, Hirshleifer, and Subrahmanyam (1998) for an overview.

30 "Table 4 rejects the behavioral models as a general description of prices" [Lewellen (2002), p. 552].
} 
serial correlations at short horizons and negative cross-serial correlations at longer horizons, ${ }^{31}$ an average of cross-serial correlations across lags clearly is not informative. Second, it also makes the test lack power. Chen and Hong (2002) criticize Lewellen's (2002) estimates as being generally not statistically significant. If short-run underreaction coexists with long-run overreaction as the behavioral models suggest, an average of cross-serial correlations across lags will cause positive short-horizon cross-serial correlations offsetting negative longer-horizon cross-serial correlations. An illustrative example is presented in Chapter 3. Hence, to be of current interest, it may be important to revisit the issue of stock price reaction to market-wide information.

Based on a one-factor model, I propose a regression-based test that is robust to serial correlation and heteroskedasticity in stock returns. This is important because there is statistical evidence that stock returns have positive short-run and negative long-run serial correlations [see Lo and MacKinlay (1988) and Chapter 3 of this dissertation]. There is also consistent evidence showing that volatilities do change over time [see Merton (1980), Poterba and Summers (1986), and French, Schwert, and Stambaugh (1987)].

When the test is used to examine three sets of portfolios-size portfolios, industry portfolios, and book-to-market portfolios-over the period 1941-2002, contrary to Lewellen (2002), I find strong evidence in support of the behavioral theories of DHS, BSV, and HS. More specifically, (1) small firms and all industries except Utility and Oil are found to underreact in the short run and overreact in the intermediate run (the 1 to 2 year interval) to market-wide information. This is broadly consistent with all three

\footnotetext{
${ }^{31}$ This is suggested by a Jegadeesh and Titman (1995- type factor model, as outlined in Section 4.2.
} 
behavioral models. (2) Value stocks show stronger short-run underreaction. This observation lends more support to HS but not BSV and DHS.

The remainder of this chapter is organized as follows. Section 4.2 presents a one-factor model motivating the empirical analysis. Section 4.3 develops the test and analyzes the size and power of the test. Section 4.4 describes the data and presents the empirical results. Section 4.5 concludes the chapter with a brief summary.

\subsection{A One-factor Model}

Consider the following one-factor model of stock returns, which is a generalization of Jegadeesh and Titman (1995). This factor model, described in the following equation, allows stock prices to react instantaneously as well as with multiple lags to factor realizations. Let

$$
r_{i, t}=\mu_{i}+\sum_{k=0}^{K} b_{i, k} f_{t-k}+e_{i, t}
$$

where $\mu_{i}$ is the unconditional expected return of stock $i, f_{t-k}$ is the unexpected common factor realization (market-wide information), $e_{i, t}$ is the firm-specific component of return at time $t$ (firm-specific information), and $b_{i, k}$ is the sensitivity of stock $i$ to the factor realization. ${ }^{32}$

Since $f_{t-k}$ is defined as the unexpected factor realization $\operatorname{cov}\left(f_{t}, f_{t-k}\right)=0$ and since $e_{i, t}$ is defined as the firm-specific component of return $\operatorname{cov}\left(e_{i, t}, e_{j, t-k}\right)=\operatorname{cov}\left(f_{t}, e_{i, t-k}\right)=0 \forall i \neq j .\left\{b_{i, k}\right.$ for $\left.i=0, \ldots, K\right\}$ is the impulse response

\footnotetext{
32 Following Jegadeesh and Titman (1995), the factor sensitivities are assumed to be constant and uncorrelated with factor realizations.
} 
function of the stock return to the common factor. The maintained hypothesis of no under- and over-reaction to the common factor then is

$$
b_{i, k}=0 \text { for } k=1,2, \ldots, K
$$

The recent behavioral models of BSV, DHS, and HS alternatively predict that stocks may underreact (delayed overreact) in the short run, $b_{i, k}>0$ for some small $k$, and overreact in the longer run $b_{i, k}<0$ for some large $k$, to market-wide information. HS also show that the cumulative impulse response function may not be monotonic. In other words, $b_{i, k}$ may alter its sign multiple times because $\left\{b_{i, k}\right.$ for $\left.i=0, \ldots, K\right\}$ is the impulse response function of the stock return to the common factor. A test of the behavioral theories involves inspecting the pattern of $b_{i, k}$. Positive $b_{i, k}$ at short horizons and negative $b_{i, k}$ at some longer horizons are broadly consistent with all three behavioral models.

Furthermore, the models in BSV and DHS emphasize cognitive biases that investors have. So their models generally predict that the misvaluation should be stronger among growth firms about which there is high uncertainty. In contrast, HS emphasize gradual information diffusion, and predict that value firms tend to have more misvaluation, because (1) value firms have more bad news (persistently poor earnings to book equity) [see Fama and French (1995)] and (2) bad news travels slowly [see Hong, Lim, and Stein (2000)]. So the impulse response functions of value and growth stocks may be used to distinguish these behavioral models. 


\subsection{A Regression-based Test}

\subsubsection{Relevant Literature}

Given the returngenerating model in Equation (1), the cross-serial covariance between the return of $i$ and $j$ is

$$
\operatorname{cov}\left(r_{i, t}, r_{j, t-n}\right)=\sum_{k=n}^{K} b_{i, k} b_{j, k-n} \sigma_{f}^{2}
$$

where $E\left(f_{t}^{2}\right)=\sigma_{f}^{2}$. So stock price reaction to the common factor determine entirely cross-serial correlation between stocks. ${ }^{33}$ As the behavioral models suggest, some stocks, $i$, under- and over-react to information ( $b_{i, k} \neq 0$ for all $k \neq 0$ ), while some other stocks, $j$, do $\quad$ not $\quad\left(b_{j, k}=0\right.$ for all $\left.k \neq 0\right)$. So $\quad \operatorname{cov}\left(r_{i, t}, r_{j, t-n}\right)=\sum_{k=n}^{K} b_{i, k} b_{j, k-n} \sigma_{f}^{2}=b_{i, n} b_{j, 0} \sigma_{f}^{2} \quad$ and $\operatorname{cov}\left(r_{j, t}, r_{i, t-n}\right)=\sum_{k=n}^{K} b_{j, k} b_{i, k-n} \boldsymbol{\sigma}_{f}^{2}=0 \quad$ for $\quad n=1, \quad \ldots, \quad K$. Since $\quad b_{j, 0} \boldsymbol{\sigma}_{f}^{2}>0$ $\operatorname{sign}\left[\operatorname{cov}\left(r_{i, t}, r_{j, t-n}\right)\right]=\operatorname{sign}\left(b_{i, n}\right)$. That is, one may infer stock under- or over-reaction to the common factor from cross-serial correlations between stock returns. For instance, if $\operatorname{cov}\left(r_{i, t}, r_{j, t-1}\right)>0$ but $\operatorname{cov}\left(r_{j, t}, r_{i, t-1}\right)=0(j$ leads $i$ since $j$ 's return predicts $i$ 's return but the reverse is not true), then it implies that $b_{i, 1}>0$ and $b_{j, 1}=0$ (stock $i$ underreacts to the common factor in the short run but stock $j$ does not). So the short-run lead-lag evidence in Lo and MacKinlay (1990) is consistent with short-run underreaction of some stocks to the common factor, which is confirmed by Jegadeesh and Titman (1995). On the other hand, if $\operatorname{cov}\left(r_{i, t}, r_{j, t-n}\right)<0$ but $\operatorname{cov}\left(r_{j, t}, r_{i, t-n}\right)=0$ for $n=1, \ldots, K(j$ again leads $i)$, then it implies that $b_{i, k}<0$ for all $k \neq 0$ and $b_{j, k}=0$ for all $k \neq 0$ (stock $i$ overreacts to the

\footnotetext{
${ }^{33}$ It is easy to see that it also determines in part serial autocorrelation of stock returns.
} 
common factor but stock $j$ does not). Hence, the negative average of cross-serial correlations across lags in Lewellen (2002) may suggest overreaction. It is indeed interpreted as evidence against the recent behavioral models of BSV, DHS, and HS, because they predict short-horizon underreaction must coexist with longer-horizon overreaction.

However, it is important to note that if stocks underreact in the short run, $b_{i, k}>0$ for some small $k$, and overreact in the long run $b_{i, k}<0$ for some large $k$ as suggested by the behavioral models, the methodology of Lewellen (2002), calculating the average of cross-serial correlations, is not appropriate. First, an average of cross-serial correlations masks different cross-serial correlations at different horizons. Therefore, the evidence in Lewellen (2002) may not necessarily imply a rejection of the recent behavioral models. Second, the test may have little power because positive cross-serial covariances at short horizons will offset negative cross-serial covariances at longer horizons. An illustrative example can be found in Chapter 3. The statistical significance in Lewellen (2002) is indeed unimpressive.

Jegadeesh and Titman (1995) estimate Equation 1 directly assuming $K=1$. However, the recent behavioral models suggest that $K>1$. If this $\dot{\mathrm{s}}$ the case, there are several drawbacks to estimating Equation 1 directly: (1) given unknown forms of the serial correlation in $e_{i, t}$, tests may have large size distortion. This also suggests that there could be large size distortion if one estimates cross-serial covariances between stock returns directly in a regression such as $r_{i, t}=\mu_{i}+\beta_{k} r_{j, t-k}+\varepsilon_{i, t}$; (2) if $b_{i, k}$ is small in magnitude, the test will have little power. These considerations lead me to use a different approach. 


\subsubsection{A Regression Based Test}

Since $b_{i, k}$ for $k \neq 0$ may be quite small in magnitude especially in the long run, ${ }^{34}$ estimating individual $b_{i, k}$ may have little power. Furthermore, (1) what is more interesting is the sign rather than the magnitude of $b_{i, k}$ and (2) the recent behavioral models predict that $b_{i, k}$ may have different signs over different horizons and the sign may changes multiple times. These observations suggest it may be more appropriate to estimate a set of sums of $b_{i, k}$ over some non-overlapping ranges. For instance,

$$
b_{i, 1}, \sum_{k=2}^{11} b_{i, k}, \sum_{k=12}^{23} b_{i, k}, \ldots
$$

which correspond to one month, one year, two years,.... Using non-overlapping ranges can differentiate different reaction patterns at different horizons. Summing up many individual $b_{i, k}$ can increase the power of the test. This is the essence of the variance ratio test of Lo and MacKinlay (1988) to detect serial correlations in stock returns. But adding up too many $b_{i, k}$ can also be potentially problematic because $b_{i, k}$ may alter its sign multiple times. A set of ranges, such as one month, one year, two years, ..., seems to be natural and is used by the literature [see Cutler, Poterba, and Summers $(1990,1991)]$.

Now consider the following regression model

$$
f_{t}=\mu+\beta_{i, p, q} R_{i, t, p, q}+\varepsilon_{t}
$$

where $\mu$ is a constant, $R_{i, t, p, q}=\sum_{k=p}^{q} r_{i, t+k}$, and $\varepsilon_{\mathrm{t}}$ is the random disturbance term. $\varepsilon_{\mathrm{t}}$, according to the one-factor model in Equation 1, (1) has a zero mean and (2) is serially

\footnotetext{
${ }^{34}$ For instance Jegadeesh and Titman (1995) find on average $b_{i, 1}=0.16$
} 
uncorrelated. By assuming it satisfies some mixing and moment conditions, quite general forms of heteroskedasticity are also allowed. ${ }^{35}$ Then

$$
\begin{aligned}
\beta_{i, p, q} & =\frac{\operatorname{cov}\left(f_{t}, R_{i, t, p, q}\right)}{\operatorname{var}\left(R_{i, t, p, q}\right)} \\
= & \frac{\sum_{k=p}^{q} \operatorname{cov}\left(f_{t}, r_{i, t+k}\right)}{\operatorname{var}\left(R_{i, t, p, q}\right)}
\end{aligned}
$$

Recall Equation 1, $r_{i, t}=\mu_{i}+\sum_{k=0}^{K} b_{i, k} f_{t-k}+e_{i, t}$, then

$$
\begin{aligned}
\beta_{i, p, q} & =\frac{\sum_{k=p}^{q} b_{i, k} \sigma_{f}^{2}}{\operatorname{var}\left(R_{i, t, p, q}\right)} \\
& =\frac{\sigma_{f}^{2}}{\operatorname{var}\left(R_{i, t, p, q}\right)} \sum_{k=p}^{q} b_{i, k}
\end{aligned}
$$

Since $\frac{\sigma_{f}^{2}}{\operatorname{var}\left(R_{i, t, p, q}\right)}$ is a constant $\beta_{i, p, q}$ is merely a rescaled $\sum_{k=p}^{q} b_{i, k}$. The null hypothesis in Equation 2 is true if $\beta_{i, p, q}=0$ for all $p$ and $q$.

This approach has several advantages: (1) it allows serial correlation in stock returns because in such a regression the stock return is a regressor instead of the dependent variable; (2) it makes statistical inference easy to interpret. A significant $\hat{\boldsymbol{\beta}}_{i, p, q}$ can only be due to under- or over-reaction to the common factor, not the serial correlation in stock returns, which may be due to under- or overreaction to firm-specific information. In contrast, Lewellen (2002) simulates standard error bands for cross-serial covariances under the null hypothesis of no serial and cross-serial covariances. A significant cross-

\footnotetext{
${ }^{35}$ For detail, see Lo and MacKinlay (1988).
} 
serial covariance estimate may be due to the presence of serial instead of cross-serial covariances. So it is hard to interpret his empirical results.

Under the null hypothesis as expressed in Equation 2, $R_{i, t, p, q}$ is uncorrelated with $\varepsilon_{\mathrm{t}}$. so $\hat{\beta}_{i, p, q}$ is consistent and asymptotically normally distributed. The heteroskedasticityconsistent variance estimator of $\hat{\beta}_{i, p, q}$ can be constructed along the lines of White (1980) given the assumption that $\varepsilon_{\mathrm{t}}$ satisfies some mixing and moment conditions. The test statistic, $z(p, q)$, is asymptotically standard normal.

If at least one $\hat{\beta}_{i, p, q}$ estimate is significant, then the null hypothesis can be rejected. Furthermore, whether the rejection is due to the short-run under- or/and long-run overreaction can be inferred by inspecting the pattern of significance of the $\boldsymbol{\beta}_{i, p, q}$ estimates. Long-run overreaction is supported by significant negative $\boldsymbol{\beta}_{i, p, q}$ estimates for some large values of $p$ and $q$, while significant positive $\beta_{i, p, q}$ estimates for some small values of $p$ and $q$ would suggest short-run undereaction.

Clearly, it is important to control the size of a joint test when simultaneously examining a set of $\beta_{i, p, q}$ estimates. That is a nominal $100 \alpha \%$ critical value is not appropriate for each $\beta_{i, p, q}$ estimate; nstead an overall size of $100 \alpha \%$ is necessary. I adjust the critical value for each individual test statistic by following the multiple comparison procedure developed by Chow and Denning (1993).

Lemma 1. Under the null hypothesis of Equation 2, the asymptotic joint 100(1$\alpha) \%$ confidence interval for a set of $z(p, q)$ statistics can be calculated as: 


$$
\left[z\left(p_{i}, q_{i}\right)\right] \pm S M M(\alpha, m) \text { for } i=1, \ldots, m
$$

where $\operatorname{SMM}(\alpha, m)$ is the asymptotic critical value of the $\alpha$-point of the studentized maximum modulus (SMM) distribution with $m$ degrees of freedom. The asymptotic $\operatorname{SMM}(\alpha, m)$ can be calculated as the upper $\alpha^{*} / 2$ point of the standard normal distribution, $z_{\alpha^{*} / 2}$, where $\alpha^{*}=1-(1-\alpha)^{1 / m}$.

\subsubsection{The Size and Power of the Test}

All size and power tests are based on 10,000 replications. To be useful for the empirical study of monthly stock returns in Section 4.4, the sample size is chosen to be 744 , which is the sample size for the empirical study, and the non-overlapping ranges, ( $p$,

$q)$ are chosen to be $(1,1),(2,11)(12,23),(24,35),(36,47)$, and $(48,60)$, which correspond to one month, one year, ..., and five years.

\subsubsection{The Size of the Test}

To gauge the quality of the test, I perform simulation experiments. The one-factor model implies that under the null hypothesis of no under- and overreaction to the common factor, stocks are not cross-serially correlated but can be serially correlated (due to under- and/or over-reaction to firm-specific information). So three different null hypotheses are considered.

First, the stock market is efficient. Stock prices follow random walks and do not under- and/or overreact to any information. Stock returns are not serially correlated.

$$
p_{i, t}=p_{i, t-1}+\varepsilon_{i, t} \quad \varepsilon_{i, t} \sim \operatorname{IIDN}(0,1)
$$


Second, stock prices underreact to firm-specific information in the short run, which is modeled by an integrated $\mathrm{AR}(1)$ process suggested by Lo and MacKinlay (1989). Stocks returns are positively autocorrelated at short horizons.

$$
p_{i, t}=p_{i, t-1}+0.2\left(p_{i, t-1}-p_{i, t-2}\right)+\varepsilon_{i, t} \quad \varepsilon_{i, t} \sim N(0,1)
$$

Third, stock prices underreact in the short run and overreact in the long run to firm-specific information, which is modeled by a process that is a generalization of the Summers (1986) and Lo and MacKinlay (1989) model and suggested by Balvers and Wu (2002). Stock returns are positively autocorrelated at short horizons and negatively autocorrelated at longer horizons.

$$
p_{i, t}=0.979 p_{i, t-1}+\sum_{i=1}^{12} 0.026\left(p_{i, t-j}-p_{i, t-j-1}\right)+\varepsilon_{i, t} \quad \varepsilon_{i, t} \sim N(0,1)
$$

Table 4-1 reports simulation results. It is apparent that the test is very reliable. Under the random walk null, The empirical sizes of the 1,5 , and 10 percent $z(p, q)$ statistic are 0.9, 4.5 and 9.7 percent. Under the integrated $\mathrm{AR}(1)$ null, the corresponding empirical sizes are 1.0, 4.8 and 9.6 percent. Finally, under the third null, the empirical sizes are $0.9,4.9$, and 10.0 percent, respectively.

\subsubsection{The Power of the Test}

To simplify the return-generating process, consider the following process, which yields short-horizon under- and longer-horizon over-reaction to the common factor.

$$
r_{i, t}=\sum_{k=0}^{12} b_{i, k} f_{t-k}+e_{i, t} \quad e_{i, t} \sim \operatorname{IIDN}(0,1)
$$


Set $b_{i, 0}=1$ and $b_{i, 1}=0.15$ which is the average estimate Jegadeesh and Titman (1995) obtain. Assign three different values, $-0.02,-0.03,-0.04$, to $b_{i, k}$ for $k=2, \ldots, 12$. The critical values are empirically determined by simulation under the random walk null hypothesis (Equation 8).

Table 4-2 reports the empirical power of the test. The rejection rates are broken down into upper and lower tail rejections to display the power of detecting under- and overreaction. The empirical power of the 1,5 , and 10 percent $z(p, q)$ statistic in detecting short-run underreaction is about 39, 59, and 69 percent. The empirical power of the test in detecting longer-horizon overreaction when $b_{i, k}=-0.02$ for $k=2, \ldots, 12$ is $3.7,10.7$, and 16.2 percent. The empirical power increases to $10.9,24.6$, and 33.6 percent when $b_{i, k}=-0.03$ for $k=2, \ldots, 12$, which is more than double. The empirical power, 26.9, 47.2, and 56.9, increases even more dramatically when $b_{i, k}=-0.04$ for $k=2, \ldots, 12$. Hence, the test has low power against the alternatives when the average of factor loadings is small.

\subsection{Data and Empirical Results}

\subsubsection{Data}

To test for stock price reaction to the common factor, I focus on the 744-month time span from January 1941 to December 2002. Monthly sampling yields a large number of observations while minimizing the biases inherent in daily and weekly data. Following Lewellen (2002), the pre-WWII period is excluded. Three sets of portfolios are used for empirical investigation, 10 size portfolios, 10 book-to-market portfolios, and 10 industry portfolios. The equal-weighted monthly returns of three sets of portfolios and the 
value-weighted market index are downloaded from Kenneth French's website. ${ }^{36}$ In addition, following Jegadeesh and Titman (1995), the demeaned value-weighted market index is used as the proxy for the common factor.

Table 4-3 reports summary statistics for the portfolios. The portfolios that have extreme (high or low) book-to-market ratios have higher variance. The corresponding magnitudes are very close. For instance, the lowest book-to-market-ratio portfolio has a variance of 0.0044 , while that of the highest book-to- market-ratio portfolio is 0.0043 . The variance of the second lowest book-to-market-ratio portfolio is 0.0033 , while that of the second highest book-to-market-ratio portfolio is 0.0030. Recall $\beta_{i, p, q}=\frac{\sigma_{f}^{2}}{\operatorname{var}\left(R_{i, p, q}\right)} \sum_{k=p}^{q} b_{i, k}$. So if $\left|\hat{\beta}_{\text {value }}\right|>\left|\hat{\beta}_{\text {growth }}\right|$ and the variance estimate of growth stocks is about the same as that of value stocks, then value stocks must have stronger misvaluation.

\subsubsection{Empirical Results}

Table 44 first reports the $\beta_{i, p, q}$ estimates and the test statistics $z(p, q)$ for the returns of 10 size-sorted portfolios. The values reported in the main rows are the actual values of the $\beta_{i, p, q}$ estimates, and the entries enclosed in parentheses are the heteroscedasticity-robust test statistics. A clear pattern emerges. Small portfolios (the first 7 deciles) underreact to the common factor in the short run: $\beta_{i, 1,1}$ estimates are all positively significant at the 5\% level. This is consistent with Lo and MacKinlay (1990) and Jegadeesh and Titman (1995). Furthermore, these same 7 portfolios also overreact to the common factor in the intermediate run (the 1 to 2 year interval). $\beta_{i, 12,23}$ estimates are

\footnotetext{
${ }^{36}$ http://mba.tuck.dartmouth.edu/pages/faculty/ken.french/
} 
all negatively significant at the 5\% level. In contrast, the big firms (the last 3 portfolios) neither under- nor overreact to the common factor. These findings are broadly consistent with all three behavioral models. Since small firms have more uncertainty/poor information and slower information diffusion [see Hong, Lim, and Stein (2000)], they ought to have misvaluation. On the other hand, big firms have less uncertainty/good information and faster information diffusion. So they don't exhibit either short-run underor longer-run overreaction to information.

Table $4-5$ reports the $\beta_{i, p, q}$ estimates and the test statistics $z(p, q)$ for returns of 10 industry portfolios. The values reported in the main rows are the actual values of the $\boldsymbol{\beta}_{i, p, q}$ estimates, and the entries enclosed in parentheses are the heteroscedasticityrobust test statistics. All industries except Utility and Oil underreact to the common factor in the short run $\left(\beta_{i, 1,1}\right.$ estimates are all positively significant at the $5 \%$ level), and overreact to the common factor in the intermediate run $\left(\beta_{i, 12,23}\right.$ estimates are negatively significant at the $5 \%$ level). The $\beta_{i, 12,23}$ estimates for Telephones and Television, Manufacturing, and Money are not statistically significant, which may be due to the low power of the test. So the evidence for industry portfolios also broadly supports the behavioral models.

Table 4-6 reports the $\beta_{i, p, q}$ estimates and the test statistics $z(p, q)$ for returns of 10 book-to-market- portfolios. Again, the values reported in the main rows are the actual values of the $\beta_{i, p, q}$ estimates, and the entries enclosed in parentheses are the heteroscedasticity-robust test statistics. All portfolios underreact to the common factor in the short run (the $\beta_{i, 1,1}$ estimates are all positively significant at the $5 \%$ level), and 
overreact to the common factor in the intermediate run $\left(\beta_{i, 12,23}\right.$ estimates are negatively significant at the 5\% level). Again, although the $\beta_{i, 12,23}$ estimate for the second lowest book-to-market-ratio portfolio is not statistically significant, this may be merely due to the low power of the test. Furthermore, value stocks seem to have stronger short-run underreaction. For instance, $\hat{\boldsymbol{\beta}}_{i, 1,1}=0.36$ with a $z(p, q)$ statistic of 5.69 for the highest book-to-market-ratio portfolio, while that of the lowest book-to-market ratio portfolio is 0.26 with a $z(p, q)$ statistic of 4.02 . Given the fact that the variance estimate of value stocks is about same as that of growth stocks, this implies that values stocks have stronger short-run underreaction to the common factor than growth stocks. This crosssectional difference is consistent with the findings in Chapter 3 and again supports HS instead of DHS and BSV. This is because BSV and DHS emphasize investor psychological biases and predict that the misvaluation should be stronger among low book-to-market-ratio firms about which there is high uncertainty. In contrast, HS emphasize gradual information diffusion and predict that high book-to-market-ratio firms have more misvaluation, because (1) they have persistently poor earnings (bad news) and (2) bad news travels slowly.

\subsection{Conclusion}

The recent behavioral models of DHS, BSV, and HS predict that short-run stock price underreaction must coexist with longer-run overreaction. So far, there has no convincing evidence regarding stock price reaction to market-wide information. Lo and MacKinlay (1990) and Jegadeesh and Titman (1995) find stock price undereaction to market-wide information, while Lewellen (2002) finds stock price overreaction to 
market-wide information. I propose a regression-based test in this chapter that is designed in particular to test the behavioral models. When the test is used to examine three sets of portfolios, size portfolios, industry portfolios, and book-to-market portfolios, over the period 1941-2002, contrary to previous studies, I find strong evidence in support of the behavioral models, especially the HS model in that value stocks have more misvaluation. 
Table 4-1 Empirical sizes of the nominal 1, 5, 10 percent tests

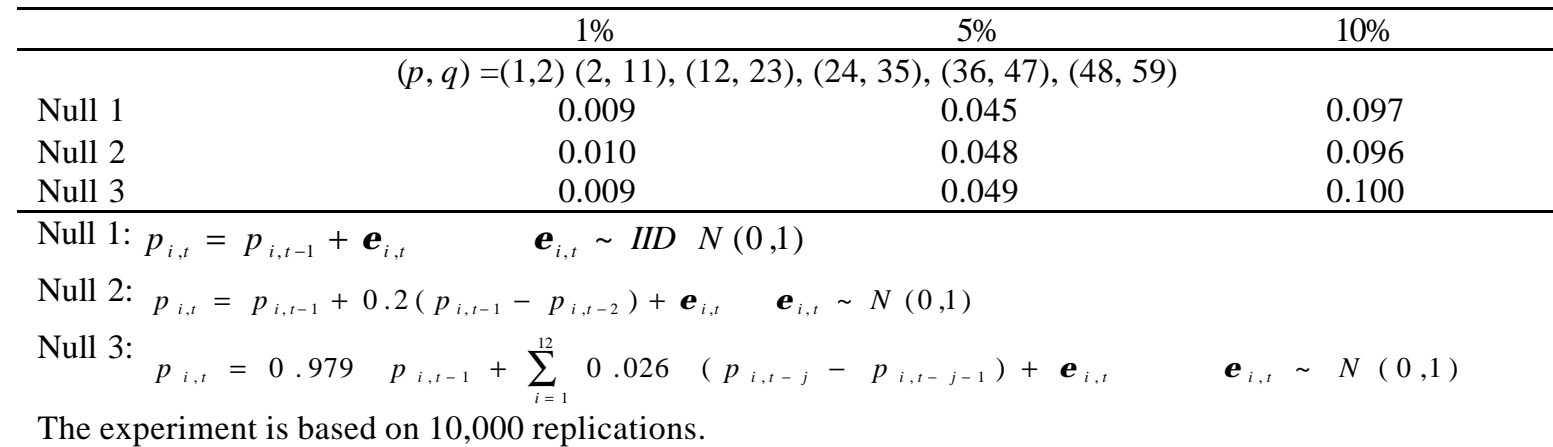

The experiment is based on 10,000 replications.

Table 4-2 Power of the two-sided tests

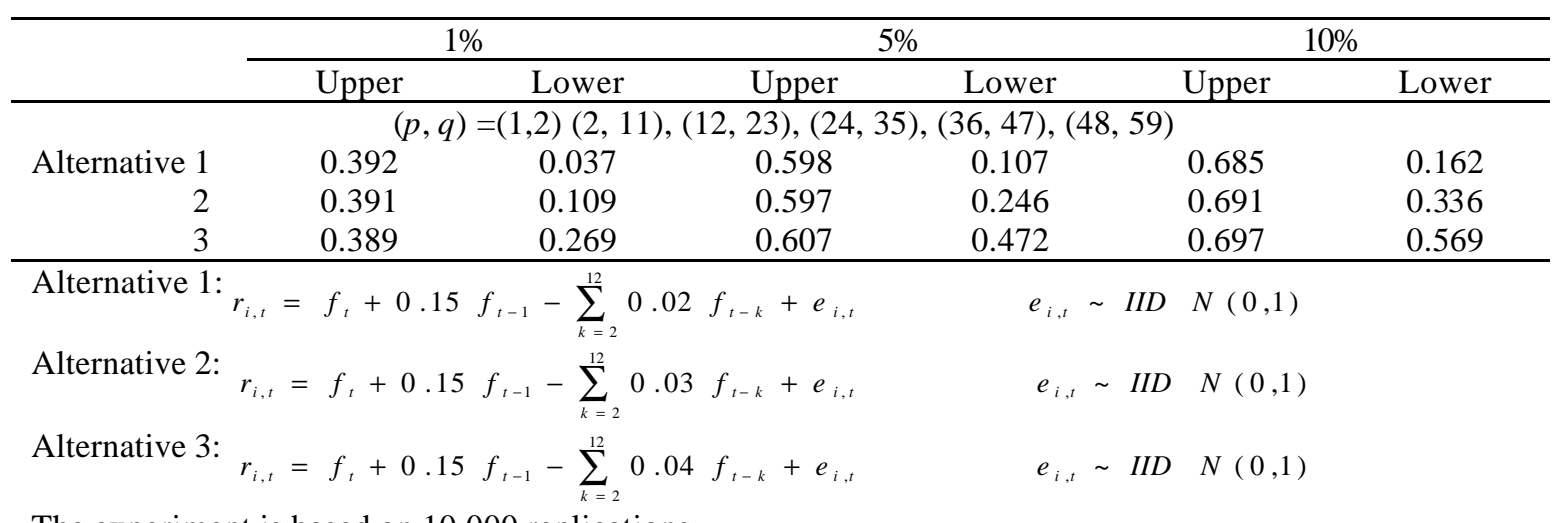

The experiment is based on 10,000 replications.

Table 4-3 Summary Statistics

\begin{tabular}{|c|c|c|c|c|c|c|c|c|}
\hline \multicolumn{3}{|c|}{ Industry } & \multicolumn{3}{|c|}{ Size } & \multicolumn{3}{|c|}{ Book-to-Market } \\
\hline & Mean & Variance & & Mean & Variance & & Mean & Variance \\
\hline NoDur & 0.0105 & 0.0024 & Small 1 & 0.0149 & 0.0048 & Low 1 & 0.0054 & 0.0044 \\
\hline Durbl & 0.0109 & 0.0037 & 2 & 0.0109 & 0.0038 & 2 & 0.0083 & 0.0033 \\
\hline Oil & 0.0124 & 0.0040 & 3 & 0.0108 & 0.0034 & 3 & 0.0096 & 0.0030 \\
\hline Chems & 0.0118 & 0.0035 & 4 & 0.0102 & 0.0032 & 4 & 0.0108 & 0.0028 \\
\hline Manuf & 0.0111 & 0.0039 & 5 & 0.0104 & 0.0030 & 5 & 0.0117 & 0.0026 \\
\hline Telcm & 0.0117 & 0.0046 & 6 & 0.0100 & 0.0027 & 6 & 0.0126 & 0.0025 \\
\hline Utils & 0.0107 & 0.0018 & 7 & 0.0102 & 0.0025 & 7 & 0.0135 & 0.0025 \\
\hline Shops & 0.0110 & 0.0037 & 8 & 0.0097 & 0.0024 & 8 & 0.0141 & 0.0025 \\
\hline Money & 0.0128 & 0.0025 & 9 & 0.0097 & 0.0021 & 9 & 0.0157 & 0.0030 \\
\hline Other & 0.0117 & 0.0039 & Big 10 & 0.0084 & 0.0019 & High 10 & 0.0174 & 0.0043 \\
\hline $\begin{array}{l}\text { NoDur: } \\
\text { Product } \\
\text { Televisi } \\
\text { Everyth }\end{array}$ & $\begin{array}{l}\text { amer } \mathrm{N} \\
\text { ems: C } \\
\text { tils: } \mathrm{U} \\
\text { e. }\end{array}$ & Durables & $\begin{array}{l}\text { 1: Con } \\
\text { ed } \mathrm{Pr}\end{array}$ & ner D & s; Oil & $\begin{array}{l}\text { Gas, } \\
\text { uring; } \\
\text { ices; }\end{array}$ & $\begin{array}{l}\text { Coal E } \\
\text { cm: Te } \\
\text { ey: Fin }\end{array}$ & $\begin{array}{l}\text { ction an } \\
\text { lones a } \\
\text { e; Othe }\end{array}$ \\
\hline
\end{tabular}


Table 4-4 Tests for returns of size portfolios 1941:01-2002:12

\begin{tabular}{|c|c|c|c|c|c|c|}
\hline$(p, q)$ & $(1,1)$ & $(2,11)$ & $(12,23)$ & $(24,35)$ & $(36,47)$ & $(48,59)$ \\
\hline \multirow[t]{2}{*}{ Small 1} & 0.416 & -0.015 & -0.058 & 0.004 & -0.023 & 0.025 \\
\hline & $(6.018)^{*}$ & $(-0.634)$ & $(-2.997)^{*}$ & $(0.208)$ & $(-1.203)$ & $(1.510)$ \\
\hline \multirow[t]{2}{*}{2} & 0.284 & -0.013 & -0.046 & 0.008 & -0.019 & 0.023 \\
\hline & $(5.150)^{*}$ & $(-0.644)$ & $(-2.920)^{*}$ & $(0.456)$ & $(-1.091)$ & $(1.526)$ \\
\hline \multirow[t]{2}{*}{3} & 0.232 & -0.015 & -0.042 & 0.008 & -0.020 & 0.020 \\
\hline & $(4.523)^{*}$ & $(-0.850)$ & $(-2.972)^{*}$ & $(0.517)$ & $(-1.251)$ & $(1.428)$ \\
\hline \multirow[t]{2}{*}{4} & 0.211 & -0.011 & -0.044 & 0.009 & -0.020 & 0.020 \\
\hline & $(4.200)^{*}$ & $(-0.606)$ & $(-3.171)^{*}$ & $(0.549)$ & $(-1.232)$ & (1.431) \\
\hline \multirow[t]{2}{*}{5} & 0.176 & -0.013 & -0.037 & 0.010 & -0.022 & 0.023 \\
\hline & $(3.626)^{*}$ & $(-0.755)$ & $(-2.794)^{*}$ & $(0.609)$ & $(-1.426)$ & (1.713) \\
\hline \multirow[t]{2}{*}{6} & 0.147 & -0.013 & -0.035 & 0.011 & -0.018 & 0.020 \\
\hline & $(3.128)^{*}$ & $(-0.817)$ & $(-2.782)^{*}$ & (0.749) & $(-1.236)$ & (1.583) \\
\hline \multirow[t]{2}{*}{7} & 0.133 & -0.012 & -0.033 & 0.013 & -0.014 & 0.023 \\
\hline & $(2.896)^{*}$ & $(-0.767)$ & $(-2.758)^{*}$ & $(0.916)$ & $(-1.017)$ & (1.869) \\
\hline \multirow[t]{2}{*}{8} & 0.097 & -0.015 & -0.029 & 0.010 & -0.013 & 0.020 \\
\hline & (2.086) & $(-0.971)$ & $(-2.519)$ & $(0.780)$ & $(-0.992)$ & (1.696) \\
\hline \multirow[t]{2}{*}{9} & 0.069 & -0.010 & -0.026 & 0.008 & -0.010 & 0.018 \\
\hline & (1.534) & $(-0.679)$ & $(-2.416)$ & $(0.672)$ & $(-0.797)$ & (1.666) \\
\hline \multirow[t]{2}{*}{ Large 10} & 0.048 & -0.001 & -0.019 & 0.007 & -0.008 & 0.019 \\
\hline & (1.038) & $(-0.093)$ & $(-1.792)$ & $(0.595)$ & $(-0.706)$ & (1.754) \\
\hline
\end{tabular}

$\boldsymbol{\beta}_{i, p, q}$ estimates are reported in the main rows, with the heteroscedasticity-robust test statistics $z(p, q)$ given in parentheses immediately below each main row.. * denotes significance at the $5 \%$ level. 
Table 4-5 Tests for returns of industry portfolios 1941:01-2002:12

\begin{tabular}{lcccccc}
\hline$(p, q)$ & $(1,1)$ & $(2,11)$ & $(12,23)$ & $(24,35)$ & $(36,47)$ & $(48,59)$ \\
\hline NoDur & 0.264 & -0.018 & -0.049 & 0.009 & -0.008 & 0.016 \\
& $(5.806)^{*}$ & $(-1.057)$ & $(-3.571)^{*}$ & $(0.553)$ & $(-0.527)$ & $(1.190)$ \\
Durbl & 0.296 & -0.012 & -0.050 & 0.004 & -0.020 & 0.028 \\
& $(5.556)^{*}$ & $(-0.599)$ & $(-3.087)^{*}$ & $(0.207)$ & $(-1.103)$ & $(1.761)$ \\
Oil & 0.099 & -0.001 & -0.029 & -0.022 & -0.021 & 0.045 \\
& $(1.607)$ & $(-0.036)$ & $(-1.467)$ & $(-1.247)$ & $(-1.140)$ & $(2.362)$ \\
Chems & 0.221 & -0.010 & -0.042 & 0.011 & -0.013 & 0.026 \\
& $(3.828)^{*}$ & $(-0.573)$ & $(-2.662)^{*}$ & $(0.676)$ & $(-0.676)$ & $(1.763)$ \\
Manuf & 0.276 & -0.016 & -0.041 & 0.011 & -0.022 & 0.025 \\
& $(4.975)^{*}$ & $(-0.832)$ & $(-2.624)$ & $(0.613)$ & $(-1.238)$ & $(1.647)$ \\
Telcm & 0.269 & -0.018 & -0.046 & 0.015 & -0.031 & 0.020 \\
& $(4.455)^{*}$ & $(-0.678)$ & $(-2.399)$ & $(0.621)$ & $(-1.360)$ & $(1.067)$ \\
Utils & 0.066 & 0.003 & -0.014 & -0.004 & -0.003 & 0.006 \\
& $(1.761)$ & $(0.209)$ & $(-1.187)$ & $(-0.426)$ & $(-0.243)$ & $(0.604)$ \\
Shops & 0.341 & -0.011 & -0.055 & 0.011 & -0.009 & 0.012 \\
& $(6.039)^{*}$ & $(-0.524)$ & $(-3.349)^{*}$ & $(0.570)$ & $(-0.471)$ & $(0.742)$ \\
Money & 0.230 & -0.014 & -0.038 & 0.012 & -0.017 & 0.012 \\
Other & $(5.112)^{*}$ & $(-0.797)$ & $(-2.576)$ & $(0.668)$ & $(-1.065)$ & $(0.832)$ \\
& 0.317 & -0.020 & -0.055 & 0.010 & -0.032 & 0.028 \\
\hline \multirow{2}{*}{ Sin } & $(5.541)^{*}$ & $(-0.946)$ & $(-3.283)^{*}$ & $(0.568)$ & $(-1.736)$ & $(1.765)$ \\
\hline
\end{tabular}

$\boldsymbol{\beta}_{i, p, q}$ estimates are reported in the main rows, with the heteroscedasticity-robust test statistics $z(p, q)$ given in parentheses immediately below each main row.. * denotes significance at the $5 \%$ level.

NoDur: Consumer Non-Durables; Durbl: Consumer Durables; Oil: Oil, Gas, and Coal Extraction and Products; Chems: Chemicals and Allied Products; Manuf: Manufacturing; Telcm: Telephones and Television; Utils: Utilities; Shops: Wholesale, Retail, and Some Services; Money: Finance; Other: Everything Else. 
Table 4-6 Tests for returns of book-to-market portfolios 1941:01-2002:12

\begin{tabular}{|c|c|c|c|c|c|c|}
\hline$(p, q)$ & $(1,1)$ & $(2,11)$ & $(12,23)$ & $(24,35)$ & $(36,47)$ & $(48,59)$ \\
\hline \multirow[t]{2}{*}{ Low 1} & 0.258 & -0.014 & -0.050 & 0.013 & -0.016 & 0.026 \\
\hline & $(4.016)^{*}$ & $(-0.642)$ & $(-2.917)^{*}$ & $(0.680)$ & $(-0.791)$ & (1.507) \\
\hline \multirow[t]{2}{*}{2} & 0.220 & -0.018 & -0.035 & 0.011 & -0.014 & 0.019 \\
\hline & $(4.167)^{*}$ & $(-0.984)$ & $(-2.473)$ & $(0.695)$ & $(-0.838)$ & (1.305) \\
\hline \multirow[t]{2}{*}{3} & 0.227 & -0.016 & -0.036 & 0.010 & -0.012 & 0.021 \\
\hline & $(4.744)^{*}$ & $(-0.903)$ & $(-2.689)^{*}$ & $(0.620)$ & $(-0.741)$ & $(1.546)$ \\
\hline \multirow[t]{2}{*}{4} & 0.239 & -0.017 & -0.040 & 0.011 & -0.011 & 0.019 \\
\hline & $(5.149)^{*}$ & $(-0.975)$ & $(-3.090)^{*}$ & $(0.725)$ & $(-0.728)$ & (1.449) \\
\hline \multirow[t]{2}{*}{5} & 0.219 & -0.012 & -0.037 & 0.010 & -0.013 & 0.020 \\
\hline & $(4.858)^{*}$ & $(-0.752)$ & $(-2.913)^{*}$ & $(0.666)$ & $(-0.860)$ & (1.573) \\
\hline \multirow[t]{2}{*}{6} & 0.211 & -0.013 & -0.038 & 0.011 & -0.015 & 0.021 \\
\hline & $(4.854)^{*}$ & $(-0.779)$ & $(-3.027)^{*}$ & $(0.718)$ & $(-1.051)$ & $(1.640)$ \\
\hline \multirow[t]{2}{*}{7} & 0.222 & -0.013 & -0.036 & 0.006 & -0.019 & 0.021 \\
\hline & $(5.016)^{*}$ & $(-0.817)$ & $(-2.826)^{*}$ & $(0.391)$ & $(-1.355)$ & $(1.605)$ \\
\hline \multirow[t]{2}{*}{8} & 0.236 & -0.012 & -0.041 & 0.002 & -0.016 & 0.023 \\
\hline & $(5.160)^{*}$ & $(-0.741)$ & $(-3.095)^{*}$ & $(0.103)$ & $(-1.176)$ & $(1.852)$ \\
\hline \multirow[t]{2}{*}{9} & 0.274 & -0.014 & -0.043 & 0.004 & -0.017 & 0.022 \\
\hline & $(5.705)^{*}$ & $(-0.839)$ & $(-3.058)^{*}$ & $(0.238)$ & $(-1.167)$ & (1.717) \\
\hline \multirow[t]{2}{*}{ High 10} & 0.357 & -0.020 & -0.052 & 0.009 & -0.027 & 0.024 \\
\hline & $(5.693)^{*}$ & $(-0.997)$ & $(-3.094)^{*}$ & $(0.461)$ & $(-1.620)$ & (1.562) \\
\hline
\end{tabular}

$\boldsymbol{\beta}_{i, p, q}$ estimates are reported in the main rows, with the heteroscedasticity-robust test statistics $z(p, q)$ given in parentheses immediately below each main row.. * denotes significance at the $5 \%$ level. 


\section{References}

Aarstol, M., 2000, "Inflation, Agency Cost, and Equity Returns," Journal of Economics and Business, 52, 387-403.

Amihud, Y., 1996, "Unexpected Inflation and Stock Returns Revisited-Evidence from Israel," Journal of Money, Credit, and Banking, 28, 22-33.

Bai, J., and P. Perron, 1998, "Estimating and Testing Linear Models with Multiple Structural Changes," Econometrica, 66, 47-78.

Bai, J., and P. Perron, 2000, "Computation and Analysis of Multiple Structural Change Models," Journal of Applied Econometrics, forthcoming.

Bai, J., and P. Perron, 2001, "Multiple Structural Change Models: a Simulation Analysis," Manuscript, Boston University.

Balvers, R. J., and Y. Wu, 2002, "Momentum and Mean Reversion Across National Equity Markets," Working paper, West Virginia University.

Balvers, R. J., Y. Wu, and E. Gilliland, 2000, "Mean Reversion Across National Stock Markets and Parametric Contrarian Investment Strategies," Journal of Finance, $55,745-772$.

Barberis, N., A. Shleifer, and R. Vishny, 1998, “A Model of Investor Sentiment," Journal of Financial Economics, 49, 307-343.

Barnes, M., J. H. Boyd, and B. D. Smith, 1999, "Inflation and Asset Returns," European Economic Review, 43, 737-754.

Bernard, V. L., and J. K. Thomas, 1989, "Past-earnings-announcement Drift: Delayed Price Response or Risk Premium?," Journal of Accounting Research, Supplement 27, 1-48.

Bernard, V. L., and J. K. Thomas, 1990, "Evidence That Stock Prices Do Not Fully Reflect the Implications of Current Earnings for Future Earnings," Journal of Accounting and Economics, 13, 305-340.

Blanchard, O. J., and D. Quah, 1989, "The Dynamic Effects of Aggregate Demand and Supply Disturbances," American Economic Review, 79, 655-673.

Bodie, Z., 1976, “Common Stocks as a Hedge against Inflation,” Journal of Finance, 31, $459-470$.

Boudoukh, J. and M. Richardson, 1993, "Stock Returns and Inflation: a Long-horizon Perspective," American Economic Review, 83, 1346-1355. 
Boudoukh, J., M. Richardson and R. F. Whitelaw, 1994, "Industry Returns and the Fisher Effect," Journal of Finance, 49, 1595-1615.

Box, G. and D. Pierce, 1970, "Distribution of Residual Autocorrelations in Autoregressive-Integrated Moving Average Time Series Models," Journal of the American Statistical Association, 65, 1509-1526.

Boyle, G. W., and J. D. Peterson, 1995, "Monetary Policy, Aggregate Uncertainty, and the Stock Market," Journal of Money, Credit, and Banking, 27, 570-582.

Boyle, G. W., and L. Young, 1988, "Asset Prices, Commodity Prices, and Money: a General Equilibrium, Rational Expectations Model," American Economic Review, 78, 24-45.

Brown, S. J., and P. F. Pope, 1996, "Post-earnings Announcement Drift," Working paper, New York University.

Campbell, J. Y., and N. G. Mankiw, 1987, "Are Output Fluctuations Transitory?," Quarterly Journal of Economics, 102, 857-880.

Campbell, J. Y., and R. J. Shiller, 1988, "The Dividend-price Ratio and Expectations of Future Dividends and Discount Factors," Review of Financial Studies, 1, 195-228.

Campbell, J. Y., and R. J. Shiller, 1989, "Stock Prices, Earnings, and Expected Dividends," Journal of Finance, 43, 661-676.

Chan, L. K. C., N. Jegadeesh, and J. Lakonishok, 1996, “Momentum Strategies,” Journal of Finance, 51, 1681-1713.

Chan, L. K. C., and A. Hameed, and W. Tong, 2000, "Profitability of Momentum Strategies in the International Equity Markets," Journal of Financial and Quantative Analysis, 35, 153-172.

Chen, J., and H. Hong, 2002, "Discussion of 'Momentum and autocorrelation in stock returns,," Review of Financial Studies, 15, 565-573.

Chopra, N, J. Lakonishok, and J. R. Ritter, 1992, "Measuring Abnormal Performance: Do stocks overreact?," Journal of Financial Economics, 31, 235-268.

Choudhry, T., 2001, "Inflation and Rates of Return on Stocks: Evidence from High Inflation Countries," Journal of International Financial Markets, Institutions and Money, 11, 75-96.

Chow, K. V., and K. C. Denning, 1993, "A Simple Multiple Variance Ratio Test," Journal of Econometrics, 58, 385-401. 
Chow, K. V., M. Pan, and R. Sakano, 1996, "On the Long-Term or Short-Term Dependence in Stock Prices: Evidence from International Stock Markets," Review of Quantitative Finance and Accounting, 6, 181-194.

Cochrane, J. H., 1988, "How Big Is the Random Walk in GNP?," Journal of Political Economy, 96, 893-920.

Cochrane, J. H., 1994, "Permanent and Transitory Components of GNP and Stock Prices," Quarterly Journal of Economics, 109, 241-265.

Cohn, R. A., and D. E. Lessard, 1981, "The Effect of Inflation on Stock Prices: International Evidence," Journal of Finance, 36, 277-289.

Conrad, J., and G. Kaul, 1988, "Time-Variation in Expected Returns," Journal of Business, 61, 409-425.

Crosby, M., 2001, Stock returns and inflation, Australian Economic Papers, v40, 156-65.

Cutler, D. M., J. M. Poterba, and L. H. Summers, 1990, "Speculative Dynamics and the Role of Feedback Traders," American Economic Review, 80, 63-68.

Cutler, D. M., J. M. Poterba, and L. H. Summers, 1990, "Speculative Dynamics," Review of Economic Studies, 58, 529-546.

Daniel, K., D. Hirshleifer, and A. Subrahmanyam, 1998, "Investor Psychology and Security Market Under- and Over-reaction," Journal of Finance, 53, 1839-1886.

Daniel, K., D., and S. Titman, 2000, "Market Efficiency in an Irrational World," NBER Working Paper, 7489.

Danthine, J. P., J. Donaldson, 1986, "Inflation and Asset Prices in an Exchange Economy," Econometrica, 54, 585-606.

Debondt, W., and R. Thaler, 1985, "Does the Stock Market Overreact?," Journal of Finance, 40, 793-805.

Debondt, W., and R. Thaler, 1987, "Further Evidence on Investor Overreaction and Stock Market Seasonality," Journal of Finance, 42, 557-582.

Domian, D. L., J. E. Gilster, and D. A. Louton, 1996, "Expected Inflation, Interest Rates, and Stock Returns," Financial Review, 31, 809-830.

Dufour, J. M., and M. King, 1991, "Optimal Invariant Tests for the Autocorrelation Coefficient in Linear Regressions with Stationary and Nonstationary Errors," Journal of Econometrics, 47, 115-143. 
Elliott, G., T. J. Rothenberg, and J. H. Stock, 1996, "Efficient Tests for an Autoregressive Unit Root," Econometrica, 64, 813-836.

Fama, E. F., 1970, "Efficient Capital Markets: A Review of Theory and Empirical Work," Journal of Finance, 25, 383-417.

Fama, E. F., 1981, "Stock Returns, Real Activity, Inflation and Money," American Economic Review, 71, 545-565.

Fama, E. F., 1991, “Efficient Capital market II,” Journal of Finance, 46, 1575-1617.

Fama, E. F., and K. R. French, 1988, "Permanent and Temporary Components of Stock Prices," Journal of Political Economy, 96, 246-273.

Fama, E. F., and K. R. French, 1995, "Size and Book-to-Market Factors in Earnings and Returns” Journal of Finance, 50, 131-155.

Fama, E. F., and G. W. Schwert, 1977, "Asset Returns and Inflation," Journal of Financial Economics, 5, 115-146.

Firth, M., 1979, "The Relationship between Stock Market Returns and Rates of Inflation," Journal of Finance, 34, 743-749.

Fisher, I., 1930, The theory of interest, Macmillan, New York.

Fisher, L., 1966, “Some New Stock-Market Indexes,” Journal of Business, 39, 191-225.

French, K., and R. Roll, 1986, "Stock Return Variances: The Arrival of Information and the Reaction of Traders, " Journal of Financial Economics, 17, 5-26.

French, K., G. W. Schwert, and R. F. Stambaugh, 1987, "Expected Stock Returns and Volatility," Journal of Financial Economics, 19, 3-30.

Fuller, W. A., 1996, Introduction to Statistical Time Series, Wiley, New York, chap. 6.

Gallagher, L.A., L. Sarno, and M. P. Taylor, 1997, "Estimating the Mean-Reverting Component in Stock Prices: A Cross-Country Comparison," Scottish Journal of Political Economy, 44, 566-582.

Gallagher, L. A., and M. P. Taylor, 2002, "The Stock Return-inflation Puzzle Revisited," Economic Letters, 75, 147-156.

Geske, R., and R. Roll, 1983, “The Monetary and Fiscal Linkage between Stock Returns and Inflation," Journal of Finance, 38, 1-33. 
Graham, F. C., 1996, "Inflation, Real Stock Returns, and Monetary Policy," Applied Financial Economics, 6, 29-35.

Groenewold, N., G. O'Bourke, and S. Thomas, 1997, "Stock Returns and Inflation: a Macro Analysis," Applied Financial Economics, 7, 127-136.

Grundy, B., and J. S. Martin, 2001, "Understanding the Nature and the Risks and the Sources of the Rewards to Momentum Investing," Review of Financial Studies, 14, 29-78.

Gultekin, N. B., 1983, "Stock Market Returns and Inflation: Evidence from Other Countries," Journal of Finance, 38, 49-65.

Hansen, L. P., and T. J. Sargent, 1980, "Formulating and Estimating Dynamic Linear Rational Expectations Models," Journal of Economic Dynamics and Control, 2, 7-46.

Hess, P. J., and B. S. Lee, 1999, "Stock Returns and Inflation with Supply and Demand Disturbances," Review of Financial Studies, 12, 1203-1218.

Hirshleifer, D., 2001, "Investor Psychology and Asset Pricing," Journal of Finance, 56, 1533-1597.

Hong, H., and J. C. Stein, 1999, "A Unified Theory of Underreaction, Momentum Trading, and Overreaction in Asset Markets," Journal of Finance, 54, 2143-2184.

Hong, H., T. Lim, and J. C. Stein, 2000, "Bad News Travels Slowly: Size, Analyst Coverage, and the Profitability of Momentum Strategies," Journal of Finance, 55, 265-295

Jaeuk, K., and B. S. Lee, 2000, “Are Common Stocks a Good Hedge against Inflation? Evidence from Pacific-Rim Countries," Pacific-Basin Finance Journal, 8, 457-82.

Jaffe, J. F., and G. Mandelker, 1976, “'The Fisher Effect' for Risky Assets: an Empirical Investigation," Journal of Finance, 31, 447-458.

Jegadeesh, N. 1990, "Evidence of Predictable Behavior of Security Returns," Journal of Finance, 45, 881-898.

Jegadeesh, N. 1991, "Seasonality in Stock Price Mean Reversion: Evidence from the U.S. and the U.K.," Journal of Finance, 46, 1427-1444.

Jegadeesh, N., and S. Titman, 1993, "Returns to Buying Winners and Selling Losers: Implications for Stock Market Efficiency,” Journal of Finance, 48, 65-91. 
Jegadeesh, N., and S. Titman, 1995, "Overreaction, Delayed Reaction, and Contrarian Profits," Review of Financial Studies, v8, 973-993.

Jegadeesh, N., and S. Titman, 2001, "Profitability of Momentum Strategies: An Evaluation of Alternative Explanations," Journal of Finance, 56, 699-720.

Jensen, M. C., 1978, "Some Anomalous Evidence Regarding Market Efficiency," Journal of Financial Economics, 6, 95-101.

Kaul, G., 1987, "Stock Returns and Inflation: the Role of the Monetary Sector," Journal of Financial Economics, 18, 253-276.

Kaul, G., 1990, "Monetary Regimes and the Relation between Stock Returns and the Inflationary Expectations," Journal of Financial and Quantitative Analysis, 25, 307-321.

Kaul, G., and N. H. Seyhun, 1990, "Relative Price Variability, Real Shocks, and the Stock Market," Journal of Finance, 45, 479-96.

Khil, J., and B. S. Lee, 2000, “Are Common Stocks a Good Hedge against Inflation? Evidence from the Pacific-Rim Countries," Pacific-Basin Finance Journal, 8, 457-82.

Kim, M. J., C. R. Nelson, and R. Startz, 1991, "Mean Reversion in Stock Prices? A Reappraisal of the Empirical Evidence," Review of Economic Studies, 58, 515528.

Lee, B. S., 1995, "The Response of Stock Prices to Permanent and Temporary Shocks to Dividends," Journal of Financial and Quantitative Analysis, 30, 1-22.

Lee, K., and S. Ni, 1996, "Stock Returns, Real Activities and Temporary and Persistent Inflation," Applied Financial Economics, 6, 433-441.

Lehmann, B. N., 1990, "Fads, Martingales, and Market Efficiency," Quarterly Journal of Economics, 105, 1-28.

Lewellen, Jonathan, 2002, "Momentum and Autocorrelation in Stock Returns," Review of Financial Studies, v15, 533-563.

Lintner, J., 1975, “Inflation and Security Return,” Journal of Finance, 30, 259-280.

Lo, A. W., and A. C. MacKinlay, 1988, "Stock Market Prices Do Not Follow Random Walks: Evidence from a Simple Specification Test," Review of Financial Studies, 1, 41-66. 
Lo, A. W., and A. C. MacKinlay, 1989, "The Size and Power of the Variance Ratio Test in Finite Samples: A Monte Carlo Investigation," Journal of Econometrics, 40, 203-238.

Lo, A. W., and A. C. MacKinlay, 1990, "When are Contrarian Profits Due to Stock Market Overreaction?," Review of Financial Studies, v3, 175-208.

Malliaropulos, D., 1999, "Identifying the Effects of Nominal and Real Shocks on the S\&P 500 Stock Price Index,” The Manchester School, 67, 304-324.

McQueen, G., 1992, "Long Horizon Mean Reverting Stock Prices Revisited," Journal of Financial and Quantitative Analysis, 27, 1-18.

McQueen, G., and S. Thornley, 1991, "Are Stock Market Returns Predictable? A Test Using Markov-Chains," Journal of Finance, 46, 239-263.

Merton, R. C., 1980, "On Estimating the Expected Return on the Market: An Exploratory Investigation," Journal of Financial Economics, 8, 323-361.

Nelson, C. R., 1976, "Inflation and Rates of Return on Common Stocks," Journal of Finance, 31, 471-483.

Ng, S., and P. Perron, 2001, "Lag Length Selection and the Construction of Unit Root Tests with Good Size and Power," Econometrica, 69, 1519-1554.

Poterba, J. M., and L. H. Summers, 1986, "The Persistence of Volatility and Stock Market Fluctuations," American Economic Review, 76, 1142-1151.

Poterba, J. M., and L. H. Summers, 1988, "Mean Reversion in Stock Prices: Evidence and Implications," Journal of Financial Economics, 22, 27-59.

Rapach, D. E., 2001, "Macro Shocks and Real Stock Prices," Journal of Economics and Business, 53, 5-26.

Richards, A. J., 1995, "Comovements in National Stock Market Returns: Evidence of Predictability, But Not Cointegration," Journal of Monetary Economics, 36, 631654.

Richards, A. J., 1997, "Winner-Loser Reversals in National Stock Market Indices: Can They Be Explained?," Journal of Finance, 52, 2129-2144.

Richardson, M., 1993, "Temporary Components of Stock Prices: A Skeptic's View," Journal of Business and Economic Statistics, 11, 199-207.

Richardson, M., and T. Smith, 1991, "Tests of Financial Models in the Presence of Overlapping Observations," Review of Financial Studies, 4, 227-254. 
Richardson, M., and T. Smith, 1994, “A Unified Approach in Testing for Serial Correlation in Stock Returns," Journal of Business, 67, 371-399.

Richardson, M., and J. Stock, 1990, "Drawing Inferences from Statistics Based on Multiyear Asset Returns," Journal of Financial Economics, 25, 323-348.

Roll, R., 1984, "A Simple Implicit Measure of the Bid/Ask Spread in An Efficient Market," Journal of Finance, 39, 1127-139.

Rouwenhorst, K. G., 1998, "International Momentum Strategies," Journal of Finance, $53,267-284$.

Schwert, G. W., 1981, “The Adjustment of Stock Prices to Inflation,” Journal of Finance, $36,15-29$.

Shiller, R. J., 1981, "The Use of Volatility Measures in Assessing Market Efficiency," Journal of Finance, 36, 291-304.

Shiller, R. J., and P. Perron, 1985, "Testing the Random Walk Hypothesis: Power versus Frequency of Observation, “Economic Letters, 18, 381-386.

Solnik, B., 1983, "The Relation between Stock Prices and Inflationary Expectations: the International Evidence," Journal of Finance, 38, 35-48.

Solnik, B., and V. Solnik, 1997, "A Multi-country Test of the Fisher Model for Stock Returns," Journal of International Financial Markets, Institutions and Money, 7, 289301.

Stambaugh, R. F., 1986, "Does the Stock Market Rationally Reflect Fundamental Values?: Discussion," Journal of Finance, 41, 601-602.

Summers, L. H., 1986, "Does the Stock Market Rationally Reflect Fundamental Values?," Journal of Finance, 41, 591-601.

Wei, K. C. J., and K. M. Wong, 1992, "Tests of Inflation and Industry Portfolio Stock Returns," Journal of Economics and Business, 44, 77-94.

White, H., 1980, “A Heteroskedasticity-Consistent Covariance Matrix Estimator and Direct Test for Heteroskedasticity," Econometrica, 48, 817-838.

White, H., and I. Domowitz, 1984, "Nonlinear Regression with Dependent Observation," Econometrica, 52, 143-162.

Working, H. 1960, "Note on the Correlation of First Difference of Average in a Random Chain," Econometrica, 28, 916-918. 